CENTRO UNIVERSITÁRIO FEI

FELIPE GUSTAVO HERNANDES LEITE

METODOLOGIA DE TESTES PARA QUALIFICAÇÃO DE SISTEMAS ELETRÔNICOS EXPOSTOS À RADIAÇÃO IONIZANTE

São Bernardo do Campo 
FELIPE GUSTAVO HERNANDES LEITE

\section{METODOLOGIA DE TESTES PARA QUALIFICAÇÃO DE SISTEMAS ELETRÔNICOS EXPOSTOS À RADIAÇÃO IONIZANTE}

Dissertação de Mestrado, apresentada ao Centro Universitário da FEI, como parte dos requisitos necessários para obtenção do título de Mestre em Engenharia Elétrica.Orientado pelo Prof. Dr. Renato Camargo Giacomini. Coorientado pela Prof. Dr ${ }^{\mathrm{a}}$. Marcilei Aparecida Guazzelli da Silveira.

São Bernardo do Campo 
Leite, Felipe Gustavo Hernandes.

Metodologia de testes para qualificação de sistemas eletrônicos expostos à radiação ionizante / Felipe Gustavo Hernandes Leite. São Bernardo do Campo, 2018.

112 p. : il.

Dissertação - Centro Universitário FEI.

Orientador: Prof. Dr. Renato Camargo Giacomini.

Coorientadora: Prof. ${ }^{a}$ Dra. Marcilei Aparecida Guazzelli da Silveira.

1. Efeitos de Radiação Ionizante. 2. Microcontroladores. 3.

Metodologia de Testes. 4. Dose Total Ionizante. 5. Efeito de Evento

Único. I. Giacomini, Renato Camargo, orient. II. Título.

Elaborada pelo sistema de geração automática de ficha catalográfica da FEI com os dados fornecidos pelo(a) autor(a). 
Título do Trabalho: Metodologia de testes para qualificação de sistemas eletrônicos expostos à radiação ionizante.

Área de Concentração: Nanoeletrônica e Circuitos Integrados

Orientador: Prof. Dr. Renato Camargo Giacomini

Data da realização da defesa: 02/03/2018

\section{ORIGINAL ASSINADA}

Avaliação da Banca Examinadora:

São Bernardo do Campo, 02 / 03 / 2018.

\section{MEMBROS DA BANCA EXAMINADORA}

Prof. Dr. Renato Camargo Giacomini

Prof. Dr. Rodrigo Trevisoli Doria

Prof. Dr. Saulo Finco
Ass. :

Ass.:

Ass. :

A Banca Julgadora acima-assinada atribuiu ao aluno o seguinte resultado:

APROVADO \

REPROVADO

\section{VERSÃO FINAL DA DISSERTACCÃO}

APROVO A VERSÃO FINAL DA DISSERTACC̃̃O EM QUE FORAM INCLUÍDAS AS RECOMENDAÇÕES DA BANCA EXAMINADORA
Aprovação do Coordenador do Programa de Pós-graduação

Prof. Dr. Carlos Eduardo Thomaz 


\section{Resumo}

A eletrônica passou por diversos avanços nas últimas décadas, proporcionando um aumento na utilização de dispositivos eletrônicos em ambientes radiativos. Exemplos de dispositivos em tais ambientes podem ser encontrados em sistemas que operam no espaço, em laboratórios de física de alta energia e na aviônica. Dispositivos eletrônicos expostos à radiação ionizante podem sofrer danos, os quais são classificados como acumulativos ou de evento único. Os efeitos do dano acumulativo no dispositivo eletrônico altera os seus parâmetros elétricos enquanto os danos de evento único geram transientes em regiões sensíveis dos dispositivos devido a carga gerada pela radiação ionizante, porém, ambos os efeitos gerados por radiação ionizante podem danificar permanentemente a funcionalidade de um dispositivo. Neste trabalho é proposto uma metodologia de testes para qualificação de microcontroladores expostos à ambientes radiativos. A metodologia foi desenvolvida com base em diversos testes experimentais, nos quais foram utilizados dois dispositivos diferentes para validação dos métodos cujos part numbers são MKE02Z64VQH4, fabricado pela NXP Semiconductors, e RM42L432, fabricado pela Texas Instruments. Os dispositivos foram submetidos a testes de radiação com fontes de raios-X, prótons, partículas alfa e íons pesados. Os dois dispositivos tiveram seu desempenho degradado e apresentaram falhas quando irradiados com raios- $X$ até uma dose de cerca de 20 krad(Si). Os testes também sugerem que as memórias flash são mais robustas em comparação com as memórias Memória Estática de Acesso Aleatório (SRAM) em relação a Single Event Upset (SEU). SEUs foram observados apenas na memória SRAM e puderam ser monitorados durante a execução de um firmware de teste, desenvolvido para esse trabalho, possibilitando a verificação da sensibilidade da memória. Também foi verificado a possibilidade de realização de testes de evento único utilizando uma fonte de partículas alfa o que torna esse tipo de teste muito mais simples, barato e rápido, uma vez que não necessita de um acelerador de partículas para sua realização.

Palavras-chave: Efeitos de Radiação Ionizante. Microcontroladores. Metodologia de Testes. Dispositivos Comerciais. Dose Total Ionizante. Efeito de Evento Único. 


\begin{abstract}
Electronics have undergone several advances in the last decades, providing an increase in the use of electronic devices in radiative environments. Examples of devices in such environments can be found in systems operating in space, in high energy physics laboratories, and in avionics. Electronic devices exposed to ionizing radiation can suffer damage, which are classified as cumulative or single event. The effects of cumulative damage on the electronic device change its electrical parameters while single-event damages generate transients in sensitive regions of the devices due to the charge generated by ionizing radiation, but both effects generated by ionizing radiation can permanently damage the functionality of a device. In this work, a methodology of tests for the qualification of microcontrollers exposed to radiative environments is proposed. The methodology was developed based on several experimental tests, in which two different devices were used for validation of the methods whose part numbers are MKE02Z64VQH4, manufactured by NXP Semiconductors, and RM42L432, manufactured by Texas Instruments. The devices were subjected to radiation tests with X-ray sources, protons, alpha particles and heavy ions. The two devices had their performance degraded and showed flaws when irradiated with X-rays up to a dose of about $20 \mathrm{krad}(\mathrm{Si})$. The tests also suggest that flash memories are more robust compared to SRAM memories over SEU. SEUs were observed only in the SRAM memory and could be monitored during the execution of a test firmware, developed for this work, allowing the verification of the memory sensitivity. It was also verified the possibility of performing single-event tests using an alpha particle source which makes this type of test much simpler, cheaper and faster, since it does not need a particle accelerator for its realization.
\end{abstract}

Keywords: Ionizing Radiation Effects, Microcontrollers, Test Methodology, COTS, Total Ionizing Dose, Single Event Effect. 


\section{Lista de Ilustrações}

Figura 1 - Exemplo de ângulo sólido em uma esfera. . . . . . . . . . . . . . . 19

Figura 2 - Animação gráfica mostrando a localização dos cinturões de Van Allen e as linhas de campo magnético. . . . . . . . . . . . . . . . . . 22

Figura 3 - Fluxo de elétrons do cinturão externo na órbita geoestacionária. . . . . . 23

Figura 4 - Distribuição de fluxos de prótons na AAS durante eventos solares em novembro de 2001 (cima) e durante um período geomagnético inativo em novembro de 2009 (baixo). . . . . . . . . . . . . . . . . 25

Figura 5 - As três interações de fótons em função do número atômico e energia. . 28

Figura 6 - Estrutura do transistor MOS . . . . . . . . . . . 32

Figura $7-$ Exemplo de curva característica $I_{D}-V_{D S} \ldots \ldots \ldots \ldots$

Figura 8 - Exemplo de curva característica $I_{D}-V_{G S}$ em escala linear e logarítmica. 33

Figura 9 - Bandas de energia em uma estrutura MOS em diferentes níveis de polarização de porta. . . . . . . . . . . . . . . . . . 34

Figura 10 - Curva característica $I_{D}-V_{G S}$ de um MOSFET . . . . . . . . . . . 36

Figura 11 - Exemplos do efeito da mobilidade de superfície nas curvas características de um MOSFET . . . . . . . . . . . . . . . . . . . 37

Figura 12 - Fotografia feita por um microscópico de um microcontrolador. . . . . . . 38

Figura 13 - Estrutura de um transistor de porta flutuante. . . . . . . . . . . . . . 39

Figura 14 - Diagrama de bandas de energia de um transistor de porta flutuante . . . . 40

Figura 15 - Posição das tecnologias de memória não-volátil em relação a custo e flexibilidade. . . . . . . . . . . . . . . . . . 41

Figura 16 - a) Matriz de células flash NOR. b) Seção transversal de uma célula flash. 42

Figura 17 - Curva característica I-V de um transistor de porta flutante na condição programado e não programado. . . . . . . . . . . . . . 43

Figura 18 - Métodos de escrita em uma célula flash NOR. . . . . . . . . . . . . . . . 44

Figura 19 - Exemplo de um circuito multiplicador Dickson. . . . . . . . . . . . . . . 44

Figura 20 - Simulação das tensões nos nós de um multiplicador Dickson. . . . . . . . 45

Figura 21 - Tensão de saída de um multiplicador Dickson com tensão de entrada de $3.3 \mathrm{~V} \ldots \ldots \ldots \ldots \ldots \ldots \ldots$

Figura 22 - Exemplo de uma célula SRAM composta por 6 transistores. . . . . . . . . 47

Figura 23 - VTC e MRE de uma célula SRAM 6T tradicional durante: a) estado de retenção e b) estado de leitura. . . . . . . . . . . . . . . . . . . . . . . . 48

Figura 24 - Principais processos no dano de TID. . . . . . . . . . . . . 50

Figura 25 - Processo de geração de cargas durante um SEE. . . . . . . . . . . . . . 51

Figura 26 - Exemplo de seção de choque de bit-flips. . . . . . . . . . . . . . . 52

Figura 27 - Curvas $I_{D}-V_{G S}$ para MOSFETs tipo $\mathrm{P}$ e $\mathrm{N}$ irradiados com diferentes doses. ............................ 54 
Figura 28 - Curvas $I_{D}-V_{G S}$ para MOSFETs tipo $\mathrm{N}$ em escala logarítmica para diferentes doses acumuladas em um dispositivo fabricado na tecnologia de $0,18 \mu m$ CMOS da TSMC. . . . . . . . . . . . . . . . 55

Figura 29 - Curvas $g_{m}-V_{G S}$ para MOSFETs tipo N. . . . . . . . . . . 56

Figura 30 - Estabilização da variação de tensão de limiar após o transistor MOSFET tipo $\mathrm{N}$ ser irradiado.

Figura 31 - Estabilização da variação de tensão de limiar após o transistor MOSFET tipo P ser irradiado.

Figura 32 - Variação da tensão de limiar em função da dose acumulada para um MOSFET tipo N. . . . . . . . . . . . . . . . . . . .

Figura 33 - Variação da tensão de limiar em função da dose acumulada para um MOSFET tipo P.

Figura 34 - Variação da tensão de limiar em função do tempo para um dispositivo irradiado polarizado. . . . . . . . . . . . . . . . . . 60

Figura 35 - Efeito do TID nas células de gate flutuante. . . . . . . . . . . . 61

Figura 36 - Distribuições de tensão de limiar para células floating gate multi-níveis. 61

Figura 37 - Tensão de saída de um circuito charge pump em função da dose. . . . . . . 62

Figura 38 - Número de erros de leitura em função da dose acumulada. . . . . . . . . 63

Figura 39 - Seção de choque de SEUs para diferentes memórias. . . . . . . . . . . . 63

Figura 40 - Corrente de alimentação de uma memória SRAM ao ser irradiada com $C o^{60} \ldots \ldots \ldots \ldots \ldots \ldots \ldots$

Figura 41 - Ponto de acionamento dos transistores de acesso de escrita antes de serem irradiados.

Figura 42 - Ponto de acionamento dos transistores de acesso de escrita após serem irradiados. ..................... 66

Figura 43 - Comparação entre a margem de ruído estático de leitura antes e após serem irradiados. . . . . . . . . . . . . . . . 67

Figura 44 - Seção de choque de SEU de uma memória SRAM comercial. . . . . . . . 68

Figura 45 - Difratômetro de raios-X Shimadzu XRD-6100 . . . . . . . . . . 70

Figura 46 - Rendimento de lacunas armadilhados obtido experimentalmente para diferentes partículas. . . . . . . . . . . . . . . 71

Figura 47 - Visão geral do acelerador Pelletron. . . . . . . . . . . . . . 73

Figura 48 - Detalhe da sala experimental. . . . . . . . . . . . 74

Figura 49 - LET médio em função do alcance em silício para diversos feixes, energias e janelas. ......................... 75

Figura 50 - Detalhe da placa de desenvolvimento FRDM-KE02Z utilizada nos testes. 76

Figura 51 - Diagrama exemplificando o uso do openSDA. . . . . . . . . . . . 77

Figura 52 - Detalhe da placa de desenvolvimento LaunchPad-RM42x utilizada nos testes. . . . . . . . . . . . . . . . . . 77 
Figura 53 - Fotografia realizada com um microscópio eletrônico de varredura (MEV) da lâmina de silício do microcontrolador MKE02Z . . . . . . . . . . . . . 79

Figura 54 - Imagem de microscopia eletrônica de varredura do corte transversal do microcontrolador MKE02Z. . . . . . . . . . . . . . . . . . 80

Figura 55 - Fotografia realizada com um microscópio digital da lâmina de silício do microcontrolador RM42L432. . . . . . . . . . . . . . . . . . . . . . 80

Figura 56 - Simulação de feixe de ${ }^{12} \mathrm{C}$ para energia de $26,6 \mathrm{MeV}$ e $47,7 \mathrm{MeV}$. . . . . 81

Figura 57 - Simulação de feixe de ${ }^{12} C$ atravessando uma lâmina de $40 \mu m$ de silício. $\quad 82$

Figura 58 - Detalhe do setup do dispositivo durante a irradiação por raios- $\mathrm{X}$, mostrando o dispositivo posicionado perpendicularmente ao feixe. . . . . . . 84

Figura 59 - Detalhe do setup do dispositivo na câmara de espalhamento. . . . . . . . 85

Figura 60 - Detalhe do setup do dispositivo na câmara de espalhamento. . . . . . . . 86

Figura 61 - Detalhe do setup do dispositivo durante a irradiação por partículas alfa. $\quad 87$

Figura 62 - Estrutura da interface SWJ-DP. . . . . . . . . . . . . . 88

Figura 63 - Fluxo de controle da interface DAP. . . . . . . . . . . . . . . . 89

Figura 64 - Fluxograma do teste via JTAG. . . . . . . . . . . . . . . . . . . . . 90

Figura 65 - Seção de choque de bit para memória SRAM em função do LET do feixe

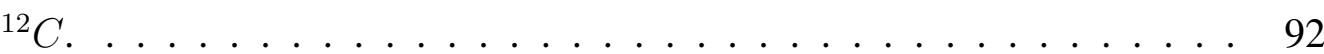

Figura 66 - Corrente de alimentação em função do tempo durante a irradiação com raios-X........................ . . . . . . . . .

Figura 67 - Arquitetura de software utilizado nos testes. . . . . . . . . . . . . 94

Figura 68 - Interface gráfica do software de teste. . . . . . . . . . . . . . 95

Figura 69 - Interface gráfica do software SRIM mostrando onde inserir os valores de densidade. . . . . . . . . . . . . . . . . . . 997

Figura 70 - Perda de energia das partículas alfa no silício ao atravessar $15 \mathrm{~mm}$ de gás argônio em diferentes pressões. . . . . . . . . . . . . . . . . . . . 98

Figura 71 - Simulações das trajetórias das partículas entre o gás argônio e silício. 99

Figura 72 - Seção de choque em função da pressão da atmosfera de argônio. . . . . . 100

Figura 73 - Detalhe do setup na câmara. . . . . . . . . . . . . . . . . . 100

Figura 74 - Corrente de alimentação versus tempo para teste de raios-X do dispositivo MKE02Z. . . . . . . . . . . . . . . . . . . 101

Figura 75 - Corrente de alimentação versus tempo para teste de raios-X do dispositivo RM42L432. . . . . . . . . . . . . . . . . . . . 102

Figura 76 - Seção de choque em função da pressão do gás argônio para o dispositivo MKE02Z. . . . . . . . . . . . . . . . . 103

Figura 77 - Seção de choque em função do LET para o dispositivo MKE02Z. . . . . . 104

Figura 78 - Fluxograma da metodologia proposta. . . . . . . . . . . . . . 106 


\section{Lista de Tabelas}

Tabela 1 - Ambientes radiativos em reatores nucleares . . . . . . . . . . . . 27

Tabela 2 - Seção de choque de bit para memória flash e SRAM em função do LET do feixe ${ }^{12} C$ e do range do íons no dispositivo. . . . . . . . . . . . . . . . . 91

Tabela 3 - Seção de choque de SEE de partículas- $\alpha$ no teste em vácuo . . . . . . . . . 96

Tabela 4 - Seção de choque de SEE de partículas- $\alpha$ no teste em ar . . . . . . . . . . . . 96

Tabela 5 - Densidade da atmosfera de argônio para diferentes pressões . . . . . . . . 97

Tabela 6 - Energia na superfície do dispositivo e alcance em silício das partículas $\alpha$ após atravessar $20 \mathrm{~mm}$ em uma atmosfera de argônio com pressão controlada. . 99 


\section{Lista de Abreviaturas}
AAS
Anomalia do Atlântico Sul.
CAST
Academia Chinesa de Tecnologia Espacial.
CBERS China-Brazil Earth Resources Satellite.
CG
Control Gate.
CITAR Circuitos Integrantes Tolerantes à Radiação Ionizante.
CMOS Complementary Metal-Oxide-Silicon.
COTS Comercial Off-The-Shelf.
DD Dano por Deslocamento.
DoD Departamento de Defesa Americano.
EEPROM Memória Programável Apagável Eletricamente Somente de Leitura.
EPROM Memória Programável Apagável Somente de Leitura.
ESA Agência Espacial Europeia.
FG Floating Gate.
INPE Instituto Nacional de Pesquisas Espaciais.
LAMFI Laboratório de Análise de Materiais por Feixes Iônicos.
LERI Laboratório de Estudos de Radiação Ionizante.
LET Linear Energy Transfer.
LHC Grande Colisor de Hádrons.
MC-SNICS Multi-Cathode Source of Negative Ions by Cesium Sputtering.
MOSFET Metal-Oxide-Silicon Field-effect Transistor.
MRE Margem de Ruído Estático.
ONO Óxido-Nitreto-Óxido.
SEB Single Event Burnout.
SEE Evento de Efeito Único.
SEFI Single Event Functional Interrupt.
SEGR Single Event Gate Rupture.
SEL Single Event Latchup.
SET Single Event Transient.
SEU Single Event Upset.
SNICS Source of Negative Ions by Cesium Sputtering.
SRAM Memória Estática de Acesso Aleatório.
SRIM Stopping and Range of Ions in Matter.
TID Dose Total Ionizante.
VTC Curva de Transferência de Tensão. 


\section{Sumário}

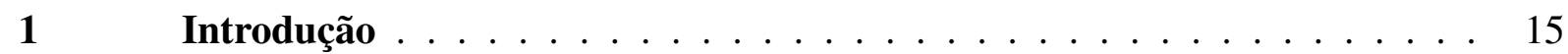

2 Revisão Bibliográfica . . . . . . . . . . . . . . . . . 17

$2.1 \quad$ Radiação Ionizante . . . . . . . . . . . . . . . . . . . . . . . . 17

2.1.1 Radioatividade . . . . . . . . . . . . . . . . . . . . 17

2.1.2 Grandezas Físicas . . . . . . . . . . . . . . . . . . . 17

2.1.2.1 Energia . . . . . . . . . . . . . . . . . . 18

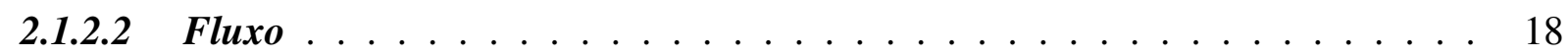

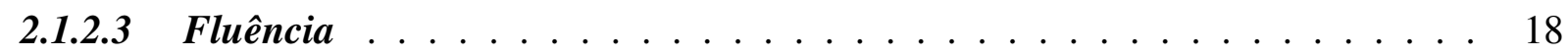

2.1.2.4 Deposição de energia . . . . . . . . . . . . . . . . . . . . . 18

2.1.2.5 Ângulo Sólido . . . . . . . . . . . . . . . . . . . . . 18

2.1.3 Tipos de radiação . . . . . . . . . . . . . . . . . . . . . . . . . . . 19

2.1.3.1 Fótons, Raios Gama e Raios-X . . . . . . . . . . . . . . . . . . . . . . . 19

2.1.3.2 Partículas Beta . . . . . . . . . . . . . . . . . . . . . . 20

2.1.3.2.1 Decaimento Beta . . . . . . . . . . . . . . . . . . . . . . . . . . 20

2.1.3.2.2 Conversão Interna . . . . . . . . . . . . . . . . . . . . . . 20

2.1.3.2.3 Elétrons Auger . . . . . . . . . . . . . . . . . . . . 21

2.1.3.3 Partículas pesadas ....................... 21

2.1.3.4 Nêutrons .......................... . . 21

$2.2 \quad$ Ambientes radiativos . . . . . . . . . . . . . . 22

2.2.1 Ambiente Espacial . . . . . . . . . . . . . . . . . . 22

2.2.1.1 Cinturões de Radiação . . . . . . . . . . . . . . . . . . . . . . 23

2.2.1.2 Raios Cósmicos _. . . . . . . . . . . . . . . . . . . 25

2.2.1.2.1 Raios Cósmicos Galáticos . . . . . . . . . . . . . . . . . . . 25

2.2.1.2.2 Raios Cósmicos Solares . . . . . . . . . . . . . . . . . . . 26

2.2.1.2.3 Raios Cósmicos Terrestres . . . . . . . . . . . . . . . . . . . . . 26

2.2.2 Reatores Nucleares . . . . . . . . . . . . . . . 26

2.2.3 Laboratórios de Física de Alta Energia . . . . . . . . . . . . . . . . . 27

2.3 Interação da Radiação na Matéria . . . . . . . . . . . . . . . . . 27

2.3.1 Interações de Fótons . . . . . . . . . . . . . . . . . . . . 28

2.3.2 Interações com Partículas Carregadas _ . . . . . . . . . . . . . . . 29

2.3.2.1 Poder de Freamento Eletrônico . . . . . . . . . . . . . . . . . . . . . . . . . . 29

2.3.2.2 Taxa de Deposição de Energia do Íon . . . . . . . . . . . . . . . . . . . . . . . 30

$2.4 \quad$ Dispositivos Semicondutores . . . . . . . . . . . . . . 30

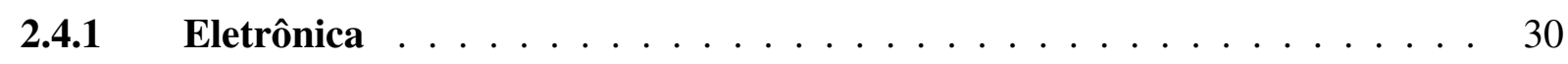

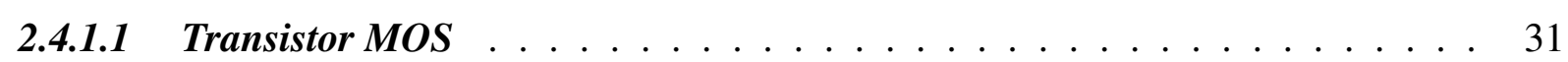

2.4.1.1.1 Tensão de Limiar . . . . . . . . . . . . . . . . . . . . . . . . . . . . . . 33

2.4.1.1.2 Cargas no óxido . . . . . . . . . . . . . . . . . . . . 34 
2.4.1.1.3 Armadilhas de Interface . . . . . . . . . . . . . . . . . . . . 34

2.4.1.1.4 Relação $I_{D}-V_{D S}$ de um transistor MOS . . . . . . . . . . . . . . . 35

2.4.1.1.5 Relação $I_{D}-V_{G S}$ de um transistor MOS . . . . . . . . . . . . . . . . 35

2.4.1.1.6 Transcondutância . . . . . . . . . . . . . . . . . . 36

2.4.1.1.7 Mobilidade de Superfície Efetiva . . . . . . . . . . . . . . . . . . . . . . 36

2.4.2 Dispositivos Programáveis . . . . . . . . . . . . . . . . 37

2.4.2.1 Transistor de Porta Flutuante . . . . . . . . . . . . . . . . . 38

2.4.2.2 Memórias Flash . . . . . . . . . . . . . . . . . . . . 40

2.4.2.2.1 Operação de Leitura . . . . . . . . . . . . . . . . . . . . . . . . . . . . . . . 42

2.4.2.2.2 Operação de Escrita . . . . . . . . . . . . . . . . . . . . . . . . . 43

2.4.2.2.3 Circuito Elevador de Tensão - Charge Pump . . . . . . . . . . . . . . . 44

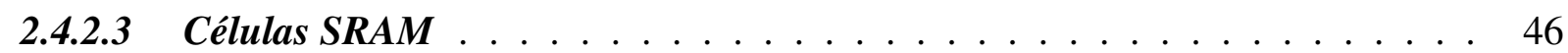

$2.5 \quad$ Conceitos e Terminologia de Sistemas Tolerantes à Falhas . . . . . . . . . . . 48

2.6 Efeitos da Radiação em Dispositivos Semicondutores . . . . . . . . . . . . . . 49

2.6.1 Dose Total Ionizante (TID) . . . . . . . . . . . . . . . . . . . . . . . 49

2.6.2 Efeito de Evento Único . . . . . . . . . . . . . . . . . . . . . . . . . . . . . 50

2.6.3 Efeitos de TID em transistores MOSFET . . . . . . . . . . . . . . . . 53

2.6.4 Efeitos de Radiação em Memórias Flash _ . . . . . . . . . . . . . . . . . . 60

2.6.5 Efeitos de Radiação em Memórias SRAM . . . . . . . . . . . . . . . . . . . 64

$3 \quad$ Procedimento Experimental . . . . . . . . . . . . . . . . . . . . . 69

$3.1 \quad$ Fontes de Radiação . . . . . . . . . . . . . . . . . . . . . . . . . 69

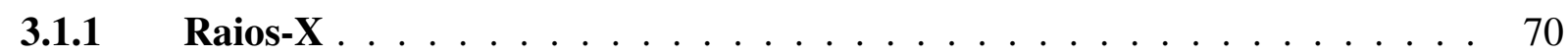

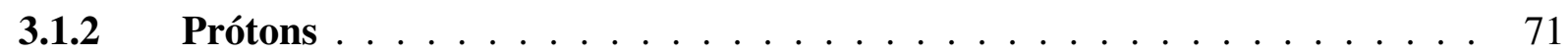

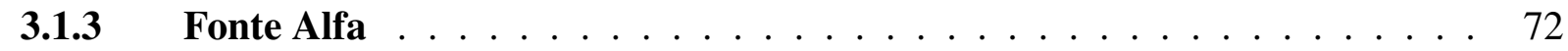

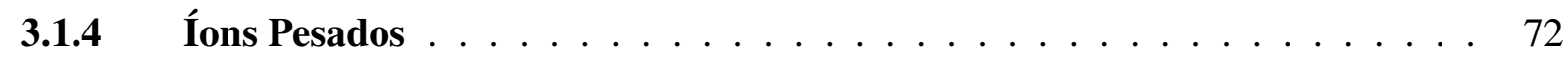

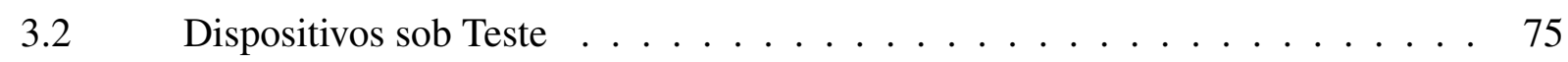

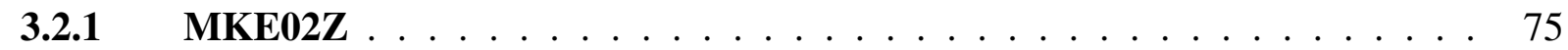

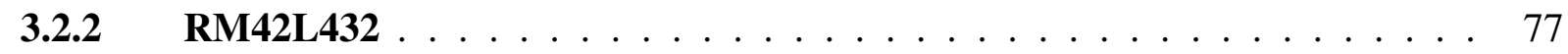

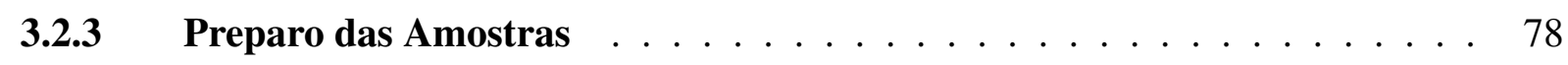

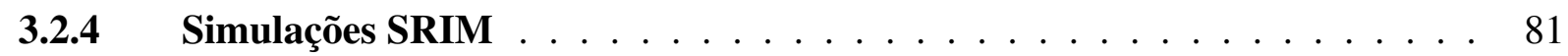

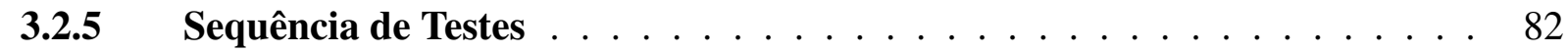

3.2.6 Estratégia de Testes . . . . . . . . . . . . . . . . . 83

3.2.6.1 Setup do teste com raios-X . . . . . . . . . . . . . . . . . . . . . 83

3.2.6.2 Setup do teste com íons pesados no Acelerador Pelletron . . . . . . . . . . . . 84

3.2.6.3 Setup do teste com íons pesados no Acelerador LAMFI . . . . . . . . . . . . 85

3.2.6.4 Setup do teste com partículas alfa com fonte ${ }^{241} A m \ldots \ldots$

3.2.6.5 Teste Estático via Depurador . . . . . . . . . . . . . . . . . . . . . . . . . . 87

3.2.6.6 Resultados do Teste Estático . . . . . . . . . . . . . . . . . . . . . . . . . . . 91

3.2.6.7 Teste Dinâmico via Programa . . . . . . . . . . . . . . . . . . . . . . . . 93 
3.2.6.8 Resultados do Teste Dinâmico . . . . . . . . . . . . . . . . . . . . . . . . . . 95

$3.3 \quad$ Verificação dos Testes . . . . . . . . . . . . . . . . . . 101

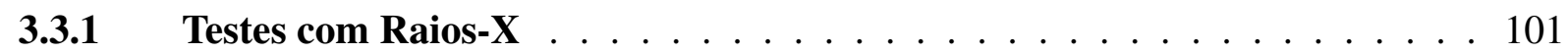

3.3.2 Testes com Partículas Alfa . . . . . . . . . . . . . . . . . 103

4 Proposta de Metodologia . . . . . . . . . . . . . . . . . . 105

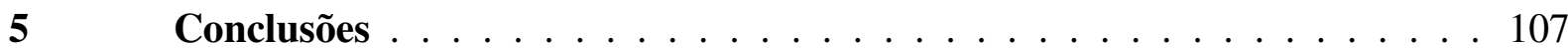

REFERÊNCIAS . . . . . . . . . . . . . . . . . . . . . . 109 


\section{Introdução}

No final da década de 1980, o Brasil participou de um acordo bilateral com a República Popular da China envolvendo o Instituto Nacional de Pesquisas Espaciais (INPE) e a Academia Chinesa de Tecnologia Espacial (CAST) para o desenvolvimento de um programa de construção de dois satélites avançados de sensoriamento remoto, ao qual foi dado o nome de Programa China-Brazil Earth Resources Satellite (CBERS). Esse programa serviria como ferramenta para monitoramento dos vastos recursos naturais e grandes áreas despovoadas localizadas nos dois países. Em 2002, o Brasil firmou um novo acordo com a China para o desenvolvimento de mais dois satélites. Neste novo acordo, a participação do Brasil aumentou de $30 \%$ para 50\%, colocando o Brasil numa condição de igualdade plena com a China. Neste contexto, há um aumento da produção científica acerca desse assunto e o surgimento de um importante programa de pesquisa científica nacional com o foco no desenvolvimento de circuitos eletrônicos tolerantes à radiação, chamado de Projeto Circuitos Integrantes Tolerantes à Radiação Ionizante (CITAR) (INPE, 2018a,b).

Circuitos que sejam tolerantes à radiação ionizante são de grande interesse para a área espacial, militar e aviônica. O desenvolvimento de um circuito eletrônico que é capaz de tolerar a exposição à radiação ionizante deve passar por um processo rigoroso de testes e qualificação dos componentes. Países que têm forte investimento no desenvolvimento militar e espacial possuem normas e padrões de testes específicos para dispositivos eletrônicos expostos a tais ambientes, por exemplo as normas MIL-STD-883H e MIL-STD-750, do Departamento de Defesa Americano (DoD) dos Estados Unidos da América, e a ESA/ECC 20100 e 22900, da Agência Espacial Europeia (ESA). Mesmo com essas normas, há muitas indefinições nas metodologias que podem ser empregadas durante os ensaios e que são definidas através de um plano de teste levando em conta o tipo de dispositivo e a sua aplicação. É tentando preencher esse espaço que esse trabalho foi desenvolvido com o propósito de estabelecer uma metodologia para qualificação de microcontroladores expostos à radiação ionizante. Um dispositivo eletrônico exposto à radiação ionizante pode sofrer desvios em seus parâmetros elétricos e ter comportamentos indesejados. Inicialmente, será feita uma breve descrição da radiação ionizante, em quais ambientes os dispositivos eletrônicos podem estar expostos a esse tipo de radiação, bem como o espectro de radiação que compõem esses ambientes e quais formas temos de simular esses ambientes em laboratório. Uma vez que microcontroladores são compostos basicamente por transistores, esse trabalho terá uma breve descrição teórica sobre esse componente e também serão discutidos os efeitos básicos que ocorrem nesses dispositivos para depois escalar para estruturas mais complexas, que compõem os microcontroladores, como as memórias estáticas de acesso aleatório e flash.

O dispositivo utilizado para o desenvolvimento da metodologia foi um microcontrolador comercial de prateleira de part number MKE02Z64VQH4 com núcleo ARM Cortex-M0+, fabricado pela NXP Semiconductors e um microcontrolador para aplicações seguras de part 
number RM42L432 com núcleo ARM Cortex-R4, fabricado pela Texas Instruments. Esses dispositivos foram submetidos a diversos experimentos com radiação ionizante: irradiação por raios-X, íons pesados, prótons e partículas alfa. Por fim, serão apresentados resultados experimentais que investigam as partes do componente estudado que são sensíveis aos efeitos da radiação ionizante. Será proposta uma estratégia de teste para avaliar o comportamento do componente exposto à radiação ionizante, bem como a discussão acerca desses resultados. 


\section{Revisão Bibliográfica}

Nesse capítulo será realizada a revisão bibliográfica com todos os pontos pertinentes para a evolução do trabalho.

\subsection{Radiação Ionizante}

A radiação ionizante é toda radiação que contém energia suficiente para liberar elétrons dos átomos, portanto, tornando o átomo ionizado. A radiação pode ser categorizada em quatro tipos gerais: partículas beta, partículas pesadas carregadas, radiação eletromagnética e nêutrons. Partículas beta incluem elétrons rápidos emitidos por decaimento nuclear bem como elétrons produzidos por outro processo. Partículas carregadas pesadas englobam todo íon energético com massa maior ou igual a uma unidade de massa atômica, incluindo a partícula alfa. Radiação eletromagnética inclui raios-X, emitidos pelo rearranjo dos elétrons em uma estrutura atômica, e raios gama que é originado de transições nucleares. Nêutrons são gerados em vários processos nucleares que constituem uma categoria mais ampla. O nível mínimo de energia de interesse é a mínima energia para produzir ionização de materiais típicos (por exemplo, silício) e esse nível está na ordem de $10 \mathrm{eV}$. O nível máximo de energia é a máxima energia encontrada na ciência nuclear (KNOLL, 1989).

\subsubsection{Radioatividade}

Nos processos nucleares mencionados acima está implícito que alguns átomos são menos estáveis que outros. Todos os átomos com número atômico maiores que 82 são radiativos, ou seja, estão sujeitos a rearranjos nucleares através da emissão de partículas sub-atômicas e radiação gama até que uma configuração atômica estável seja alcançada (HOLMES-SIEDLE, 2007). A atividade de um radioisótopo é definido como a taxa de decaimento e é dado pela lei fundamental do decaimento radiativo:

$$
\frac{d N}{d t}=-\lambda N
$$

onde $\mathrm{N}$ é o número de núcleos radiativos e $\lambda$ é a constante de decaimento. A unidade em SI é o becquerel $(\mathrm{Bq})$ definido por um decaimento por segundo e é relacionado com a unidade histórica curie $(\mathrm{Ci})$ da seguinte forma:

$$
1 B q=2,703 \cdot 10^{-11} \mathrm{Ci}
$$

\subsubsection{Grandezas Físicas}

A seguir será apresentado uma série de grandezas físicas utilizadas nessa área de estudo. 


\subsubsection{Energia}

A energia é medida usando a unidade elétron volt $(\mathrm{eV})$, definida como a energia cinética de um elétron acelerado por uma diferença de potencial de 1 volt. A energia de um fóton de raios-X ou raio gama pode ser calculada através da equação:

$$
E=h v
$$

onde h é a constante de Planck $\left(h=6.626 \cdot 10^{-34} \mathrm{~J} \cdot s\right)$ e v é frequência do fóton (KNOLL, 1989; HOLMES-SIEDLE, 2007). O fator de conversão entre eletron-volt e joule é: $1 \mathrm{eV}=$ $1,6.10^{-19} \mathrm{~J}$. Outra unidade tradicional de energia é o erg que corresponde a $10^{-7} \mathrm{~J}$, porém menos utilizada nesta área de pesquisa.

\subsubsection{Fluxo}

O fluxo, também conhecido como taxa de fluência ou densidade de fluxo, é o número de partículas que atravessa uma área definida por unidade de tempo. A unidade de fluxo é $\mathrm{cm}^{-2} \cdot \mathrm{s}^{-1}$ e pode ter o símbolo da partícula adicioformatting the text table of content latexnado à unidade (HOLMES-SIEDLE, 2007).

\subsubsection{Fluência}

É a integral do fluxo de partículas no tempo e pode ser entendido como a quantidade de partículas que atravessou uma determinada área durante um determinado período. A unidade é $\mathrm{cm}^{-2}$ e também pode ter o símbolo da partícula adiconado à unidade (HOLMES-SIEDLE, 2007).

\subsubsection{Deposição de energia}

O rad e gray (Gy) são unidades universais de deposição de energia. 1 rad foi absorvido pela amostra de interesse quando 100 ergs por grama foi depositado. 1 gray foi absorvido quando 1 joule por kilograma foi depositado no material. Portanto, um rad corresponde a $10^{-2}$ gray ou 1 centigray (cGy) (HOLMES-SIEDLE, 2007).

\subsubsection{5 Ângulo Sólido}

$\mathrm{O}$ ângulo sólido $\Omega$ subtendido por uma superfície $\mathrm{S}$ é definido como a área de superfície $\Omega$ de uma unidade de esfera coberta pela projeção da superfície na esfera (MATHWORLD., 2018). Pode ser calculado através da equação 4 : 


$$
\Omega=\frac{A}{r^{2}}
$$

Onde A é a área da superfície e r é o raio entre o centro da esfera e a superfície. A figura 1 ilustra o ângulo sólido em uma esfera.

Figura 1 - Exemplo de ângulo sólido em uma esfera.

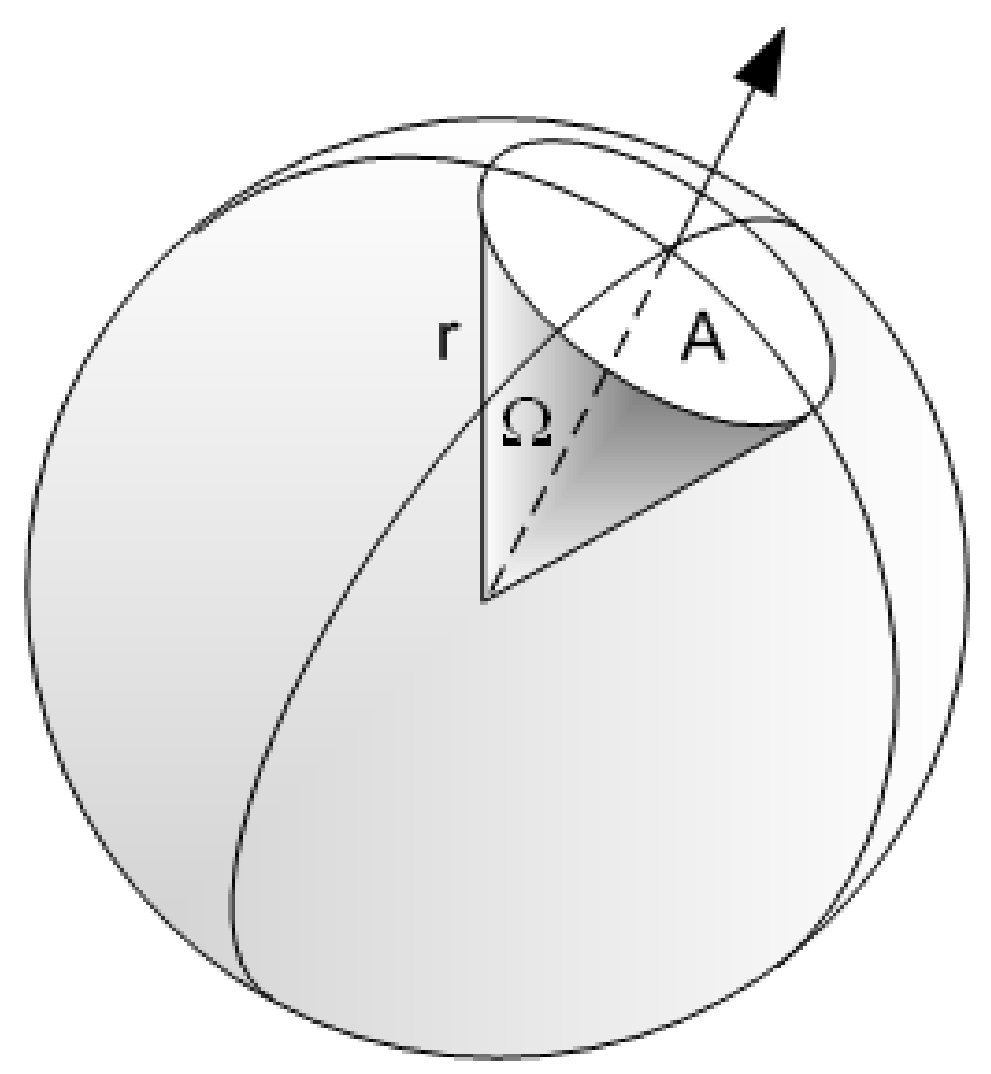

Fonte: (HAADE, 2018)

\subsubsection{Tipos de radiação}

Nessa seção será abordado com mais detalhes os tipos de radiação mencionados no início da revisão bibliográfica.

\subsubsection{Fótons, Raios Gama e Raios-X}

O fóton é uma partícula estável que não possui carga elétrica e massa. O fóton pode interagir com os átomos modificando o seu estado de energia. $\mathrm{O}$ fóton pode ser absorvido pelo átomo, elevando o estado de energia do átomo, ou pode ser emitido pelo átomo, reduzindo o estado de energia do átomo. Os fótons com energia suficiente para ionizar um meio material podem interagir por meio de três processos principais: efeito fotoelétrico, onde toda a energia do fóton é transferida a um elétron atômico; efeito Compton, onde apenas uma parte da energia do fóton é transferida a um elétron, havendo portanto um fóton espalhado a um dado ângulo; 
e produção de pares, em que um fóton se transforma em um par elétron-pósitron. As seções de choque de ocorrência de cada um destes efeitos dependem da energia do fóton e do número atômico do meio. De modo geral, ao atravessar um meio material, a intensidade de um feixe de fótons decai de forma exponencial com o aumento da espessura do meio (KNOLL, 1989; HOLMES-SIEDLE, 2007; SCHWANK; SHANEYFELT; DODD, 2013).

Os fótons com comprimento de onda curto constituem os raios gama e raios-X. Os nomes diferentes são decorrentes do contexto e da época de suas descobertas. Raios gama são emitidos através de interações nucleares, enquanto os raios-X são originados em colisões eletrônicas ou de partículas carregadas. Eles tem como característica serem levemente ionizantes e altamente penetrantes e não deixam nenhuma atividade radioativa no material irradiado. (KNOLL, 1989; HOLMES-SIEDLE, 2007; KAPLAN, 1955; SCHWANK; SHANEYFELT; DODD, 2013).

\subsubsection{Partículas Beta}

Partículas beta possuem a mesma massa do elétron mas podem ser carregadas tanto positivamente (pósitron) quanto negativamente (elétron). Pelo seu tamanho e sua carga, eles penetram mais facilmente no material comparando com as partículas alfa, entretanto são facilmente defletidos. Sua alta velocidade, normalmente próxima da velocidade da luz, significa que eles são levemente ionizantes. (KNOLL, 1989; HOLMES-SIEDLE, 2007). As formas possíveis de emissão das partículas beta estão descritas a seguir.

\subsection{Decaimento Beta}

A fonte mais comum de partículas beta é radioisótopos que decaem por emissão beta. A maioria dos radionuclídeos produzidos por bombardeamento de nêutrons de materiais estáveis são beta-ativos. Desse modo, espécies com diferentes meia-vidas podem ser obtidos, variando de milhares de anos até tão curto quanto o necessário para a aplicação. Cada transição de decaimento beta é caracterizado por uma energia de decaimento fixa. A partícula beta aparece com uma energia que varia desde zero até o ponto final de energia beta (KNOLL, 1989).

\subsection{Conversão Interna}

O espectro contínuo produzido por qualquer fonte beta é inapropriado para algumas aplicações. Por exemplo, para calibração de um detector de elétrons, é muito mais conveniente usar uma fonte monoenergética de elétrons. O processo nuclear de conversão interna pode ser a fonte de elétrons de conversão, o qual é, sob algumas circunstâncias, quase monoenergética.

O processo de conversão interna começa com um estado nuclear excitado, que pode ser formado por um processo anterior, provavelmente um decaimento beta de uma espécie pai. $\mathrm{O}$ 
método mais comum de de-excitação é através de emissão de um fóton de raio gama. Para alguns estados excitados, emissões gama podem ser inibidos e o processo de conversão interna pode se tornar significativa (KNOLL, 1989).

\subsection{Elétrons Auger}

O processo dos elétrons Auger é análogo ao processo de conversão interna quando a excitação é originada no átomo ao invés do núcleo. A energia de excitação do átomo pode ser transferida diretamente para um elétron das camadas mais externas, ejetando o elétron do átomo com uma energia dada pela diferença entre a energia de excitação atômica e a energia da camada de onde o elétron foi ejetado. Essa fonte produz um espectro muito discreto, com diferentes grupos correspondendo a diferentes transições. Em todos os casos, a energia é relativamente baixa comparando com partículas beta e conversão de elétrons (KNOLL, 1989).

\subsubsection{Partículas pesadas}

Por possuírem carga elétrica, as partículas interagem muito facilmente nos meios materiais, seja com o campo elétrico nuclear, seja com o campo elétrico atômico (mais provável). As partículas carregadas perdem energia de maneira quase contínua ao longo do meio material, interagindo com praticamente cada átomo no caminho e transferindo pequenas porções de energia. O elevado número de interações envolvidas e a natureza probabilística destas interações tornam este um processo estocástico, de modo que apenas valores médios de transferência de energia podem ser conhecidos. À perda média de energia por unidade de comprimento de trajetória dá-se o nome de poder de freamento, ou stopping power. A perda gradual de energia das partículas carregadas dá origem a um alcance máximo destas, cujas variáveis são a energia e carga do íon e do número atômico do meio, quando se tratar de partículas carregadas pesadas. Convém mencionar que elétrons sofrem grandes desvios de trajetórias nas interações, ao passo que íons pesados sofrem pouco desvio (KNOLL, 1989; SCHWANK; SHANEYFELT; DODD, 2013).

\subsubsection{Nêutrons}

Os nêutrons são partículas indiretamente ionizantes, uma vez que, por não possuírem carga elétrica, não interagem com os elétrons. Para gerar ionização, um nêutron deve interagir com o núcleo de um átomo do meio e, por espalhamento (elástico ou inelástico) produzir um átomo de recuo que provocará ionizações, ou provocar uma reação nuclear, e neste caso as partículas carregadas oriundas da reação irão produzir as ionizações no meio (KNOLL, 1989). 


\subsection{Ambientes radiativos}

A seção anterior tratou sobre a radiação e suas fontes mais comuns, já nesta seção será feita uma breve descrição dos principais ambientes que podem ter efeitos degradantes em dispositivos eletrônicos e sistemas devido à radiação ionizante: ambiente espacial, reatores nucleares e laboratórios.

\subsubsection{Ambiente Espacial}

O ambiente radiativo espacial é composto por uma variedade de partículas energéticas que possuem energia na ordem de $\mathrm{keV}$ até $\mathrm{GeV}$. As partículas podem tanto estar aprisionadas no campo magnético da Terra, como também atravessando o sistema solar (HOLMES-SIEDLE, 2007; SCHWANK; SHANEYFELT; DODD, 2013). A figura 2 ilustra os tipos de radiação que podem ser encontrados na órbita terrestre. Os principais componentes do ambiente espacial são:

a) Partículas energéticas aprisionadas no campo magnético da terra formando os cinturões de radiação, conhecidos como cinturões de Van Allen.

b) Raios cósmicos compostos por um baixo fluxo de íons pesados estendendo até energias além de $\mathrm{TeV}$ e incluindo todos os íons da tabela periódica.

c) Erupções solares que produzem prótons energéticos com uma pequena composição de partículas alfa, íons pesados e elétrons. Possui energias de centenas de eV até $\mathrm{MeV}$.

Figura 2 - Animação gráfica mostrando a localização dos cinturões de Van Allen e as linhas de campo magnético.

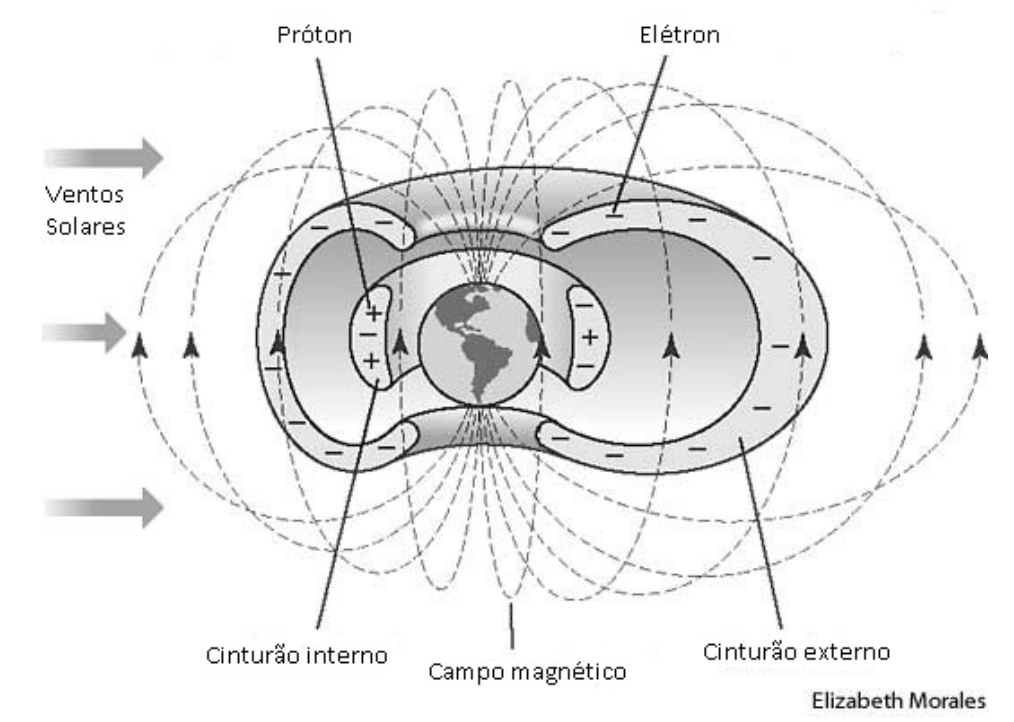

Fonte: (DICTIONARY, 2017) 


\subsubsection{Cinturões de Radiação}

Os cinturões conhecidos como cinturões de Van Allen (vide figura 2) são compostos principalmente por elétrons, com energia de até alguns $\mathrm{MeV}$, e prótons, de algumas centenas de $\mathrm{MeV}$, que estão presos no campo magnético da Terra. O campo magnético não é simétrico e apresenta distorções locais causados pelo desvio entre o eixo magnético e eixo geográfico da Terra. Uma importante distorção é conhecida como Anomalia do Atlântico Sul (AAS), onde o Brasil está exatamente localizado na região dessa anomalia. Os elétrons apresentam dois fluxos: a zona interna e a zona externa. A zona interna se estende até aproximadamente $2.4 \operatorname{Re}$ (onde $\operatorname{Re}$ é o raio da Terra), enquanto a zona externa vai desde $2.8 \mathrm{Re}$ até $12 \mathrm{Re}$. Os elétrons nesse ambiente apresentam um limite inferior de energia de cerca de $100 \mathrm{keV}$ até o limite superior de cerca $7 \mathrm{MeV}$ com a maioria das partículas ocorrendo na zona externa. A figura 3 mostra o fluxo de elétrons do cinturão externo na órbita geoestacionária durante o início do mês de junho de 2017 . O limite de $100 \mathrm{keV}$ é devido ao fato de elétrons abaixo dessa energia não apresentarem grande poder de penetração, ou seja, só penetram em materiais que possuem uma proteção muito fina ou inexistente, não sendo relevante para estudos cujo propósito de desenvolvimento de equipamentos para uso espacial (HOLMES-SIEDLE, 2007; SCHWANK; SHANEYFELT; DODD, 2013).

Figura 3 - Fluxo de elétrons do cinturão externo na órbita geoestacionária.

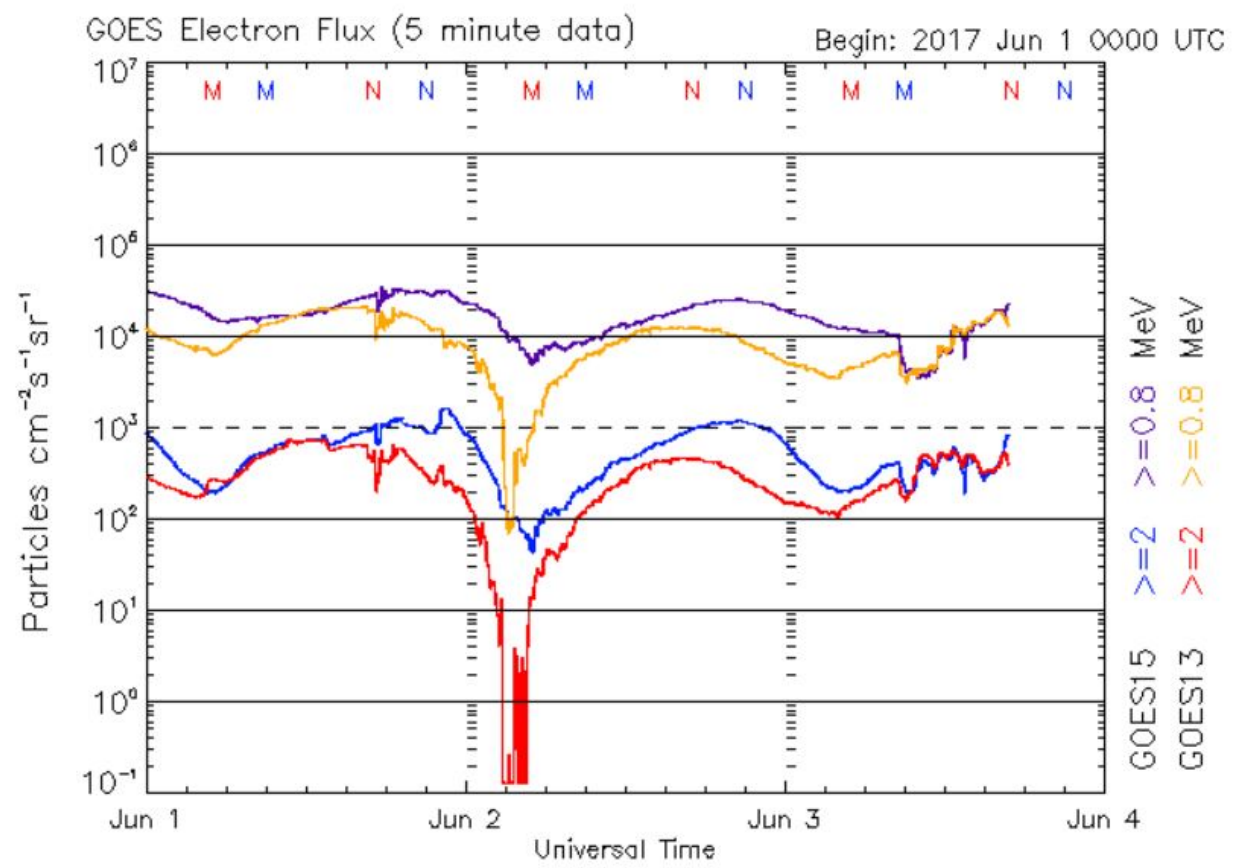

Fonte: Adaptado de National Oceanic, and Atmosphere Administration NOAA/USA

Os prótons armadilhados, com energias de até alguns $\mathrm{GeV}$, são encontrados no cinturão interno com picos de intensidade próximo do equador magnético em altitudes de cerca de 3000 km. É comumente observado como a Anomalia do Atlântico Sul, o qual é uma consequência 
do desvio do campo magnético da Terra em relação ao seu centro de massa. Na figura 4 é possível observar a distribuição do fluxo de prótons na região da AAS durante eventos solares em novembro de 2001 e durante um período de inatividade geomagnética em novembro de 2009. Para altitudes até $2000 \mathrm{~km}$, a radiação é mais intensa sobre o Atlântico Sul e a parte sudoeste do Oceano Pacífico, portanto, para sistemas utilizados nessas regiões, é importante que sua eletrônica seja qualificada e tolerante à radiação ionizante. Acima de $8000 \mathrm{~km}$, a intensidade varia conforme a atividade solar e atividade do campo magnético da Terra (QIN et al., 2014; SCHWANK; SHANEYFELT; DODD, 2013). 
Figura 4 - Distribuição de fluxos de prótons na AAS durante eventos solares em novembro de 2001 (cima) e durante um período geomagnético inativo em novembro de 2009 (baixo).
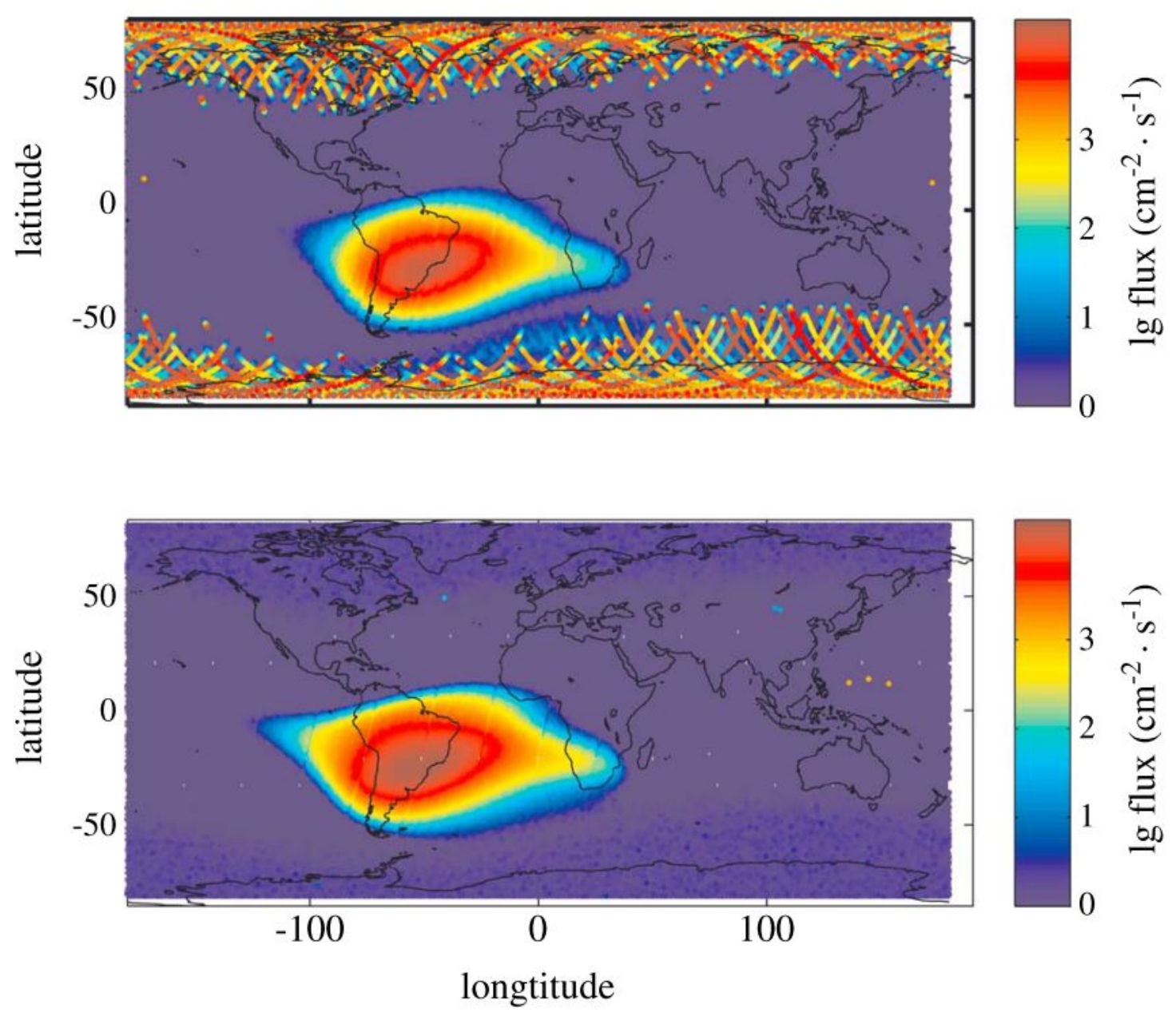

Fonte: (QIN et al., 2014)

\subsubsection{Raios Cósmicos}

Há três fontes de raios cósmicos: galático, solar e terrestre.

\subsection{Raios Cósmicos Galáticos}

Raios Cósmicos Galáticos são raios primários que são originados fora do sistema solar e fornecem um baixo fluxo contínuo de partículas. É composto por cerca de $85 \%$ de prótons, $14 \%$ de partículas alfa e 1\% de núcleos pesados com energias até $1 \mathrm{GeV}$ (HOLMES-SIEDLE, 2007; SCHWANK; SHANEYFELT; DODD, 2013). 


\subsection{Raios Cósmicos Solares}

Além de produzir uma intensa emissão de UV e raios-X, as explosões solares aceleram material solar à velocidades elevadas. Essas partículas são similares aos raios cósmicos galáticos porém, devido a diferente origem, não são idênticas em sua composição. Durante uma explosão solar, raios cósmicos são dominados por material solar de baixo peso atômico com baixas e médias energias. A distribuição de energia não é a mesma para diferentes explosões. A maioria das explosões solares não são orientadas para a Terra, portanto, não tem efeito sobre os equipamentos e espaçonaves que orbitam a Terra. Entretanto, missões espaciais que exploram o espaço profundo podem ser atingidos por essas explosões solares que não afetam a Terra e devem levar em conta a atividade solar nos requisitos desses projetos (HOLMES-SIEDLE, 2007; SCHWANK; SHANEYFELT; DODD, 2013).

\subsection{Raios Cósmicos Terrestres}

A radiação cósmica que penetra na atmosfera terrestre é rapidamente transformada por interações que produzem várias radiações secundárias. Essas radiações secundárias são os principais componentes de radiação cósmica na superfície terrestre. Essa radiação secundária é composta principalmente por neutrôns e pode interagir com semicondutores em aplicações terrestres, produzindo efeitos similares a prótons no espaço. A fluência dos nêutrons podem variar bastante de acordo com a localização na superfície terrestre e também pode variar com a altitude: a fluência dos nêutrons pode ser 200 vezes maior a uma altitude de 35 mil pés se comparado a fluência ao nível do mar. (HOLMES-SIEDLE, 2007; JOHNSTON, 2010; SCHWANK; SHANEYFELT; DODD, 2013).

\subsubsection{Reatores Nucleares}

Um reator nuclear é uma câmara blindada contra a radiação onde é realizado uma reação nuclear com o objetivo de pesquisa, geração de materiais físseis ou geração de energia. Os reatores nucleares apresentam três níveis de ambientes radioativos que precisam ser considerados (KAPLAN, 1955; HOLMES-SIEDLE, 2007):

a) Dentro do núcleo do reator

b) Dentro da contenção

c) Dentro da contenção em caso de acidente

Os tipos de radiação encontrados nesses ambientes estão resumidos na tabela 1 .

É muito improvável que dispositivos eletrônicos irá operar dentro do núcleo, entretanto controladores e alguns outros dispositivos podem ser instalados na câmara de contenção e a radiação exposta na tabela 1 deve ser levado em conta nos projetos desses dispositivos (HOLMESSIEDLE, 2007). 
Tabela 1 - Ambientes radiativos em reatores nucleares

\begin{tabular}{l|l|l|l|l}
\hline \multirow{2}{*}{ Tipos de reatores } & \multicolumn{3}{|c}{ Núcleo } & \multicolumn{2}{c}{ Contenção } \\
& Nêutrons $\left(\mathrm{cm}^{-2} \cdot \mathrm{s}^{-1}\right)$ & Gama $\left(\mathrm{rad} \cdot \mathrm{h}^{-1}\right)$ & Normal (Mrad) & Acidente $(\mathrm{Mrad})$ \\
\hline PWR & $10^{10}-10^{14}$ & $10^{5}-10^{10}$ & $50(\mathrm{em} 40$ anos $)$ & 150 \\
\hline BWR & $10^{10}-10^{14}$ & $10^{5}-10^{10}$ & $50(\mathrm{em} 40$ anos) & 26 \\
\hline FBR & $10^{10}-10^{14}$ & $10^{5}-10^{10}$ & 10 (em 40 anos) & $10^{4}$ \\
\hline
\end{tabular}

Fonte: (HOLMES-SIEDLE, 2007)

\subsubsection{Laboratórios de Física de Alta Energia}

O Grande Colisor de Hádrons (LHC) do CERN é um colisor síncrotron que acelera dois feixes intensos de partículas que circulam em direções opostas e colide em pontos específicos onde estão detectores que são capazes de detectar as partículas provenientes da colisão e, então, é possível estudar as interações entre partículas. O LHC é um dos principais aceleradores do mundo e está sendo utilizado para descobertas importantes no mundo científico, por este motivo é importante conhecer os detalhes do ambiente radiativo do acelerador para ser possível desenvolver e testar dispositivos que serão utilizados em tais ambientes. A eletrônica utilizada no LHC estará exposta a altos fluxos de hádron. Nos experimentos, píons são o principal componente destes fluxos perto do ponto de colisão. Nêutrons dominam o fluxo de partículas nos experimentos restantes, principalmente onde dispositivos comerciais de prateleira - Comercial Off-The-Shelf (COTS) na sigla em inglês - são utilizados. Em resumo, o dispositivo estará exposto a danos por radiação, irradiação de nêutrons com energia equivalente de $1 \mathrm{MeV}$ podendo causar danos estruturais devido a deslocamento atômico e também irradiação de várias espécies de partículas com energias variadas (FACCIO, 2000; HOLMES-SIEDLE, 2007).

\subsection{Interação da Radiação na Matéria}

Após a descrição teórica sobre radiação ionizante, seus principais tipos e os ambientes onde os dispositivos eletrônicos sofrem uma degradação devido à radiação ionizante, será descrito como a interação da radiação ionizante com a matéria ocorre.

A interação da radiação com alvos depende de uma série de fatores como massa, cargas, energia cinética da partícula incidente, massa atômica e densidade do material. Há um número específico de tipos de interações que podem ocorrer entre partículas e os átomos do material. Se a partícula incidente for um fóton poderá ocorrer o efeito fotoelétrico, o espalhamento Compton ou a produção de pares. Se for uma partícula carregada poderá ocorrer o espalhamento Rutherford e interações nucleares. Se a partícula for um nêutron poderá ocorrer interações nucleares como espalhamento elástico, espalhamento inelástico e reações de transmutação (MCLEAN; OLDHAM, 1989; SCHWANK; SHANEYFELT; DODD, 2013). 


\subsubsection{Interações de Fótons}

Nos três casos em que o fóton pode interagir com os átomos, as interações produzem elétrons livres. A probabilidade de cada interação (efeito fotoelétrico, espalhamento Compton ou produção de pares) depende da energia do fóton e do número atômico do material-alvo. Na figura 5 é apresentado uma figura onde pode ser observado o efeito dominante para diferentes materiais em função da energia do fóton (MCLEAN; OLDHAM, 1989; SCHWANK; SHANEYFELT; DODD, 2013).

Figura 5 - As três interações de fótons em função do número atômico e energia.

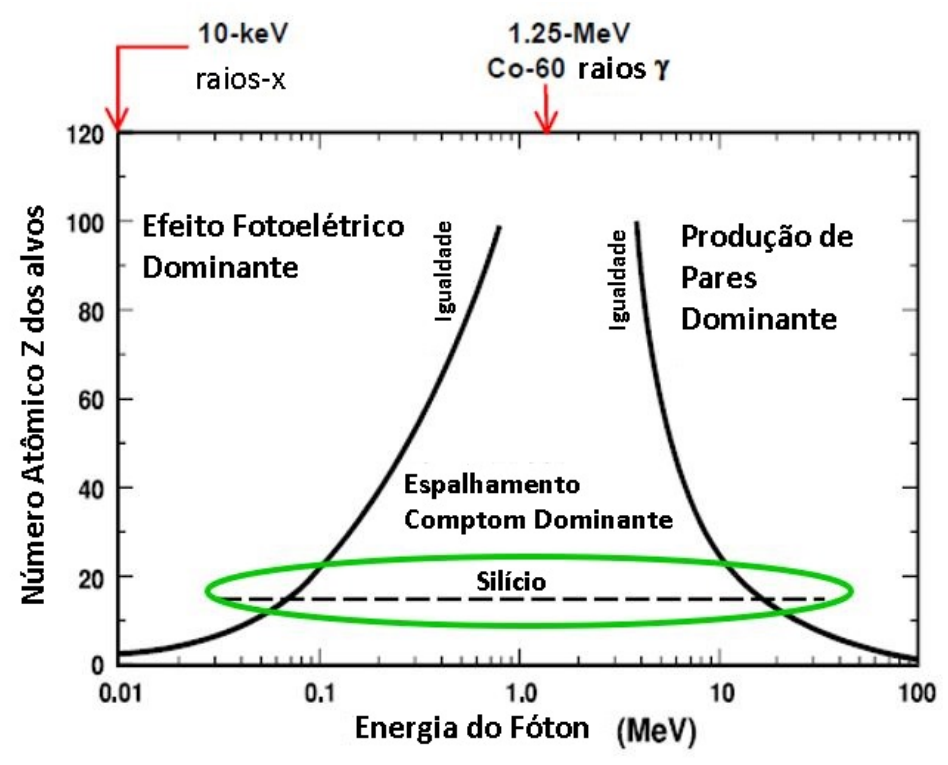

Fonte: (MCLEAN; OLDHAM, 1989)

No efeito fotoelétrico, a energia do fóton incidente pode ser completamente absorvida pelo elétron emitido (fotoelétron). Se um elétron da camada $\mathrm{K}$ for emitido, então um elétron da camada L pode ocupar o espaço deixado pelo elétron da camada K. Esse processo pode dar origem a um raios- $X$ característico ou a um elétron de baixa energia, dependendo do valor do número atômico do material-alvo (MCLEAN; OLDHAM, 1989; SCHWANK; SHANEYFELT; DODD, 2013).

Já o espalhamento Compton não envolve a absorção completa da energia do fóton incidente. Nesse efeito, a energia do fóton é muito maior que a energia de atração dos elétrons do átomo. O fóton incidente fornece uma parte da energia para espalhar um elétron atômico enquanto o fóton espalhado, já com uma energia menor, continua a atravessar o material (MCLEAN; OLDHAM, 1989).

A produção de pares, por sua vez, tem um limiar de energia em torno de 1,02 MeV. Acima dessa energia, o fóton pode ser completamente absorvido e causar a formação de um par elétron-pósitron. A figura 5 ilustra as três interações do fóton na matéria. Para o silício, o efeito 
fotoelétrico é dominante para energias menores que $50 \mathrm{keV}$ e a produção de pares é o principal efeito para energias acima de $20 \mathrm{MeV}$ (MCLEAN; OLDHAM, 1989).

\subsubsection{Interações com Partículas Carregadas}

Partículas carregadas interagem com o material principalmente através do espalhamento de Rutherford. Essa interação pode causar a excitação e ionização dos elétrons atômico, além de poder transferir energia suficiente para deslocar os átomos de suas posições na estrutura do material. A ionização do material é o principal efeito das interações de partículas carregadas, especialmente elétrons, prótons, partículas alfa e íons pesados em semicondutores e isolantes (MCLEAN; OLDHAM, 1989; SCHWANK; SHANEYFELT; DODD, 2013). A seguir será descrito o principal processo de perda de energia das partículas em meios materiais e como a taxa de deposição de energia no material é calculada.

\subsubsection{Poder de Freamento Eletrônico}

O poder de freamento eletrônico é a principal componente dominante do processo de perda de energia de partículas aceleradas em meios materiais. A interação do íon com os elétrons atômicos do meio pode provocar excitações, por exemplo raios-X, quando o parâmetro de impacto é alto ou ionizações, quando o parâmetro de impacto é baixo. Se a velocidade do íon é grande comparada à dos elétrons atômicos, podemos calcular o poder de freamento pela teoria de Bethe-Bloch, na qual é descrita através da equação 5:

$$
\frac{d E}{\rho d x}=\frac{4 \pi N Z_{2} Z_{1}^{* 2} e^{4}}{m_{e} v^{2}}\left[\ln \left(\frac{2 m_{e} v^{2}}{I}\right)+\frac{C(v)}{Z_{2}}+\frac{v^{2}}{c^{2}}-\ln \left(1-\frac{v^{2}}{c^{2}}\right)-\delta\right]
$$

onde I é a energia média de ionização, $\delta$ é a correção de densidade (efeito do campo elétrico na trajetória da partícula em altas velocidades), $\mathrm{C}(\mathrm{v}) / Z_{2}$ é a correção de camadas (leva em consideração que os elétrons atômicos não são estacionários), $m_{e}$ é massa do elétron, $\mathrm{v}$ é a velocidade da partícula, c é a velocidade da luz, $Z_{2}$ o número atômico dos átomos constituintes do meio e $Z_{1}^{*}$ a carga efetiva do íon em trânsito. A captura de elétrons do meio modifica a carga efetiva do íon pesado, alterando sua interação com os elétrons num processo onde a perda de energia é bem elevada, a qual chamamos de pico de Bragg. Para cálculo do poder de freamento, perdas de energia e outros parâmetros importantes nos laboratórios de Física Nuclear, utiliza-se parametrizações semi-empíricas. A mais utilizada atualmente é a devida a Ziegler, Biersack e Littmark (ZBL) e baseia-se num conjunto amplo de dados experimentais (AGUIAR, 2014; LINARES, 2009; NAKAMURA; GROUP, 2010; SCHWANK; SHANEYFELT; DODD, 2013). 


\subsubsection{Taxa de Deposição de Energia do Íon}

Define-se transferência linear de energia (Linear Energy Transfer (LET)) como a quantidade de energia depositada por unidade de trajetória do íon no meio, enquanto o poder de freamento é a perda de energia por unidade de trajetória do íon no meio. A energia depositada é aquela perdida pelo íon, então, leva-se a acreditar que esses valores devessem ser iguais porém devemos levar em consideração que o LET é uma quantidade definida localmente de modo que elétrons ejetados devido ao depósito de energia com energia superior a uma energia de corte $\Delta$ não são contabilizadas na energia depositada no volume considerado. Entretanto, é muito difícil realizar os cálculos de LET com valores de corte e prever em quais condições cada valor de energia de corte será válido. Então, para simplificar, os cálculos de LET podem ser feitos considerando $\Delta=\infty$, onde o poder de freamento de colisão do íon no meio é numericamente igual ao LET (OKUNO; YOSHIMURA, 2010; AGUIAR, 2014; ATTIX; TOCHILIN; ROESCH, 1966; SCHWANK; SHANEYFELT; DODD, 2013).

\subsection{Dispositivos Semicondutores}

Após uma breve descrição teórica sobre a radiação ionizante, os principais ambientes radiativos onde sistemas eletrônicos podem operar e as formas que essas radiações interagem com a matéria, será apresentada uma breve teoria sobre dispositivos semicondutores e como a radiação ionizante pode afetar tais dispositivos.

Os semicondutores são materiais que possuem características elétricas em uma região intermediária entre o isolante elétrico e o condutor elétrico. Eles permitem a construção de dispositivos eletrônicos que controlam a direção e a intensidade de corrente elétrica. O semicondutor mais utilizado é o silício, elemento da família IV-A e possui quatro elétrons de valência. Um conjunto de átomos de silício pode ser arranjado de forma amorfa ou na forma cristalina, de modo que o potencial apresenta periodicidade. Em um átomo simples, os elétrons ocupam níveis de energia discretos. Quando vários átomos estão próximos e possuem a mesma configuração eletrônica, a estrutura formada apresenta uma faixa de energia onde são permitidos elétrons e uma faixa de energia proibida. Essa faixa surge devido ao princípio de exclusão de Pauli, onde somente dois elétrons de spins opostos podem ocupar o mesmo nível energético (COLINGE, J. P.; COLINGE, C. A., 2007).

\subsubsection{Eletrônica}

Muito mudou desde o efeito transistor descoberto por Bardeen, Schockley e Brattain em 1947 (BRINKMAN; HAGGAN; TROUTMAN, 1997). Na época, o transistor era vísivel ao olho humano e fabricado a partir de uma folha de ouro pressionado contra uma lâmina de germânio. Hoje os transistores estão no limite físico de alguns átomos compondo o óxido 
de porta e com tamanhos cada vez menores, o que proporcionou a construção de circuitos eletrônicos cada vez mais complexos e com maior desempenho. Diferentemente do transistor criado nos laboratórios Bell, os transistores atuais são em sua maioria baseados na tecnologia MOS (Metal-Óxido-Silício) na qual é possível construir circuitos com uma densidade enorme de transistores em uma pastilha de silício (BRINKMAN; HAGGAN; TROUTMAN, 1997).

\subsubsection{Transistor MOS}

O transistor MOS ou Metal-Oxide-Silicon Field-effect Transistor (MOSFET) é o dispositivo semicondutor mais utilizado na indústria da microeletrônica. Para exemplificar o crescimento do emprego desses dispositivos na fabricação de circuitos integrados durante as últimas décadas, podemos citar a famosa lei de Moore onde Gordon Moore, em 1965, fez uma previsão de um crescimento exponencial de potência e número de transistores empregados na fabricação dos circuitos integrados. Essa lei se tornou a regra de ouro que guiou a indústria eletrônica durante décadas e o transistor MOS configurou-se como protagonista devido a sua enorme capacidade de escalamento (INTEL, 2015).

O MOSFET é um dispositivo de quatro terminais chamados de porta, dreno, fonte e substrato, como mostrado na figura 6. Ele é baseado em uma estrutura chamada capacitor MOS que consiste de uma camada de metal ou semicondutor altamente dopado, uma camada de isolante geralmente composto por dióxido de silício e o semicondutor. Através de uma tensão no terminal de porta, é possível controlar as características do canal entre fonte e dreno e, portanto, controlar a corrente elétrica que flui entre esses terminais. O MOSFET apresenta duas regiões de condução de corrente distintas em sua curva característica $I_{D}-V_{D S}$ : região de triodo e região de saturação. Essas duas regiões estão exemplificadas na figura 7. 
Figura 6 - Estrutura do transistor MOS .

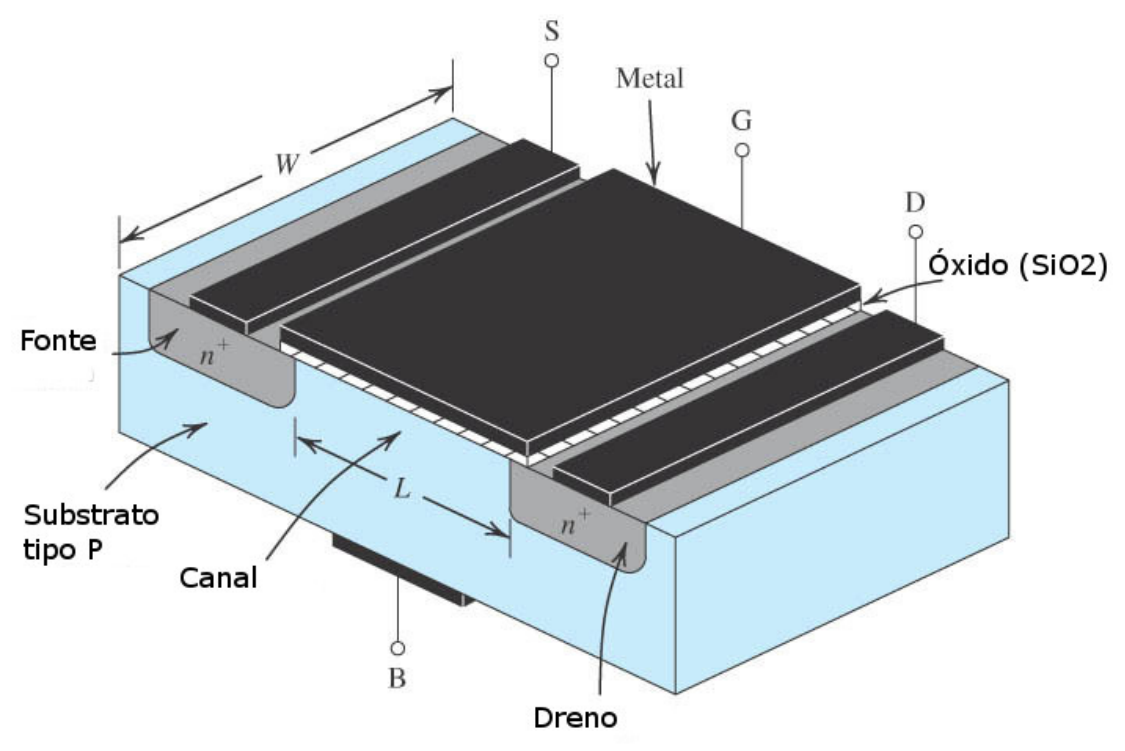

Fonte: (SEDRA; SMITH, 2015)

Figura 7 - Exemplo de curva característica $I_{D}-V_{D S}$.

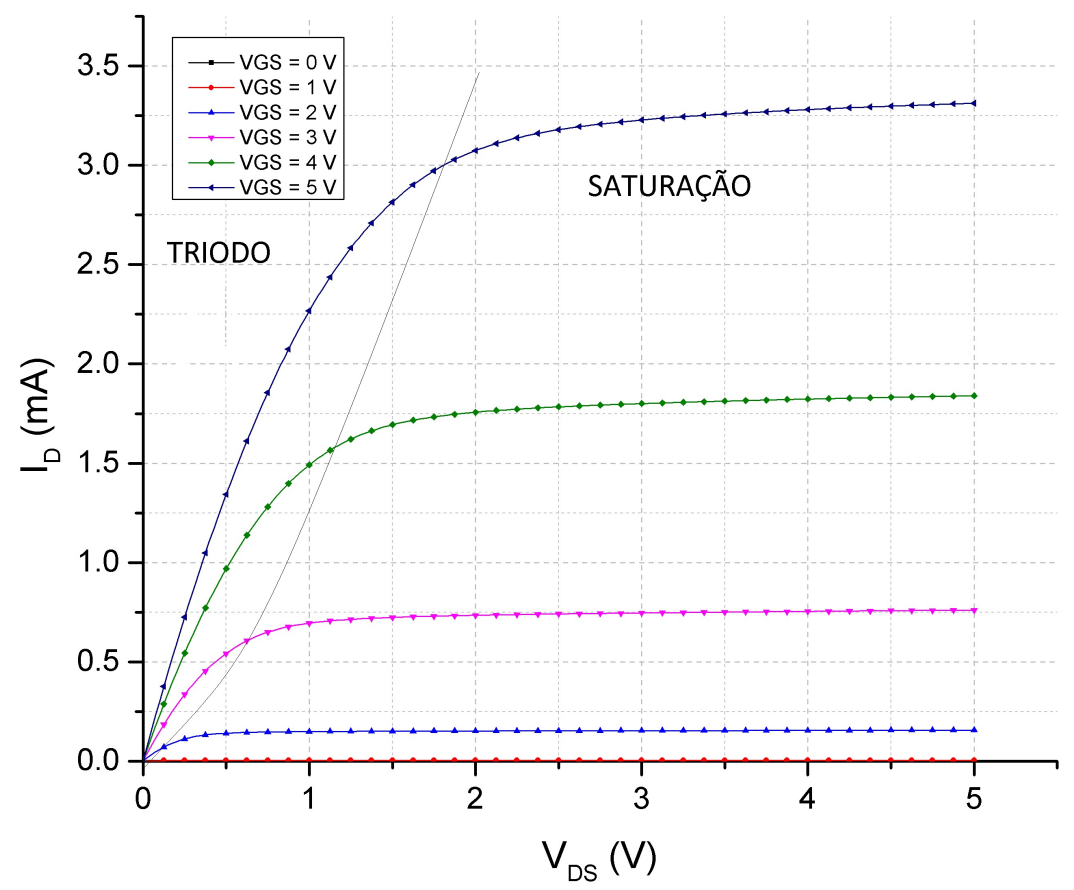

Fonte: Medidas experimentais do autor.

O dispositivo também possui uma segunda curva característica: curva $I_{D}-V_{G S}$. Ela fornece alguns parâmetros e informações sobre o dispositivo como, por exemplo, a tensão de limiar e a inclinação de sublimiar. A tensão de limiar será descrita teoricamente na seção se- 
guinte. A figura 8 mostra exemplos dessas curvas e como esses parâmetros podem ser extraídos graficamente.

Figura 8 - Exemplo de curva característica $I_{D}-V_{G S}$ em escala linear e logarítmica.

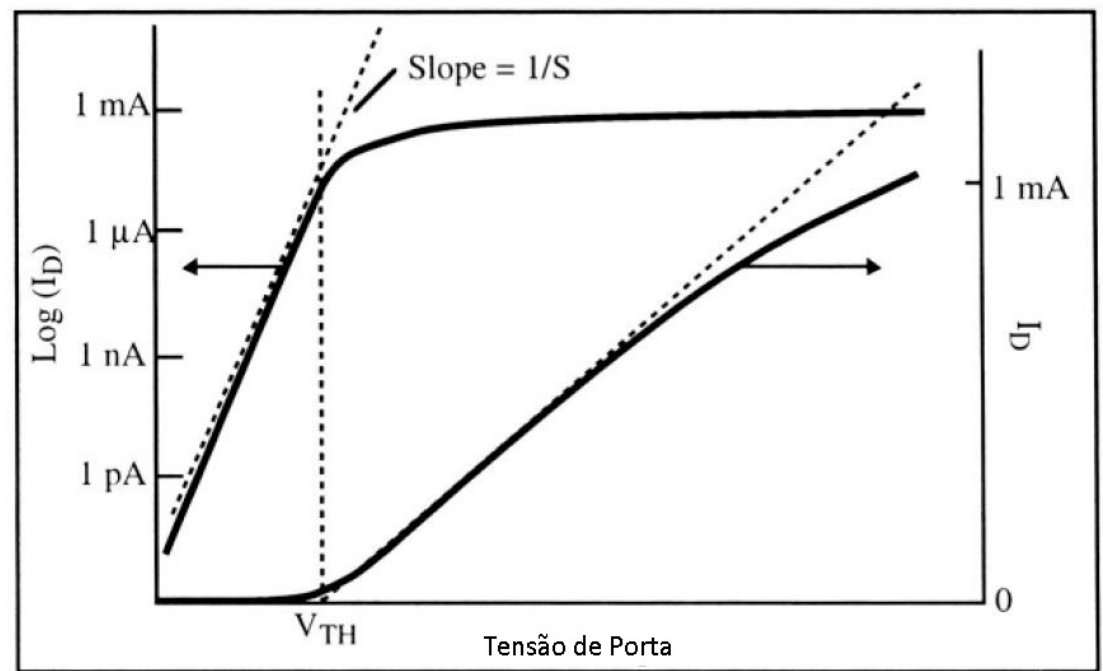

Fonte: (COLINGE, J. P.; COLINGE, C. A., 2007)

A seguir serão descritos alguns parâmetros do MOSFET que podem ser afetados pela radiação ionizante. As formas como esses parâmetros são afetados serão descritas em uma outra seção quando os efeitos da radiação em semicondutores serão explicados em maior detalhe.

\subsection{Tensão de Limiar}

Através da análise do diagrama de bandas de energia do capacitor MOS, apresentado na figura 9 - onde Ec é a energia da banda de condução, Ev é a energia da banda de valência, Ei é o nível de Fermi para o silício intrínseco e Ef é o nível de Fermi do silício dopado - é possível extrair a equação 6 que descreve a tensão de limiar, a qual é definida como a tensão onde a concentração de portadores minoritários na região do canal se iguala com a concentração de portadores majoritários:

$$
V_{T H 0}=\Phi_{m s}-\frac{Q_{o x}}{C_{o x}}+\frac{2 q N_{i t} E_{F}}{C_{o x}}+2 E_{F}+\frac{\sqrt{4 q \varepsilon_{S i} N_{a} E_{F}}}{C_{o x}}
$$

onde $V_{T H 0}$ é a tensão de limiar da estrutura MOS, $\Phi_{m s}$ é a diferença da função trabalho do silício e do material de porta, $Q_{o x}$ é a densidade de cargas aprisionadas no óxido, $C_{o x}$ é a capacitância do óxido por unidade de área, q é a carga do elétron, $N_{i t}$ é a densidade intrínseca de portadores do silício, $E_{F}$ é o nível de Fermi do silício, $\varepsilon_{S i}$ é a permissividade do silício e $N_{a}$ é a densidade de portadores majoritários. A figura 9 mostra o diagrama de bandas de energia para diferentes polarizações de porta de uma estrutura MOS, onde a figura A é o diagrama de bandas de faixa plana, a figura B é o diagrama de bandas do dispositivo em acumulação, a figura 
C é o diagrama de banda do dispositivo em depleção e a figura $\mathrm{D}$ é o diagrama de bandas do dispositivo em inversão.

Figura 9 - Bandas de energia em uma estrutura MOS em diferentes níveis de polarização de porta.

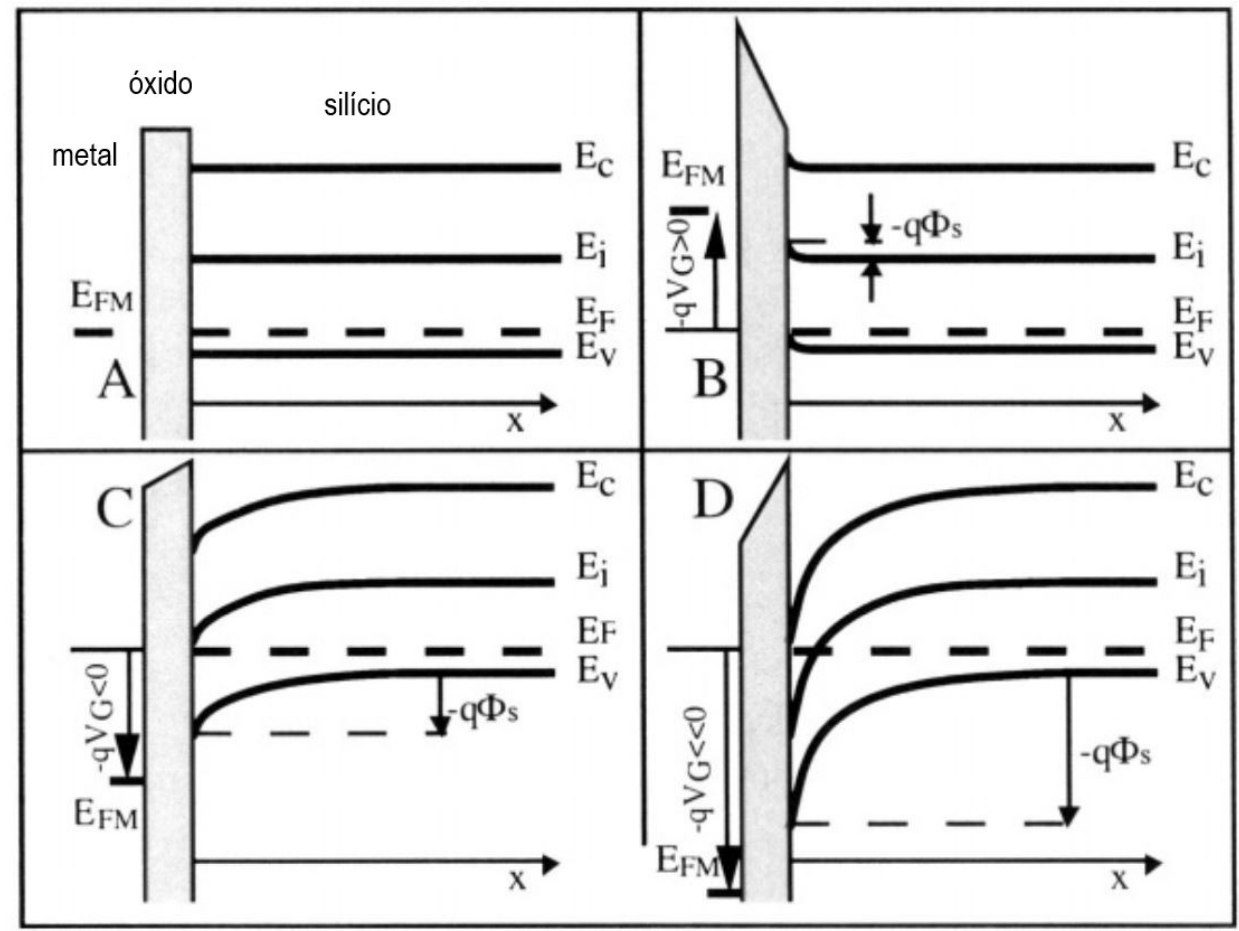

Fonte: (COLINGE, J. P.; COLINGE, C. A., 2007)

\subsection{Cargas no óxido}

É possível observar que a densidade de cargas no óxido de porta afeta a tensão de limiar do dispositivo através do termo $\frac{Q_{o x}}{C_{o x}}$ apresentado na equação 6. As cargas no óxido são aprisionadas durante o crescimento do óxido no processo de fabricação devido a presença de imperfeições nas ligações entre átomos de silício e oxigênio ou pela presença de íons metálicos no material. Essas cargas podem apresentar tanto caráter fixo ou móvel dentro do óxido, ou seja, a distribuição espacial dessas cargas podem ser alteradas com a aplicação de um campo elétrico. Também já foi reportado em estudos anteriores que as cargas afetam outros parâmetros do MOSFET como, por exemplo, a mobilidade de portadores (COLINGE, J. P.; COLINGE, C. A., 2007; PHANSE et al., 1993).

\subsection{Armadilhas de Interface}

A presença da interface entre $\mathrm{Si}-\mathrm{SiO}_{2}$ introduz uma perturbação na periodicidade na estrutura cristalina do semicondutor e isso provoca que algumas ligações entre átomos de silício 
fiquem incompletas, criando estados de energia dentro da faixa proibida (bandgap) na região de interface. Esses estados são conhecidos como estados de interface ou armadilhas de interface e podem ser carregadas tanto positivamente quanto negativamente. A contribuição desses estados de energia de interface na equação da tensão de limiar são modelados através da equação 7:

$$
V_{i t}=\frac{2 q \cdot N_{i t} \cdot \Phi_{F}}{C_{o x}}
$$

onde $V_{i t}$ é a tensão que deve ser aplicada à porta para compensar a densidade de cargas na interface, $N_{i t}$ é a densidade de estados de interface dado em $\mathrm{cm}^{-2} . V^{-1}$, $\Phi_{F}$ é o nível de Fermi e $C_{o x}$ é a capacitância do óxido por unidade de área (COLINGE, J. P.; COLINGE, C. A., 2007).

\subsection{Relação $I_{D}-V_{D S}$ de um transistor MOS}

A relação entre corrente do canal, $I_{D}$, e a tensão de dreno, $V_{D S}$, pode ser extraída considerando o canal como um simples material resistivo obtendo a seguinte equação:

$$
I_{D}=\mu \cdot C_{o x} \cdot \frac{W}{L} \cdot\left[\left(V_{G S}-V_{T H}\right) \cdot V_{D S}-\frac{1}{2} \cdot V_{D S}^{2}\right]
$$

onde $\mu$ é a mobilidade do portador, $C_{o x}$ é a capacitância do óxido por unidade de área,

$\frac{W}{L}$ é a razão de aspecto do MOSFET, $V_{G S}$ é a tensão de porta aplicada, $V_{T H}$ é a tensão de limiar e $V_{D S}$ é a tensão aplicada ao dreno. Essa equação está numa forma simplificada onde são desconsiderados alguns efeitos de segunda ordem como, por exemplo, o efeito da polarização do substrato e é válida somente na região de triodo (COLINGE, J. P.; COLINGE, C. A., 2007; SEDRA; SMITH, 2015). O transistor atinge a região de saturação quanto a tensão entre fonte e dreno, $V_{D S}$, é igual a diferença entre a tensão de porta, $V_{G}$, e a tensão de limiar $V_{T H}$, resultando na equação:

$$
I_{D}=\mu \cdot C_{o x} \cdot \frac{W}{L} \cdot\left[\frac{\left(V_{G S}-V_{T H}\right)^{2}}{2}\right]
$$

\subsection{Relação $I_{D}-V_{G S}$ de um transistor MOS}

A relação $I_{D}-V_{G S}$ para um transistor operando em saturação é muito importante pois fornece informações e parâmetros do dispositivo, descritos na sequência desse trabalho, que podem ser usados para avaliar danos causados pela radiação ionizante. 
Figura 10 - Curva característica $I_{D}-V_{G S}$ de um MOSFET.

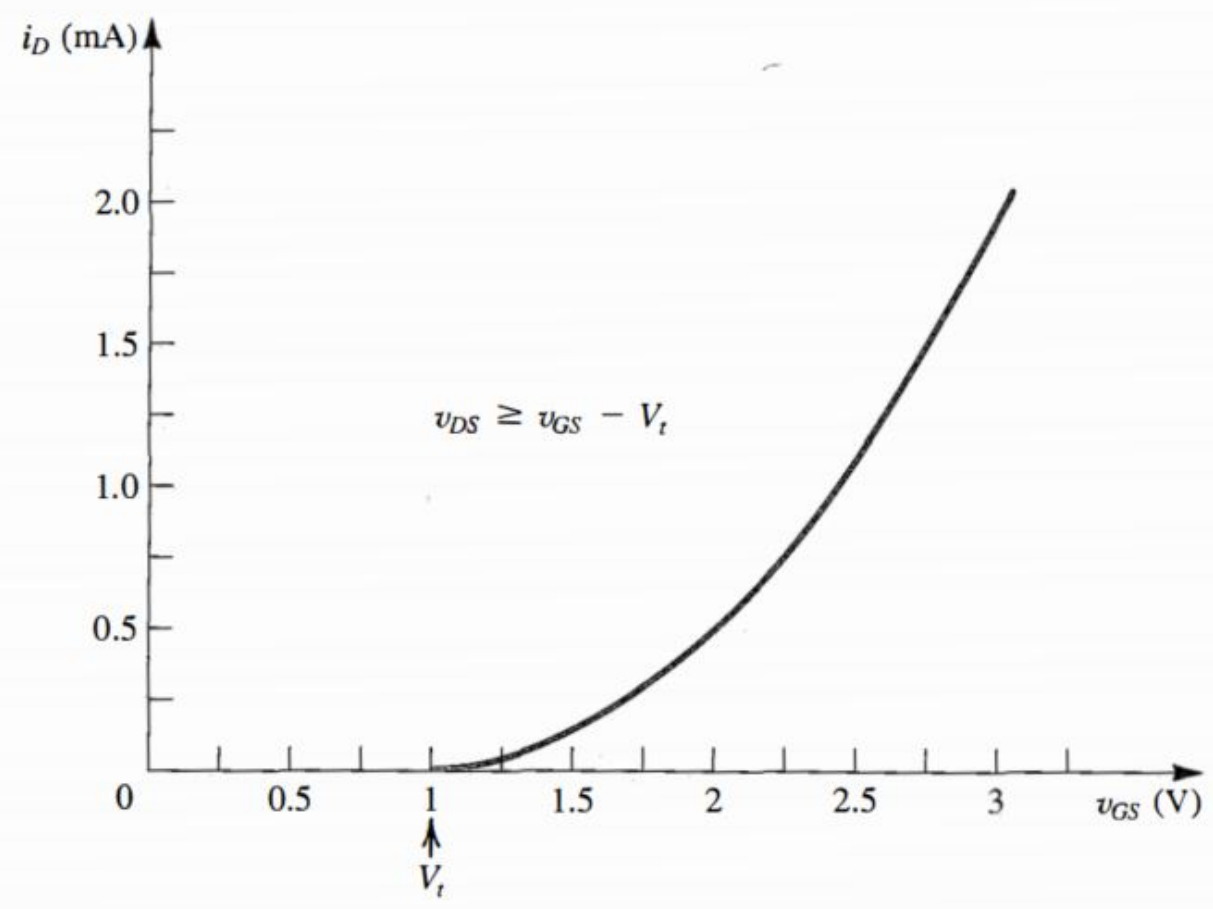

Fonte: (SEDRA; SMITH, 2015)

\subsection{Transcondutância}

A transcondutância do transistor é definida como a variação da corrente de dreno devido a uma variação da tensão de porta (COLINGE, J. P.; COLINGE, C. A., 2007), dado por:

$$
g_{m}=\mu \cdot C_{o x} \cdot \frac{W}{L} \cdot V_{D S}
$$

A transcondutância pode ser entendida como a capacidade de variar a corrente que flui no canal devido a tensão de porta e pode ser usado para avaliar os danos causados pela radiação ionizante.

\subsection{Mobilidade de Superfície Efetiva}

A mobilidade dos portadores de um MOSFET, $\mu$, utilizada nos modelos apresentados nesse trabalho não é a mobilidade dos portadores no silício e sim a mobilidade de superfície. A mobilidade de superfície é mais baixa em relação a mobilidade no silício pois leva em conta a interação dos portadores com a interface silício-óxido. A mobilidade de superfície depende de como os portadores interagem com a superfície e, portanto, depende do campo elétrico aplicado no dispositivo que atraem os portadores para a interface (COLINGE, J. P.; COLINGE, C. A., 2007). A figura 11 mostra os efeitos da mobilidade nas curvas características do MOSFET, 
como a curva $I_{D}-V_{G S}$ e curva de transcondutância. Esse parâmetro também pode ser utilizado para avaliar os danos causados pela radiação ionizante.

Figura 11 - Exemplos do efeito da mobilidade de superfície nas curvas características de um MOSFET.

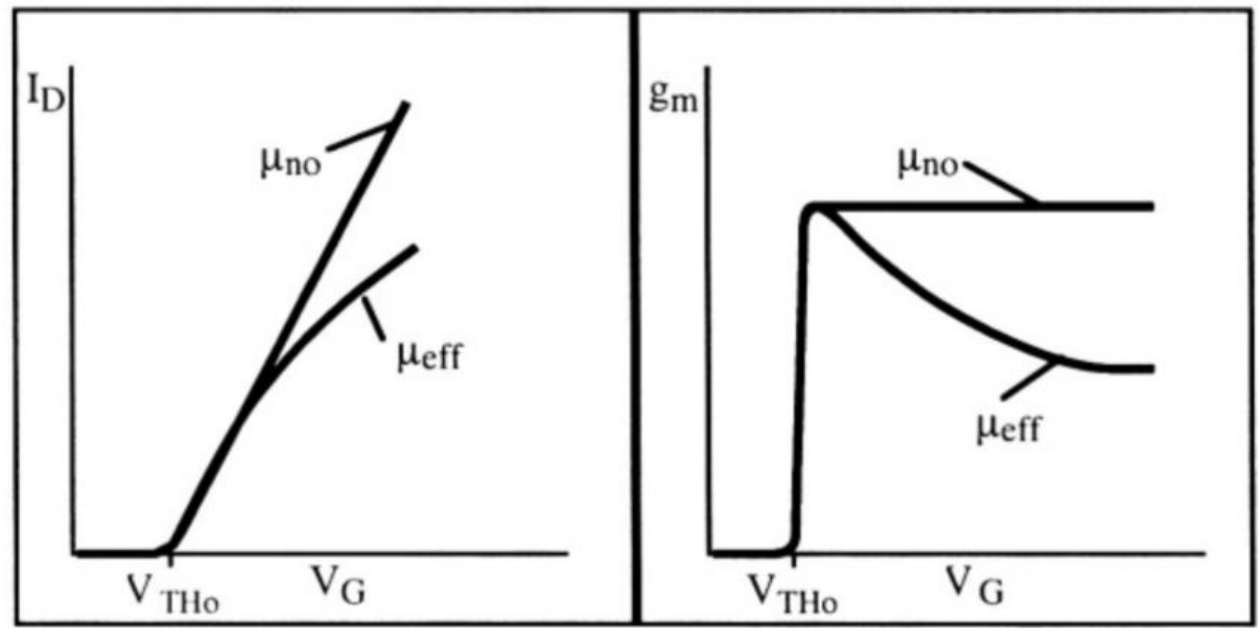

Fonte: (COLINGE, J. P.; COLINGE, C. A., 2007)

\subsubsection{Dispositivos Programáveis}

Como o foco do trabalho é criar uma metodologia de teste para microcontroladores, se torna necessário uma breve descrição teórica sobre dispositivos programáveis. Um dispositivo eletrônico programável é uma combinação de dispositivos digitais e circuitos, construídos a partir de transistores, que podem executar uma tarefa ou sequência de instruções programadas com um mínimo de intervenção humana (TOCCI; WIDMER; MOSS, 2016). Os microprocessadores e microcontroladores são dispositivos programáveis atualmente muito utilizados na indústria eletrônica devido à sua performance, custo e disponibilidade no mercado. Eles são compostos por circuitos lógicos que controlam a entrada e saída de informações, buscando as instruções a serem executadas em uma memória e realizando operações com os valores gravados na memória. No caso de microcontroladores atuais de 32-bits, a memória de programa é construída utilizando uma memória não-volátil flash NOR desenhada a partir de um transistor de gate flutuante. A memória volátil é baseada na arquitetura de RAM estática (SRAM). A figura 12 mostra um exemplo do layout de um microcontrolador em uma pastilha de silício onde é possível observar algumas regiões retangulares grandes, que são as memórias, e uma região mais heterogênea, onde são implementados os circuitos lógicos do dispositivo. 
Figura 12 - Fotografia feita por um microscópico de um microcontrolador.

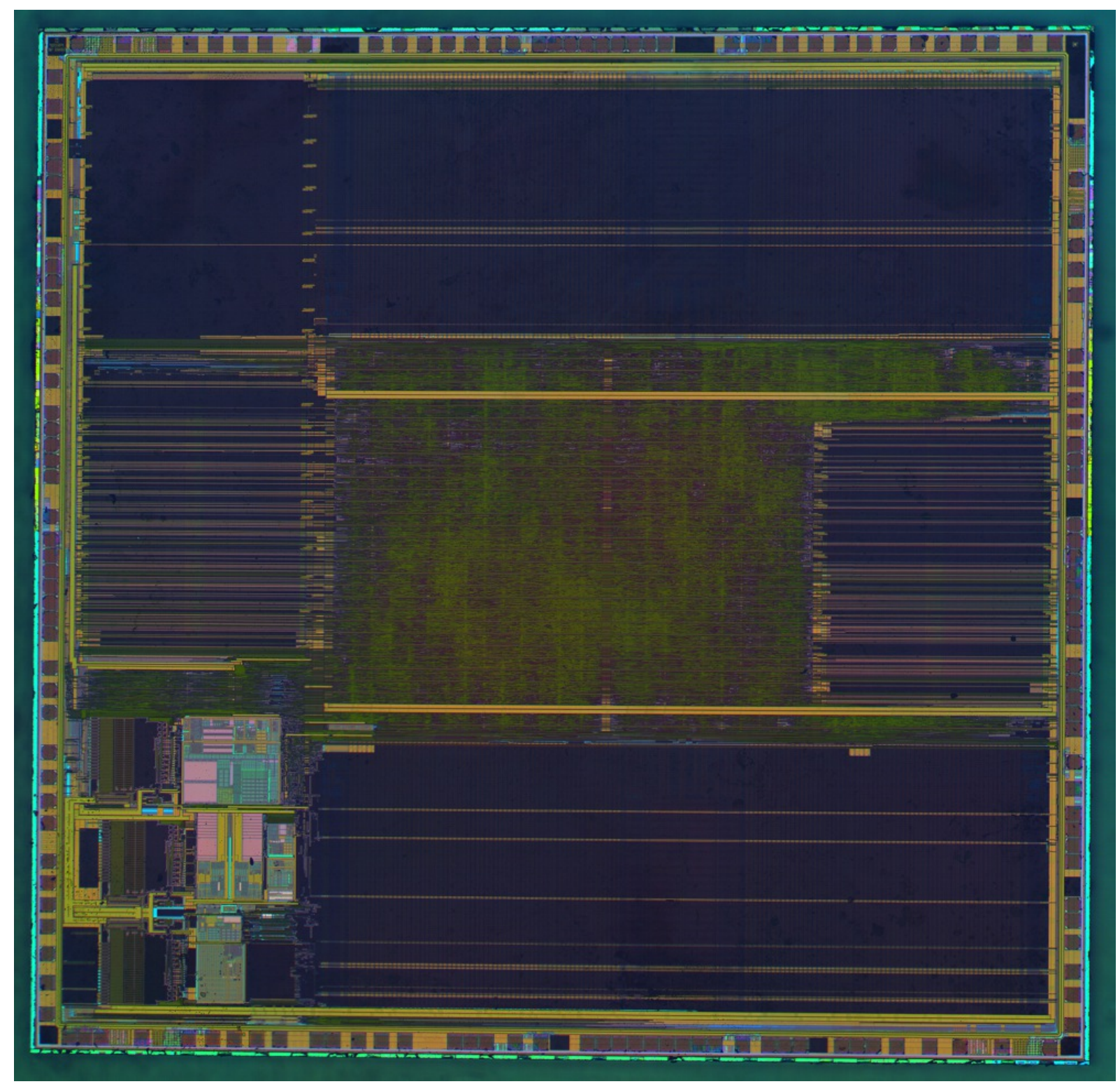

Fonte: Autor

\subsubsection{Transistor de Porta Flutuante}

Um transistor MOS de porta flutuante tem um papel importante nas memórias nãovoláteis, como a Memória Programável Apagável Somente de Leitura (EPROM), Memória Programável Apagável Eletricamente Somente de Leitura (EEPROM) e flash. A figura 13 mostra a estrutura de um transistor de porta flutuante. A condutividade do transistor de porta flutuante determina a informação armazenada na célula de memória. $\mathrm{O}$ transistor de porta flutuante leva esse nome por ter uma porta completamente cercada por dielétrico, chamada de porta flutuante Floating Gate (FG), na qual é controlada através de acoplamento capacitivo por uma porta de controle Control Gate (CG). Por ser eletricamente isolado, o FG atua como um dispositivo ar- 
mazenador de cargas e a carga injetada nesse eletrodo é mantida, permitindo uma modulação da tensão de limiar ( $V_{T H}$ visto pelo $C G$ ) da célula. Geralmente o dielétrico de porta entre o canal e o FG posui uma espessura na ordem de 9-10 nm e é chamado de óxido de tunelamento, uma vez que o tunelamento Fowler-Nordheim é o mecanismo utilizado para apagar a informação armazenada na célula (LENZLINGER; SNOW, 1969). Já o dielétrico que separa o FG do CG é formado por uma camada tripla de Óxido-Nitreto-Óxido (ONO) e foi introduzida para melhorar a qualidade do óxido de tunelamento, uma vez que o crescimento térmico do óxido de silício atinge temperaturas elevadas e pode comprometer a qualidade do óxido de tunelamento. A espessura da camada ONO tem entre 15-20 nm de espessura equivalente de óxido (WANG, 1979; BEZ et al., 2003). A figura 14 mostra, em termos de diagramas de banda de energia, o armazenamento de informação binária em um transistor de porta flutuante.

Figura 13 - Estrutura de um transistor de porta flutuante.

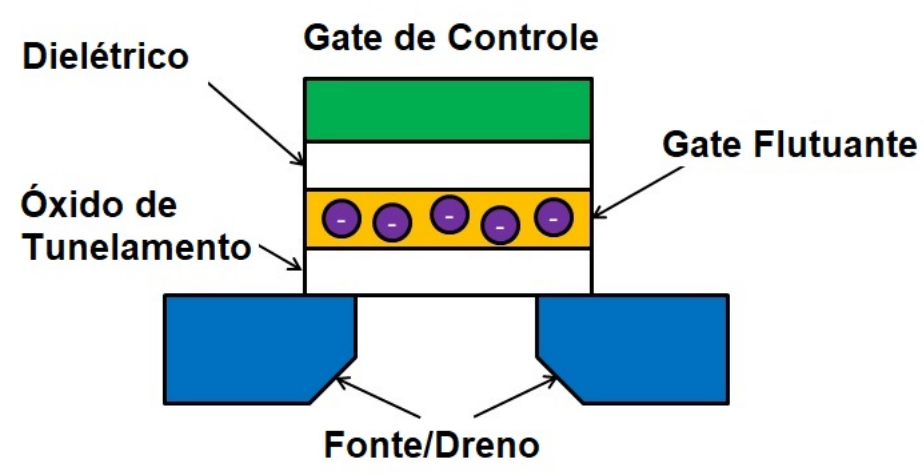

Fonte: (BEZ et al., 2003) 
Figura 14 - Diagrama de bandas de energia de um transistor de porta flutuante .

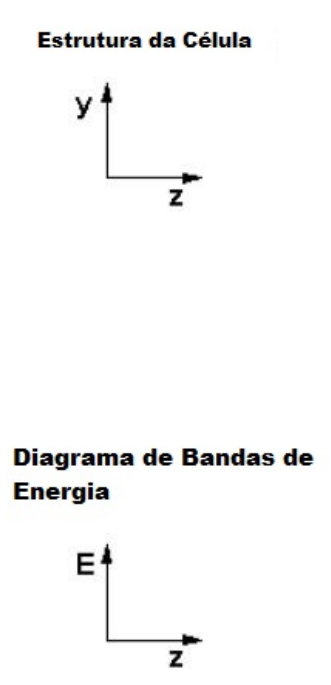

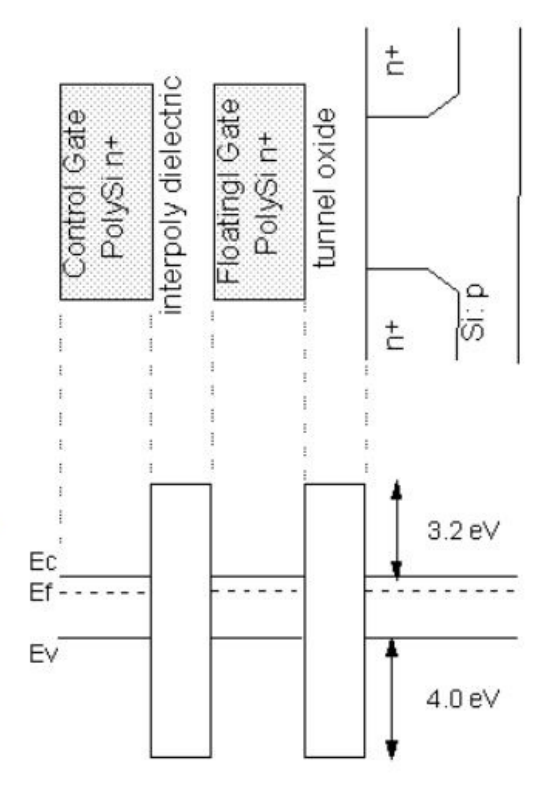

Neutro - "1"

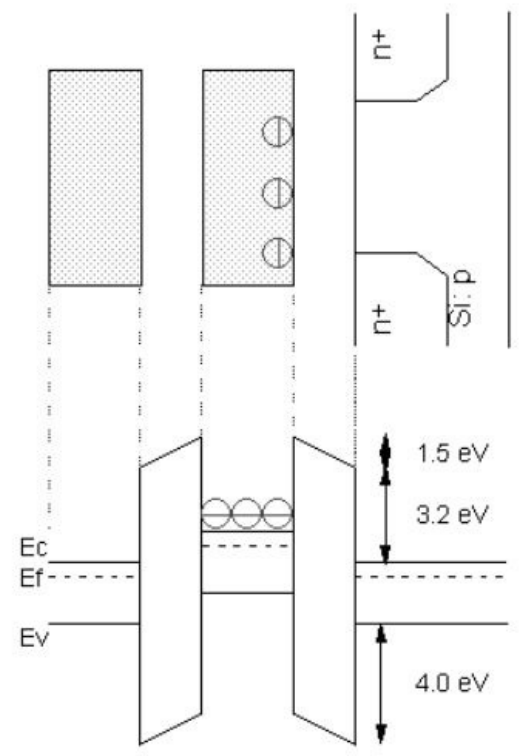

Carregado - "0"

(BEZ et al., 2003)

\subsubsection{Memórias Flash}

As memórias flash são memórias não-voláteis que ocupam um espaço importante na construção de dispositivos programáveis modernos. Na década de 1980, era utilizado a EPROM, um tipo de memória não-volátil que necessitava de uma fonte UV para apagar as células de memória. Como um avanço, surgiu a flash EEPROM como uma alternativa para a EPROM. A flash EEPROM tinha como principal característica ser apagável eletricamente e o termo "flash"era devido ao fato de todas as células de memória serem apagadas todas ao mesmo tempo. A figura 15 ilustra a relação das diferentes memórias flash em relação a custo e flexibilidade de uso. A princípio as memórias flash eram apenas alternativas para as EPROM com a vantagem de não precisar de uma fonte UV para apagar as memórias, mas no início dos anos 2000 a memória flash já era considerada uma tecnologia madura e foi adotada como o dispositivo de armazenamento não-volátil tanto de código quanto de dados para os dispositivos eletrônicos (BEZ et al., 2003). 
Figura 15 - Posição das tecnologias de memória não-volátil em relação a custo e flexibilidade.

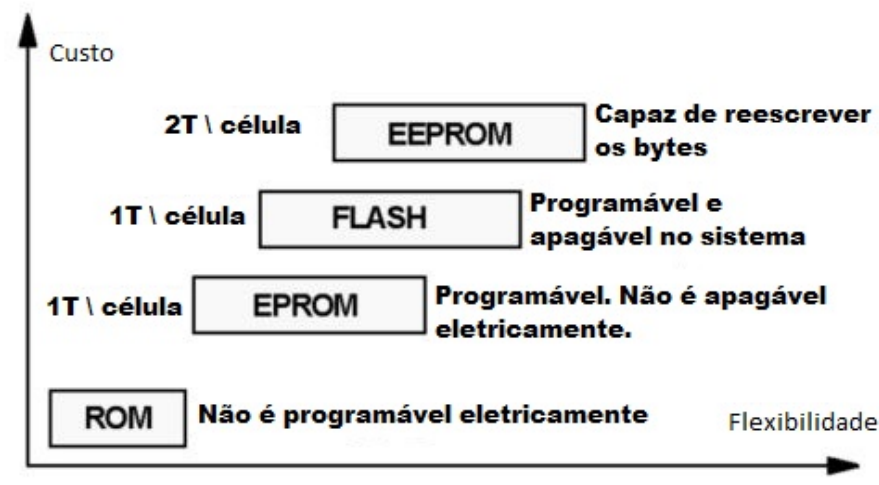

Fonte: (BEZ et al., 2003)

Baseado nas necessidades de mercado, surgiram dois tipos principais de memórias flash:

a) Armazenamento de código, onde o programa é armazenado e é executado pelo microcontrolador/microprocessador.

b) Armazenamento de dados, onde arquivos (imagem, música, voz, etc.) são armazenados.

Diferentes tipos de arquiteturas foram propostas e elas podem ser divididas em tipos de acesso e nos mecanismos utilizados para programação e apagamento das células. Em meio a diversas arquiteturas, hoje a indústria possui dois tipos que podem ser considerados padrões: flash NOR de terra comum, que por sua versatilidade está sendo utilizado tanto para armazenamento de código quanto armazenamento de dados, e a flash NAND, otimizada para o mercado de armazenamento de dados. Como principal característica, pode-se citar que a flash NOR é capaz de endereçar individualmente cada célula de memória ou palavra. Por outro lado, na flash NAND, a memória só é acessada através de blocos (BEZ et al., 2003). A figura 16 mostra a memória flash do tipo NOR a nível de transistor e a seção transversal de uma célula flash. Na figura é possível observar a capacidade de leitura de informação em cada transistor individualmente. 
Figura 16 - a) Matriz de células flash NOR. b) Seção transversal de uma célula flash.
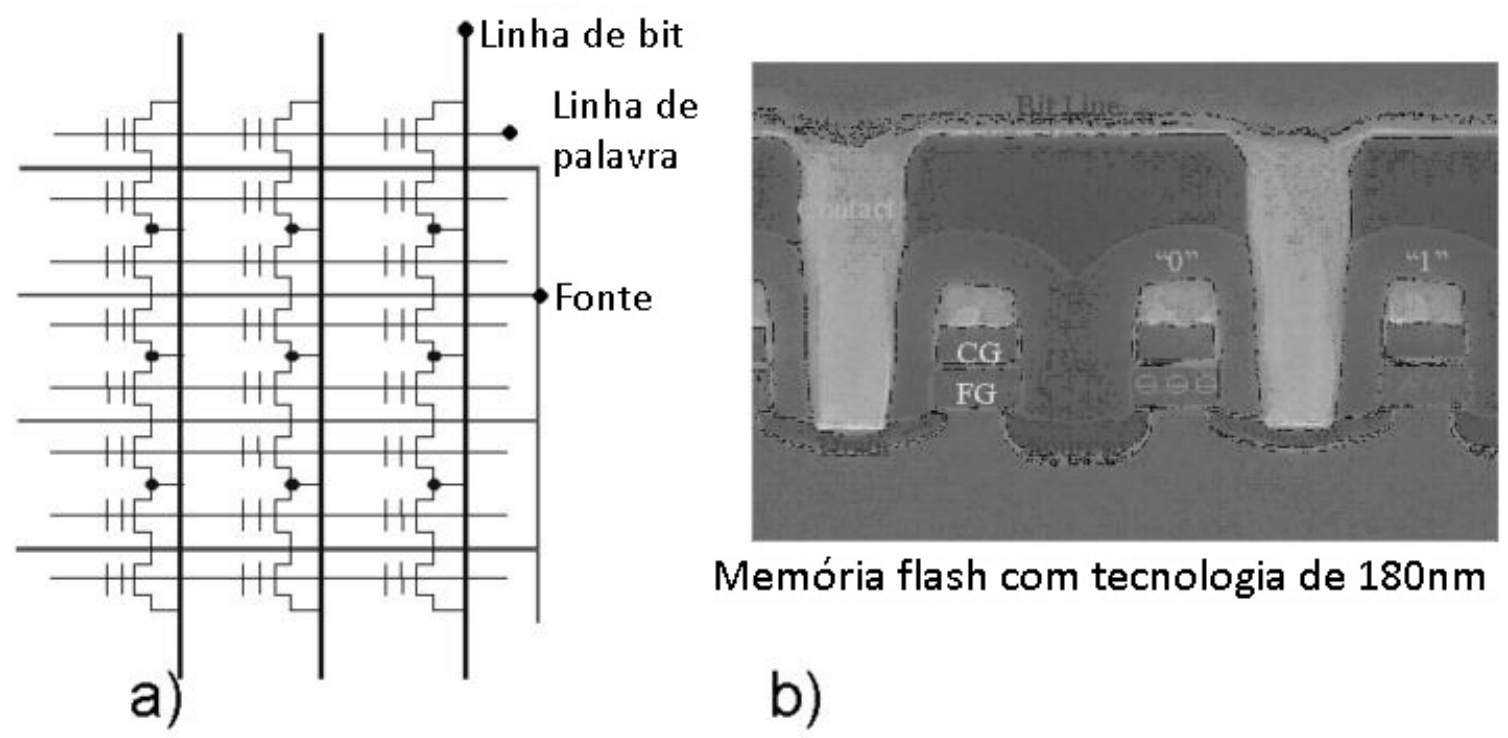

Memória flash com tecnologia de $180 \mathrm{~nm}$

b)

Fonte: (BEZ et al., 2003)

\subsection{Operação de Leitura}

O valor armazenado na célula de memória flash pode ser determinado através da variação da tensão de limiar do transistor de gate flutuante. A maneira mais rápida de verificar a variação de tensão de limiar é através da leitura de corrente fluindo no canal do transistor de porta flutuante para uma tensão de porta fixa. Uma vez que a carga esteja armazenada na porta flutuante, basta aplicar uma tensão de leitura na porta de tal modo que na célula programada, ou seja, com carga na porta flutuante, a corrente seja muito menor do que na célula que não foi programada, como exemplificado na figura 17 (BEZ et al., 2003). 
Figura 17 - Curva característica I-V de um transistor de porta flutante na condição programado e não programado.

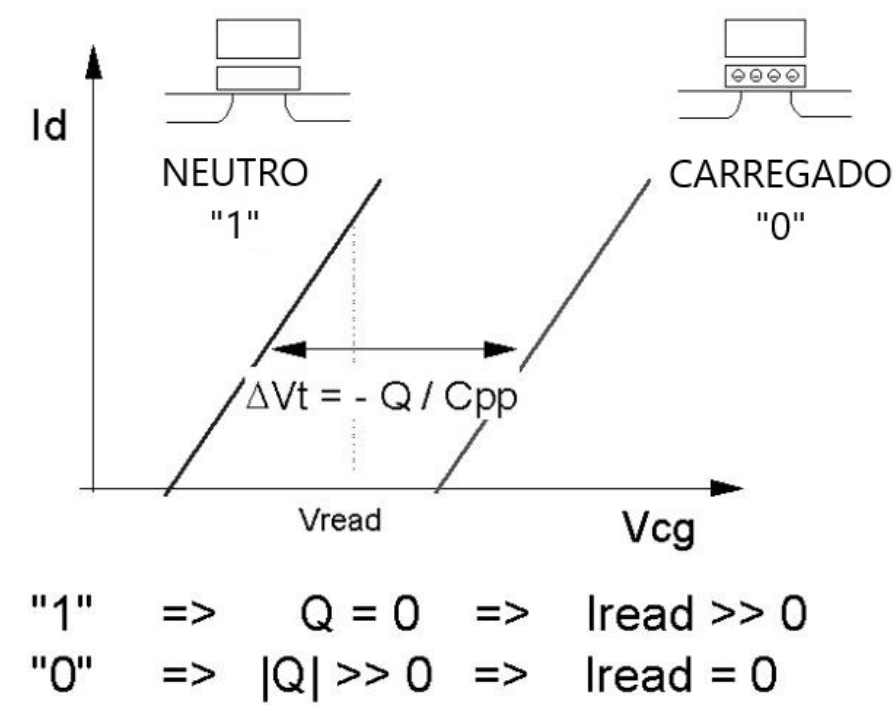

Fonte: (BEZ et al., 2003)

\subsection{Operação de Escrita}

Do ponto de vista físico, há um problema em escrever uma célula flash devido ao poço de potencial formado pela porta flutuante envolvida totalmente de dielétrico. Esse problema pode ser resolvido explorando diferentes efeitos físicos e no caso das memórias utilizadas atualmente, os principais efeitos para programar uma célula flash são: injeção de elétrons quentes e tunelamento de Fowler-Nordheim (BEZ et al., 2003). A figura 18 ilustra os métodos de escrita em uma célula flash composta de um transistor de gate flutuante. 
Figura 18 - Métodos de escrita em uma célula flash NOR.

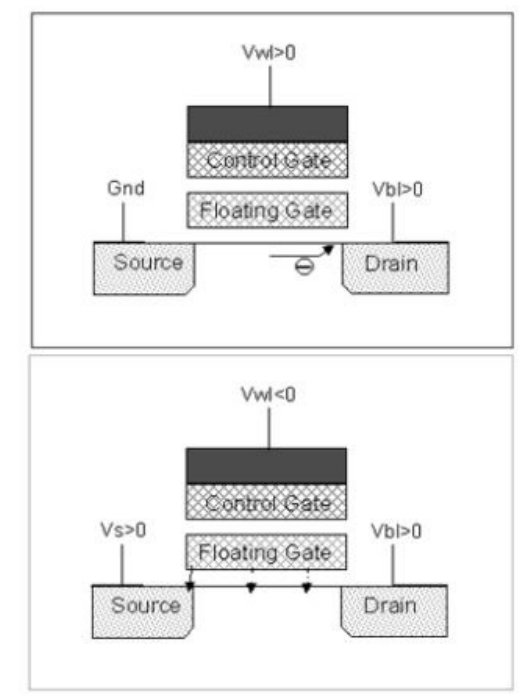

- Programando: Injeção de elétrons quentes na porta flutuante através do lado do dreno

Apagando:

Corrente de tunelamento Fowler-Nordhein através do óxido entre a porta flutuante e o canal

Fonte: (BEZ et al., 2003)

Os mecanismos de escrita necessitam de tensões elevadas para a programação da célula. Os circuitos muitas vezes são alimentados com tensões menores do que as necessárias para a operação de escrita, portanto, para a geração dessas tensões elevadas é utilizado um circuito que eleva a tensão chamado charge pump e o funcionamento do circuito será descrito a seguir.

\subsection{Circuito Elevador de Tensão - Charge Pump}

O circuito charge pump tem como objetivo gerar tensões maiores do que a tensão de alimentação de um determinado circuito, por exemplo, as memórias flash. Um exemplo de topologia que é muito utilizada em circuitos integrados é o multiplicador charge pump Dickson e é mostrado na figura 19 (DICKSON, 1976; TANZAWA; TANAKA, 1997; BELLOTTI et al., 2013).

Figura 19 - Exemplo de um circuito multiplicador Dickson.

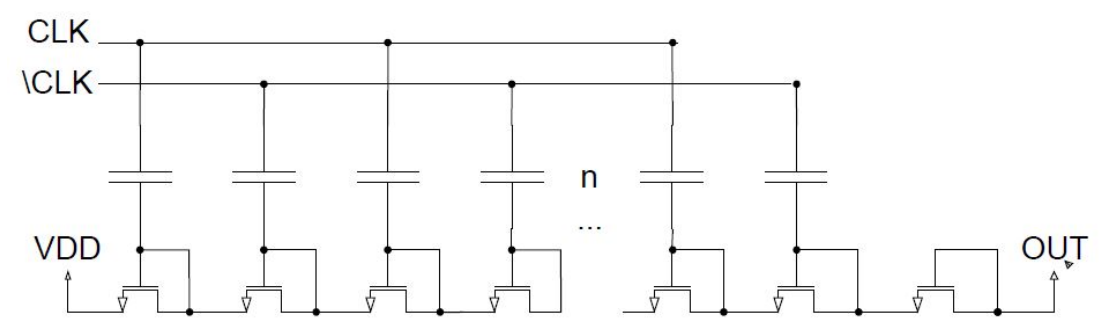

Fonte: (DICKSON, 1976)

Essa topologia é um avanço em relação a outros circuitos elevadores de tensão, como por exemplo o multiplicador Cockcroft-Walton, e é construído com a utilização apenas de transis- 
tores e capacitores. Essa topologia permite que o circuito seja construído totalmente dentro do circuito integrado e portanto se torna muito interessante para circuitos que precisam operar com tensões maiores que a tensão de alimentação, como é o caso das memórias flash . O circuito possui duas linhas de clock que possuem mesma amplitude e estão defasados $180^{\circ}$ entre si. Os clocks estão acoplados capacitivamente a nós alternados do circuito de modo a injetar uma certa quantidade de energia nos nós do circuito durante cada fase de carga e descarga dos capacitores. A cada estágio do multiplicador a tensão é aumentada de uma quantidade dada principalmente pela contribuição do acoplamento capacitivo ao nó do circuito (DICKSON, 1976).

Figura 20 - Simulação das tensões nos nós de um multiplicador Dickson.

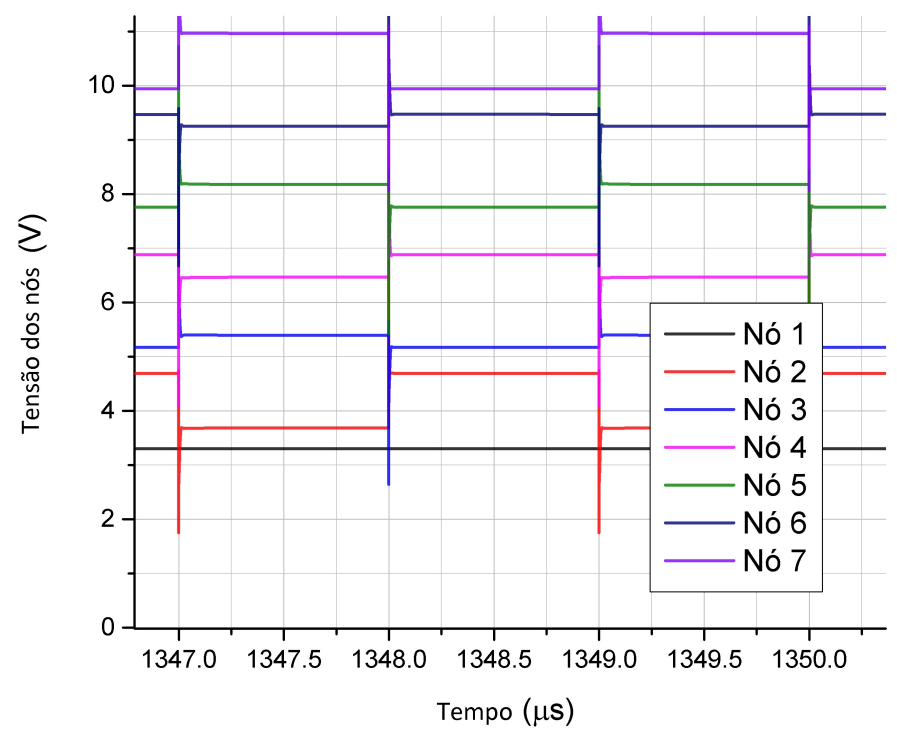

Fonte: Autor 
Figura 21 - Tensão de saída de um multiplicador Dickson com tensão de entrada de 3.3V

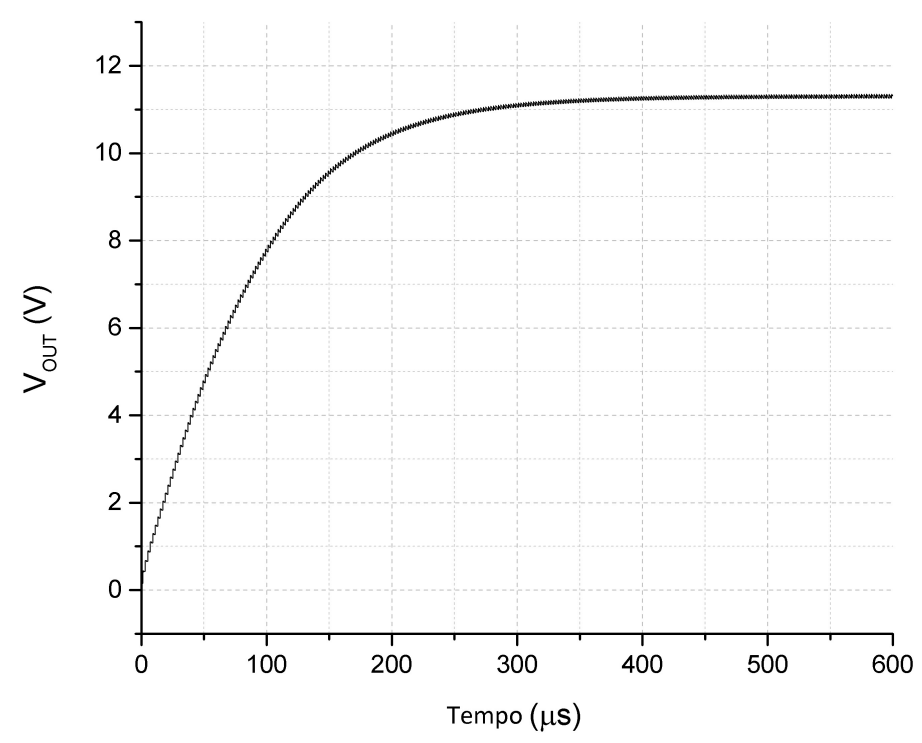

Fonte: Autor

As figuras 20 e 21 foram obtidas através de uma simulação SPICE. A figura 20 ilustra as tensões nos nós quando o circuito atinge o regime estável onde é possível observar o acréscimo relativo a contribuição de cada estágio. A figura 21 ilustra a tensão de saída do circuito.

\subsubsection{Células SRAM}

No desenvolvimento de um programa, os valores de variáveis, chamadas de funções e interrupções utilizam o armazenamento na memória volátil do dispositivo programável. A memória SRAM é a principal memória utilizada para armazenamento desses dados e é composta por células SRAM. Uma célula SRAM é composta por inversores ligados numa configuração bi-estável onde é possível armazenar o estado de um bit por célula, vide figura 22. O acesso geralmente é feito por transistores chamados transistores de acesso e é utilizado para ler e escrever na célula. Há diversas arquiteturas de células SRAM e os números de transistores empregados são diferentes em cada arquitetura apresentando características diferentes quanto a imunidade a ruído, área ocupada no silício ou número de processos empregados na fabricação. Há três modos de operação em memórias SRAM: stand-by, leitura e escrita. Cada modo pode ser definido com sua própria margem de operação. Quando a célula está em stand-by, o sinal wordline (WL) está em nível lógico baixo e para manter o dado armazenado, os dois inversores precisam manter o funcionamento bi-estável (BIRLA; K. SINGH; PATTANAIK, 2011; CALHOUN; CHANDRAKASAN, 2006). 
Figura 22 - Exemplo de uma célula SRAM composta por 6 transistores.

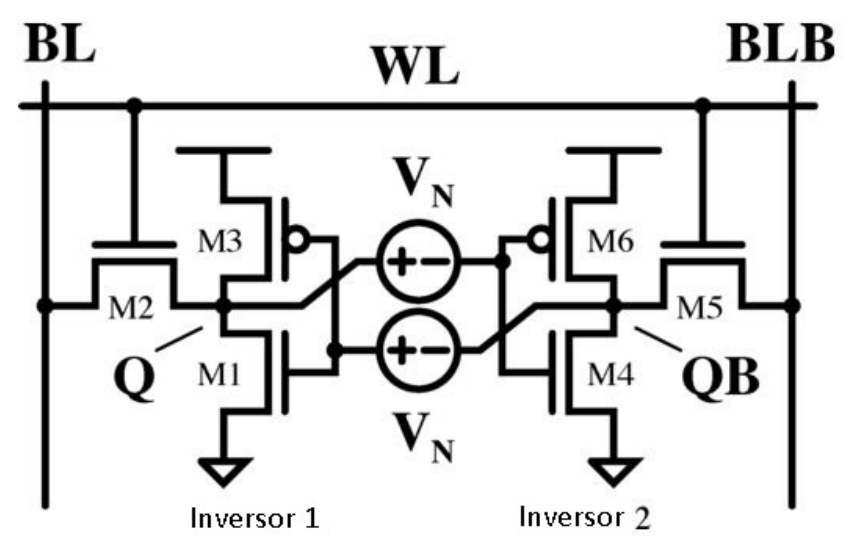

Fonte: (CALHOUN; CHANDRAKASAN, 2006)

A melhor forma de medir a capacidade da célula SRAM de reter a informação é através da análise de Margem de Ruído Estático (MRE). O MRE é a máxima tensão que pode ser introduzida nas saídas dos inversores na qual a célula ainda retem o dado, ou seja, MRE quantifica a tensão necessária para ocorrer um bit-flip no conteúdo da célula. A figura 23 mostra um jeito comum de representar graficamente o MRE para uma célula armazenando dado. Nesse gráfico é plotado a Curva de Transferência de Tensão (VTC) de um inversor e o inverso $V T C^{-1}$ do outro inversor. O resultado é uma curva popularmente chamada de "curva borboleta"e é utilizada para determinar o MRE. O MRE é definido como o comprimento do maior quadrado que pode ser colocado dentro da curva (BIRLA; K. SINGH; PATTANAIK, 2011; CALHOUN; CHANDRAKASAN, 2006). 
Figura 23 - VTC e MRE de uma célula SRAM 6T tradicional durante: a) estado de retenção e b) estado de leitura.
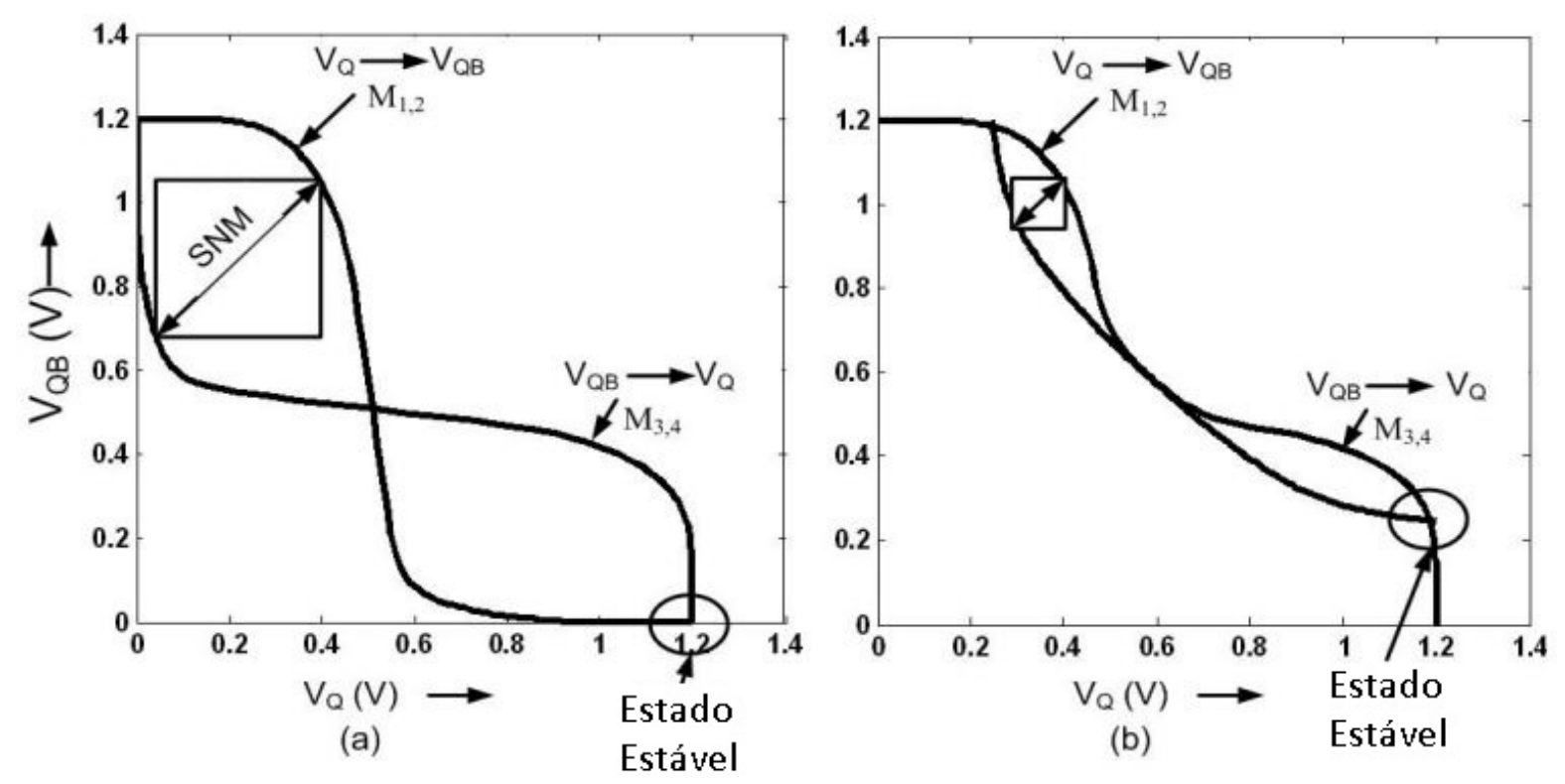

Fonte: (SINGH et al., 2008)

Apesar do MRE ser importante no estado de retenção de dados, é possível notar que durante a operação ativa (leitura/escrita) o MRE é menor e, portanto, mais crítico e representa uma limitação significante da operação da célula SRAM. Essa degradação do MRE ocorre devido ao pré-carregamento das linhas de bit ao $V_{D D}$ no momento de leitura. Isso faz com que, quando o transistor de acesso é ligado, haja uma divisão de tensão entre o transistor de acesso e os transistores do inversor, fazendo com que o dado "0"armazenado na célula aumente para uma tensão maior que o ground do circuito (SINGH et al., 2008).

\subsection{Conceitos e Terminologia de Sistemas Tolerantes à Falhas}

Antes de descrever os efeitos da radiação ionizante em dispositivos eletrônicos, será definido formalmente os conceitos de falha, falta e defeito. Esses conceitos serão usados durante as análises dos experimentos.

a) Serviço: O serviço entregue pelo sistema é o comportamento o qual é entregue ao usuário (GERACI et al., 1991; LAPRIE, 1995).

b) Falha: Incapacidade do sistema ou componente de executar suas funções ou entregar o serviço de acordo com a especificação. A falha ocorre porque o sistema estava em um estado errôneo (GERACI et al., 1991; LAPRIE, 1995).

c) Erro: A diferença entre o valor calculado, observado ou medido e o valor especificado ou teoricamente correto. O processamento de um estado de erro pode levar a uma falha (GERACI et al., 1991; LAPRIE, 1995). 
d) Falta: Um defeito em um dispositivo ou componente que pode levar a um estado de erro do sistema (GERACI et al., 1991; LAPRIE, 1995).

\subsection{Efeitos da Radiação em Dispositivos Semicondutores}

Como visto nas seções anteriores, há uma variedade de fontes de radiação e ambientes com radiação nos quais os sistemas eletrônicos podem ser expostos. $\mathrm{O}$ ambiente espacial, ambiente de aceleradores de partículas e aviônica são os de maiores interesses de estudos nessa área e são os que mais demandam de dispositivos robustos capazes de operar nessa condições de maneira confiável. De maneira geral, deve-se manter em mente a aplicação do sistema e as condições do ambiente, em termos de radiação, no qual será submetido. Sistemas que serão utilizados no ambiente espacial deverá ser capaz de tolerar longos períodos de exposição à radiação a uma taxa de dose baixa. Já sistemas utilizados em aceleradores de partículas e laboratórios de física de alta energia devem suportar pequenos períodos de exposição à cargas com uma energia elevada. Esses danos podem ser classificados como Dose Total Ionizante (TID), Evento de Efeito Único (SEE), e Dano por Deslocamento (DD). Quanto maior a performance do circuito e menor as dimensões dos transistores empregados na construção do circuito, geralmente são maiores os danos causados pela radiação ionizante (MCLEAN; OLDHAM, 1989). Nas próximas seções, serão descritos os mecanismos relacionado a TID e SEE, não abordando os danos por deslocamento (DD) uma vez que os efeitos dominantes nos experimentos realizados são TID e SEE. Após essa descrição, serão abordados os efeitos de TID e SEE nas estruturas apresentadas anteriormente no texto.

\subsubsection{Dose Total Ionizante (TID)}

Um dos maiores efeitos associados a ionização devido a radiação é o acúmulo de cargas aprisionadas, os quais alteram a distribuição espacial de cargas no material e interferem na operação normal do dispositivo. Os efeitos devido a TID são especialmente importantes em dispositivos MOS devido aos óxidos. Quando a radiação ionizante incide sobre o óxido de porta, no caso de um transistor MOS, pares elétron-lacuna são criados pelo depósito da energia da radiação. A mobilidade de elétrons no óxido de silício é muito maior que a mobilidade das lacunas e eles escapam do óxido rapidamente. Na figura 24 é mostrado uma ilustração do diagrama de energia mostrando o processo de geração dos pares elétron-lacuna e do aprisionamento das cargas no óxido. Logo no início da criação dos pares elétron-lacuna, tipicamente no primeiro picosegundo, uma fração dos pares irão se recombinar e a quantidade dependerá do tipo e da energia da partícula. As lacunas que não são recombinados são praticamente imóveis e permanecem próximo do ponto de geração, causando um desvio da tensão de limiar do dispositivo MOS. O segundo processo é o transporte de lacunas para a interface $\mathrm{Si}-\mathrm{SiO} 2$, o que causa uma alteração no campo elétrico de porta. Esse processo é muito sensível ao campo aplicado, 
temperatura, espessura do óxido e etc. Algumas lacunas podem ser armadilhados em níveis profundos de energia causando um desvio remanescente na tensão de limiar que dura por muito tempo. Outra componente importante do TID é as cargas induzidas nas armadilhas de interface. Essas armadilhas são localizadas na faixa proibida de energia do silício. Sua ocupação é determinada pela tensão aplicada na porta (OLDHAM; MCLEAN, 2003).

Figura 24 - Principais processos no dano de TID.

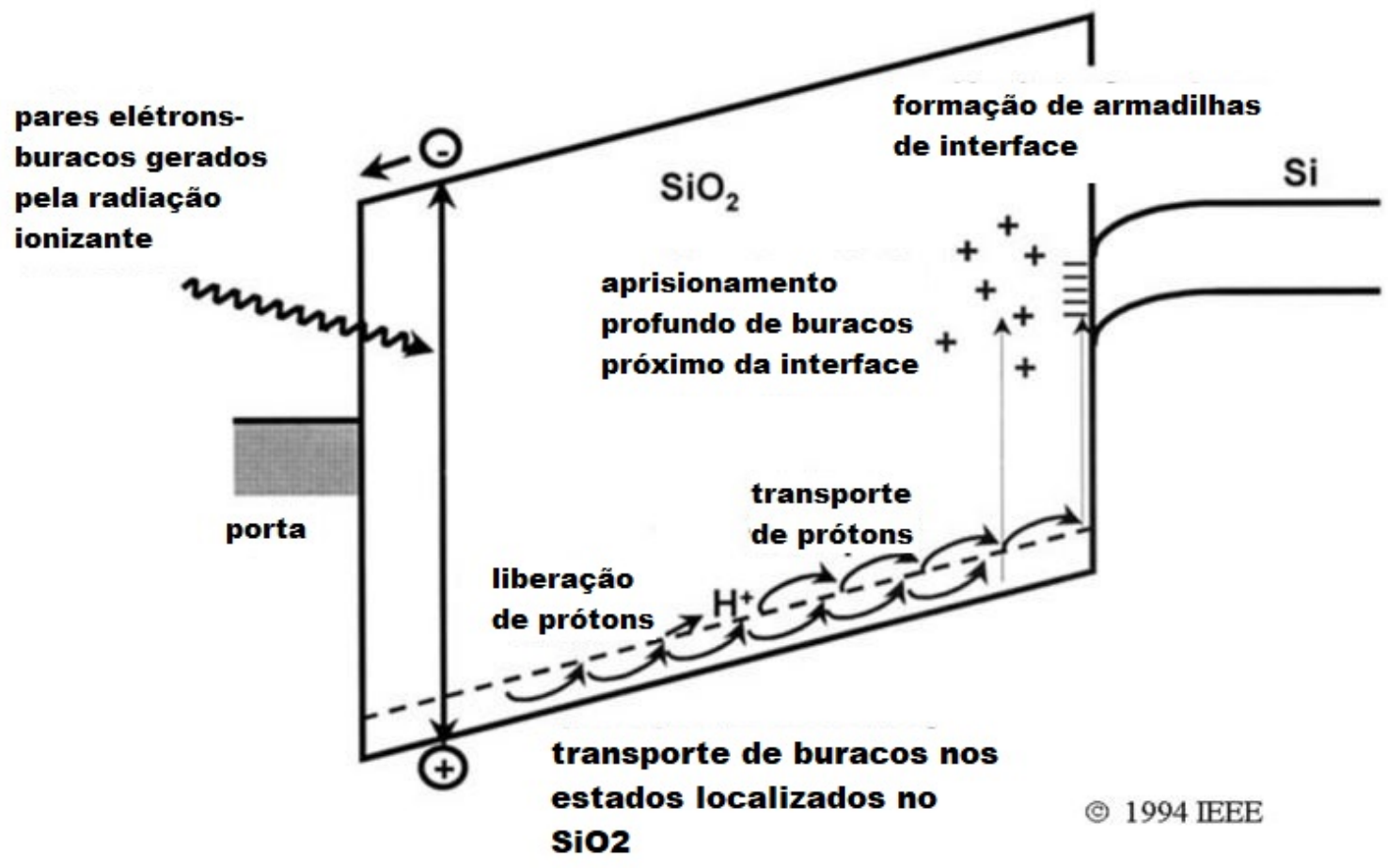

Fonte: (OLDHAM; MCLEAN, 2003)

Acredita-se também que os íons de Hidrogênio são liberados enquanto as lacunas se movem através do óxido. Os íons de Hidrogênio também podem se aproximar da interface $\mathrm{Si} / \mathrm{SiO}_{2}$ onde podem reagir e formar novas armadilhas de interface (SCHWANK et al., 2008). Os danos gerados por radiação podem ser medidos em termos de energia depositada por unidade de massa, sendo a dose de radiação medida na unidade Gy.

$$
1 G y=\frac{1 J}{k g}=0.01 \mathrm{rad}
$$

\subsubsection{Efeito de Evento Único}

A energia depositada no semicondutor pela radiação ionizante gera pares elétron-lacuna na região ativa do dispositivo e são acelerados pelo campo elétrico aplicado ao dispositivo causando perturbações no circuito em operação, e esse fenômeno é chamado de Efeito de Evento Único (ou Single Event Effect, em inglês). As partículas causadoras de SEE são, no geral, os 
íons pesados, desde partículas alfa até elementos transurânicos, e também produtos de reações e processos de espalhamento, que podem envolver nêutrons, prótons e partículas sub-nucleares. Como os processos envolvidos que podem provocar a ionização do meio, é muito mais prático estudar os SEE a partir da deposição de energia no dispositivo. Em silício, uma partícula com LET de $1 \mathrm{MeV} / \mu \mathrm{m}$ irá criar $2,8.10^{5}$ pares elétron-lacuna por $\mu \mathrm{m}$, o que corresponde a uma densidade de carga de aproximadamente $\pm 44.5 \mathrm{fC} / \mu \mathrm{m}$. Os testes devem ser realizados de modo que seja possível determinar o LET mínimo que seja capaz de gerar uma carga que resulte em um evento detectável no dispositivo, e a partir de qual LET ocorre a saturação dos eventos. Os dispositivos se tornam cada vez mais sensíveis a SEE conforme o avanço da tecnologia, pelo fato da cargas necessárias para armazenamento de informações serem menores. A ionização primária é também capaz de criar outros pares elétron-lacuna no semicondutor, em um processo que dura um intervalo da ordem de picossegundos. A alta concentração de pares elétron-lacuna na região do traço e em volta dela, muito maior do que a concentração de pares devido aos dopantes, forma o chamado plasma elétron-lacuna, uma região que exibe comportamento coletivo dos pares e que perturba o campo elétrico, se comportando como um condutor independente, que irá coletar todas as cargas geradas na ionização, num processo chamado de efeito funil (funnelling). Portadores de carga começam então a se movimentar pelo plasma e em volta dele até sua dissipação, quando os pares restantes irão se difundir pelo semicondutor. $\mathrm{O}$ pulso de corrente no semicondutor é então formado pela soma das contribuições direta e através do funnelling (BAUMANN, 2001; LEROY; RANCOITA, 2009; AGUIAR, 2014). A figura 25 ilustra graficamente os três processos básicos de coleta de cargas assim como a corrente em função do tempo durante um evento.

Figura 25 - Processo de geração de cargas durante um SEE.

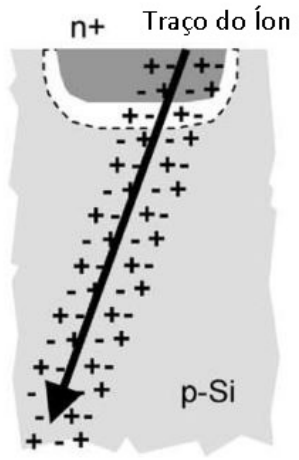

(a)

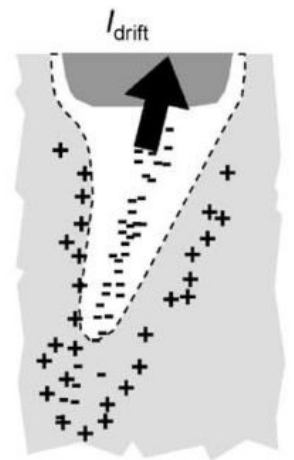

(b)

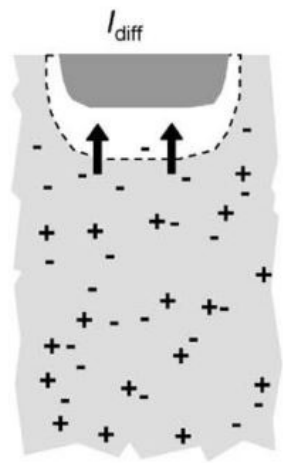

(c)

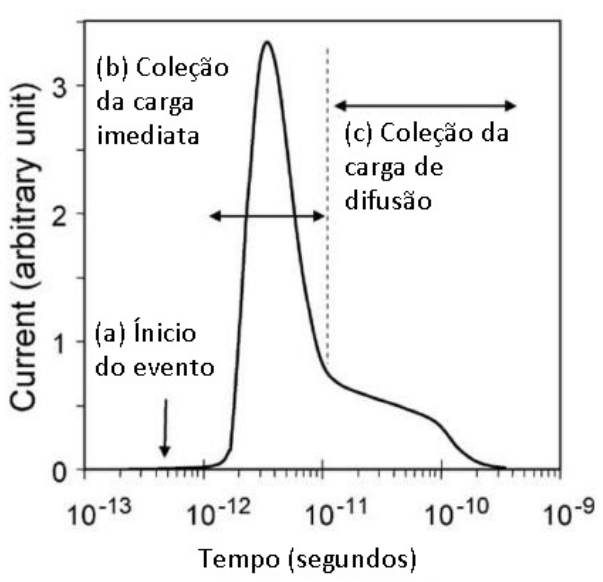

Fonte: (BAUMANN, 2001)

A figura 26 ilustra uma curva típica de ajuste de seção de choque em função do LET. Esta curva representa a quantidade de eventos observados em função do LET, sendo possível 
definir qual é o intervalo de LET onde o dispositivo apresenta uma baixa probabilidade de sofrer eventos.

Figura 26 - Exemplo de seção de choque de bit-flips.

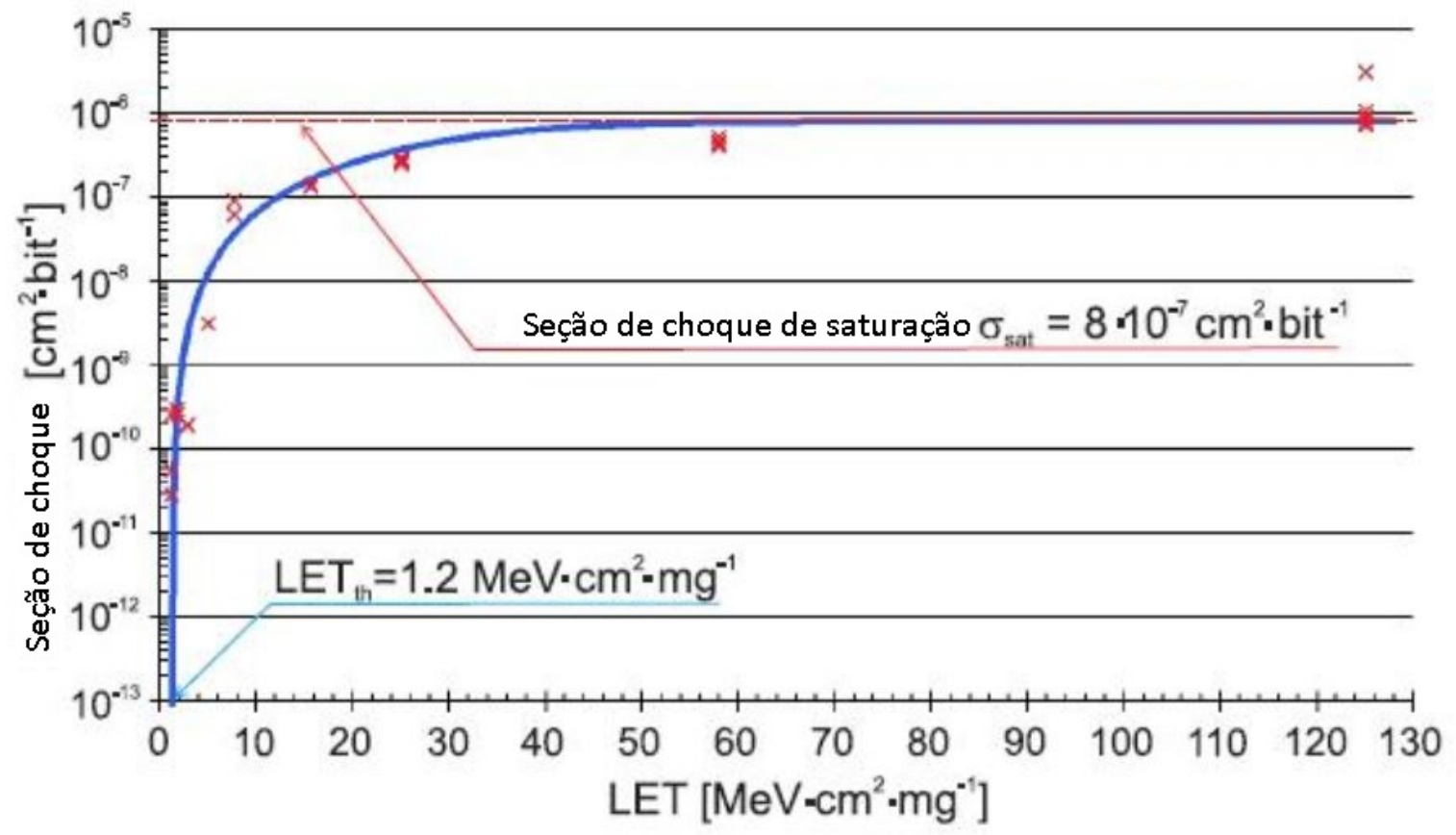

Fonte: (MAKOWSKI, 2006)

A integral da carga coletada deve ser maior ou igual à carga crítica (mínima carga cujo efeito pode ser observado) do dispositivo, para que seja caracterizado um SEE. O mínimo valor de LET que gera no dispositivo uma carga crítica $Q_{C}$ capaz de provocar um SEE é chamado de LET de limiar (threshold LET, $L E T_{t h}$ ). Os estudos que visam quantificar a taxa de SEE o fazem por meio da medida da seção de choque de SEE, uma medida indireta da probabilidade de ocorrência de eventos. A seção de choque é calculada por:

$$
\sigma=\frac{\text { eventos }}{\Phi}
$$

onde $\Phi$ é a fluência do feixe acumulada durante o ensaio, em [partículas $/ \mathrm{cm}^{2}$ ], o que faz com que a unidade de seção de choque seja uma unidade de área. Na condição de irradiação perpendicular, a seção de choque representa a área média do dispositivo sensibilizada durante o ensaio. No caso em que toda a área sensível apresente efeitos, tem-se a seção de choque de saturação, isto é, seu valor não aumenta, mesmo que aumente-se o LET incidente e, portanto, a carga depositada.

Esse tipo de efeito pode ser classificado como efeito recuperável e não-recuperável. Os efeitos recuperáveis são chamados de Single Event Upset (SEU), Single Event Functional Interrupt (SEFI) e Single Event Transient (SET). Os efeitos não-recuperáveis levam a um estado inoperante do sistema devido a incidência do íon pesado e podem ser classificados em Single 
Event Latchup (SEL), Single Event Gate Rupture (SEGR) e Single Event Burnout (SEB). No SEU, um soft error ${ }^{1}$ ocorre pela indução de cargas geradas por uma partícula energética. Quando um pico de tensão momentâneo ocorre em um nó sensível do circuito integrado devido a uma partícula energética, caracteriza-se um SET.

SEFI ocorre quando um erro causa um reset, travamento ou um comportamento anormal do sistema que não precisa de um power cycling ${ }^{2}$ para voltar ao correto funcionamento. O SEB é geralmente associado a dispositivos de potência. A corrente gerada por radiação ionizante excede a densidade de corrente suportada pelo dispositivo e causa a queima do silício.

De uma maneira mais específica, um SEL apresenta um estado com um consumo de corrente elevado causado pela passagem de partículas energéticas em regiões sensíveis da estrutura do dispositivo que resulta na perta de funcionalidade do dispositivo. Esse efeito pode causar um dano permanente no dispositivo. Se o dispositivo não foi danificado permanentemente, um power cycle é necessário para a recuperação funcional do sistema. SEGR é um evento no qual uma partícula resulta na quebra do óxido, criando um caminho por onde flui corrente elétrica através do terminal de porta do dispositivo, danificando permanentemente o dispositivo.

\subsubsection{Efeitos de TID em transistores MOSFET}

As cargas aprisionadas no óxido afetam diversos parâmetros elétricos dos MOSFETs, como por exemplo a tensão de limiar e mobilidade de portadores. O dano ionizante devido à dose de radiação acumulada no dispositivo é causado pela geração de pares elétrons-buracos no óxido. Alguns desses pares gerados pela radiação ionizante são recombinados. Os elétrons não recombinados, devido a sua alta mobilidade, conseguem sair do óxido. Por sua vez, os buracos ficam armadilhados no óxido e/ou em estados de interface entre óxido e silício. Esses buracos armadilhados, tanto no óxido como na interface, alteram os termos referente a carga no óxido e a armadilhas de interface, conforme descrito na equação 6, e portanto altera a tensão de limiar. As figuras de 27 à 34 mostram alguns importantes resultados de diversos experimentos que exploram os mecanismos físicos responsáveis pelos efeitos de TID devido à raios-X em MOSFETs (OLDHAM; MCLEAN, 2003; BARNABY, 2006; LEITE et al., 2014, 2015).

\footnotetext{
${ }^{1}$ Um tipo de erro onde o sinal ou dado está errado. Não danifica componentes de hardware do sistema e geralmente um power cycle resolve o erro.

${ }^{2}$ Ação de desligar a alimentação de energia do sistema e, logo após, ligar novamente.
} 
Figura 27 - Curvas $I_{D}-V_{G S}$ para MOSFETs tipo $\mathrm{P}$ e $\mathrm{N}$ irradiados com diferentes doses.

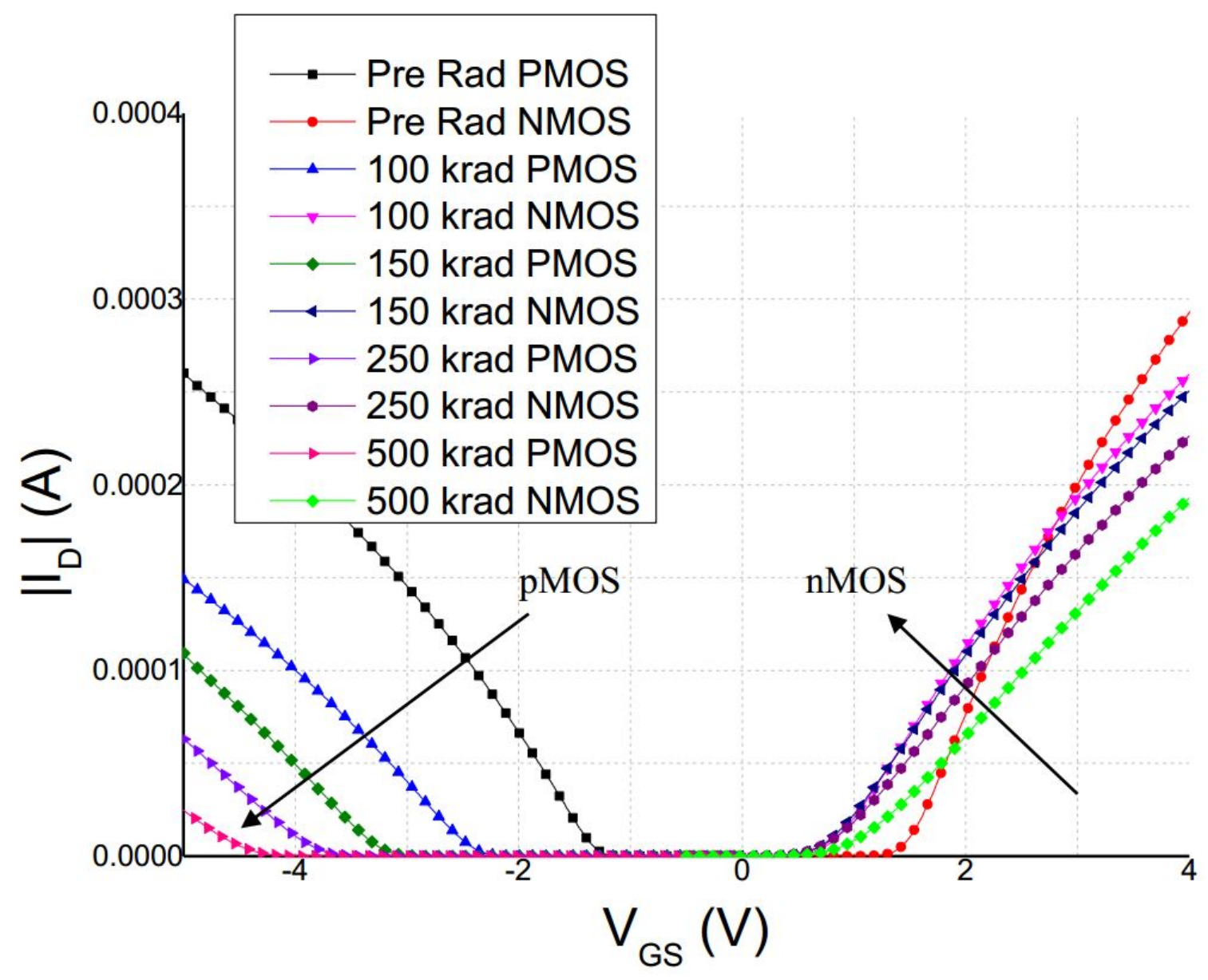

Fonte: Autor 
Figura 28 - Curvas $I_{D}-V_{G S}$ para MOSFETs tipo $\mathrm{N}$ em escala logarítmica para diferentes doses acumuladas em um dispositivo fabricado na tecnologia de $0,18 \mu \mathrm{m}$ CMOS da TSMC.

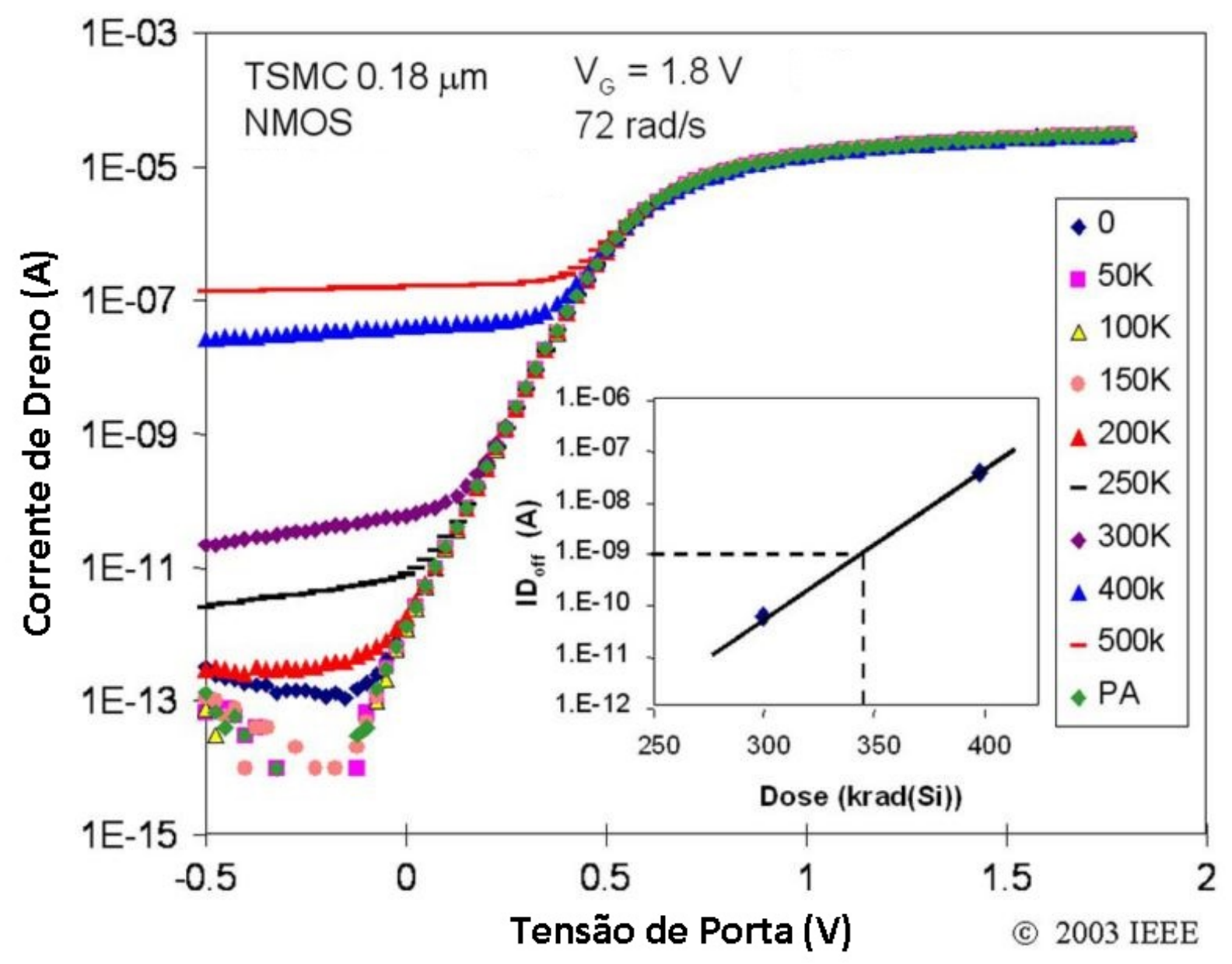

Fonte: (BARNABY, 2006)

A figura 27 mostra as curvas $I_{D}-V_{G S}$ para MOSFETs tipo $\mathrm{P}$ e $\mathrm{N}$ irradiados até 500 $\operatorname{krad}(\mathrm{Si})$. É possível observar as variações na tensão de limiar e na inclinação das curvas (LEITE et al., 2014). Já a figura 28 mostra uma série de medidas para um MOSFET tipo $\mathrm{N}$ fabricado em tecnologia 0,18 $\mu \mathrm{m}$ Complementary Metal-Oxide-Silicon (CMOS) da TSMC onde é possível perceber a variação da corrente $I_{O F F}{ }^{3}$. Essa grande variação implica em um maior consumo de corrente dos transistores que não tem o canal formado em um sistema, aumentando de maneira significativa o seu consumo de corrente (BARNABY, 2006).

\footnotetext{
${ }^{3}$ Corrente consumida quando o transistor não possui a formação de canal.
} 
Figura 29 - Curvas $g_{m}-V_{G S}$ para MOSFETs tipo N.

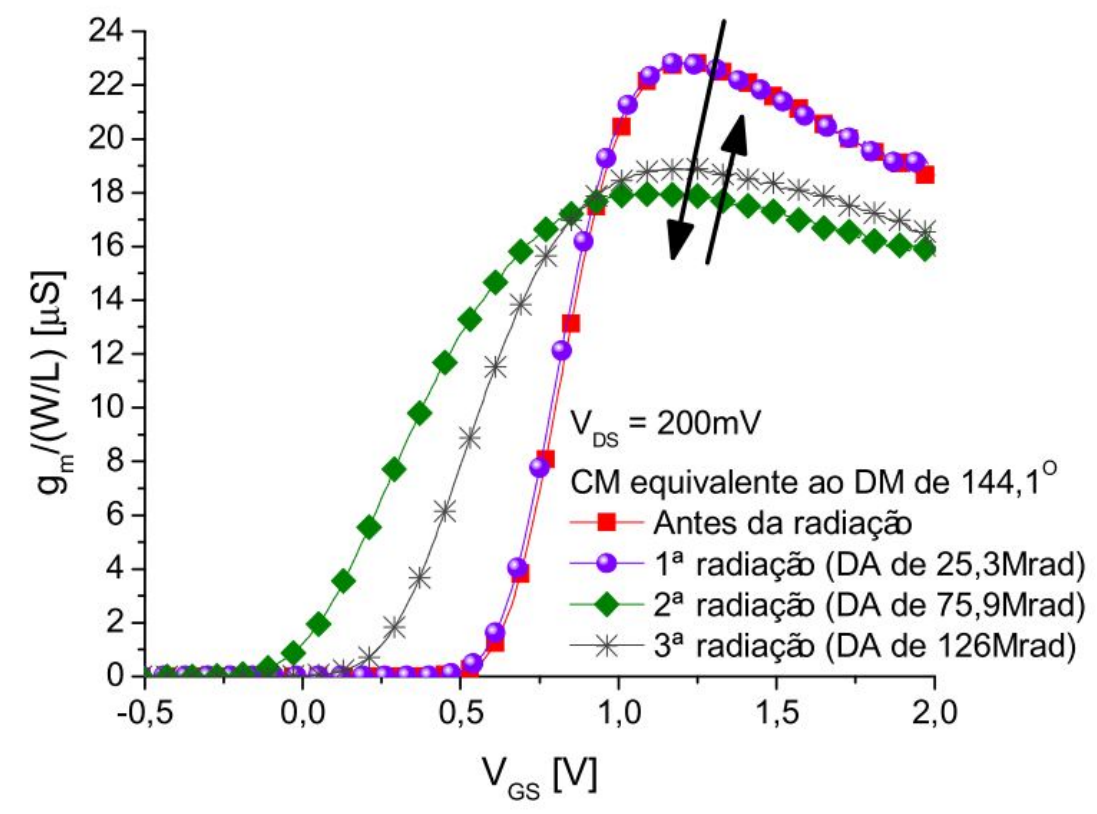

Fonte: (ALATI, 2012)

A figura 29 mostra a variação da transcondutância devido à dose acumulada em um transistor tipo N. Nota-se a mudança no valor da transcondutância e também a mudança na inclinação da curva ao longo do acúmulo da dose, indicando também mudanças no valor da mobilidade de superfície do dispositivo. 
Figura 30 - Estabilização da variação de tensão de limiar após o transistor MOSFET tipo N ser irradiado.

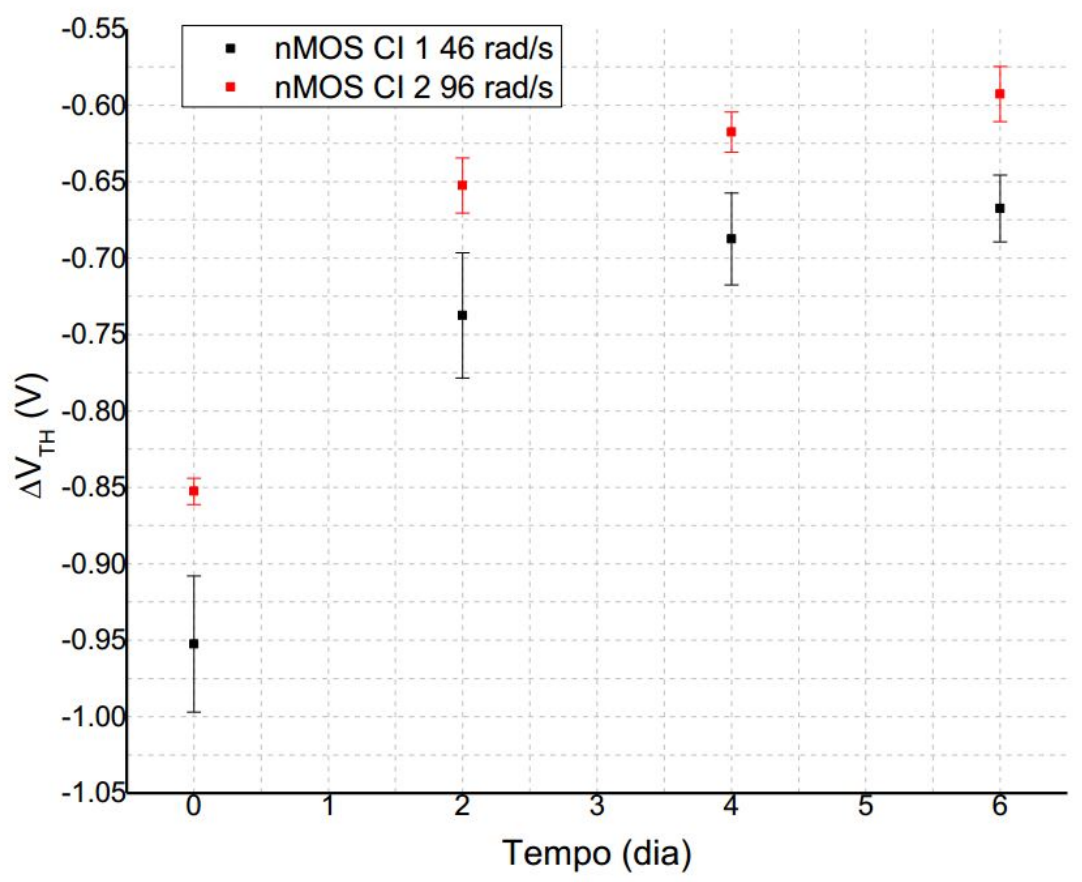

Fonte: Autor

Figura 31 - Estabilização da variação de tensão de limiar após o transistor MOSFET tipo P ser irradiado.

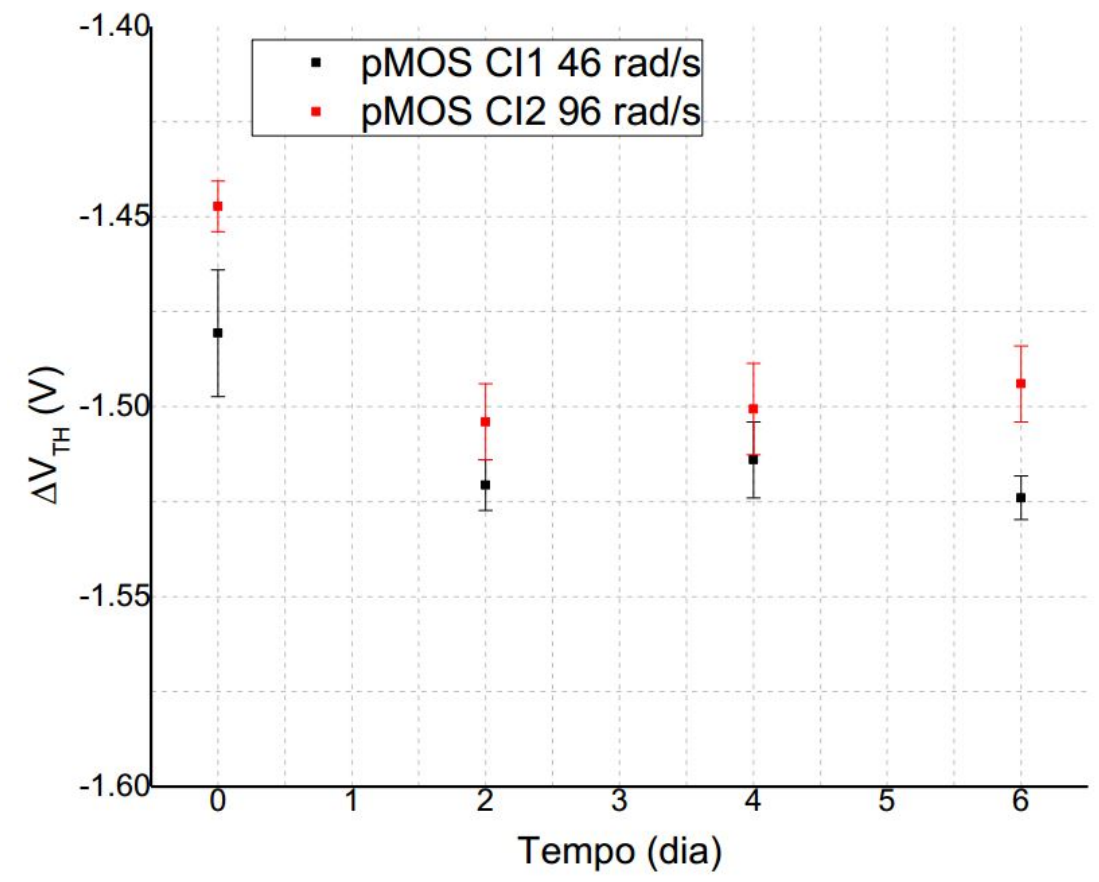

Fonte: Autor 
A figura 30 mostra a estabilização da variação de tensão de limiar após um MOSFET tipo $\mathrm{N}$ ser irradiado com uma dose arbitrária para duas taxas de dose diferentes. A figura 31 mostra a estabilização da variação de tensão de limiar após um MOSFET tipo P ser irradiado com uma dose arbitrária para duas taxas de dose diferentes. Para os dois dispositivos e para ambas as doses, a tensão de limiar alcança um estado estável em cerca de 6 dias em temperatura ambiente de $25^{\circ} \mathrm{C}$ (LEITE et al., 2014).

Figura 32 - Variação da tensão de limiar em função da dose acumulada para um MOSFET tipo $\mathrm{N}$.

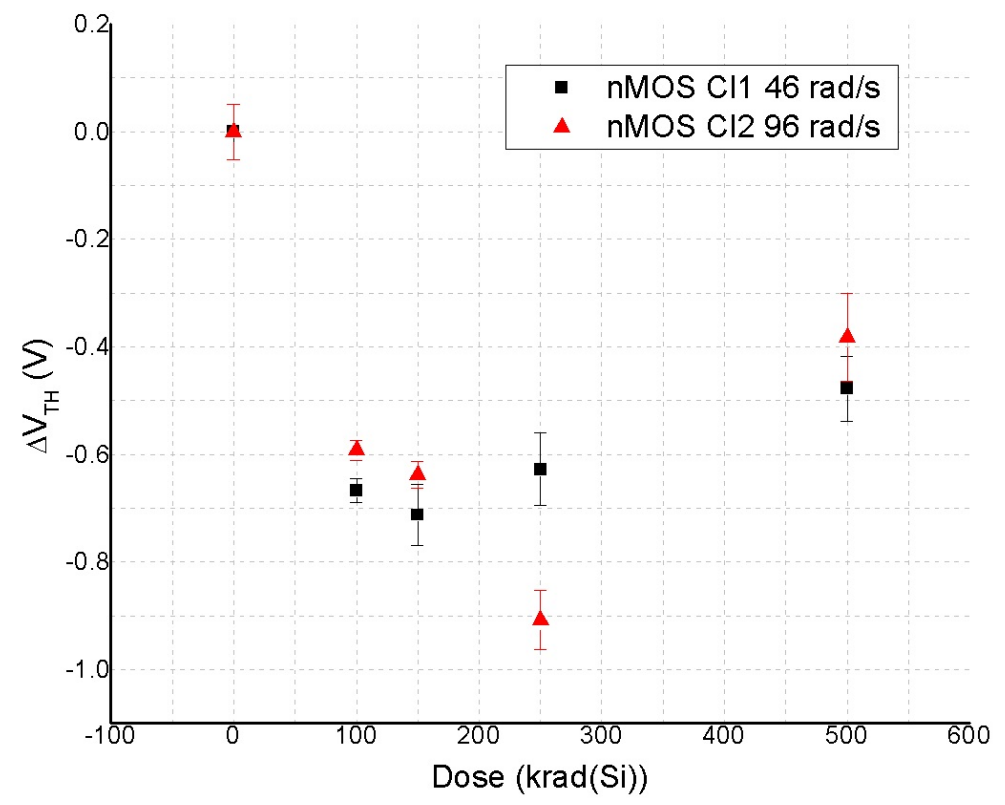

Fonte: Autor 
Figura 33 - Variação da tensão de limiar em função da dose acumulada para um MOSFET tipo P.

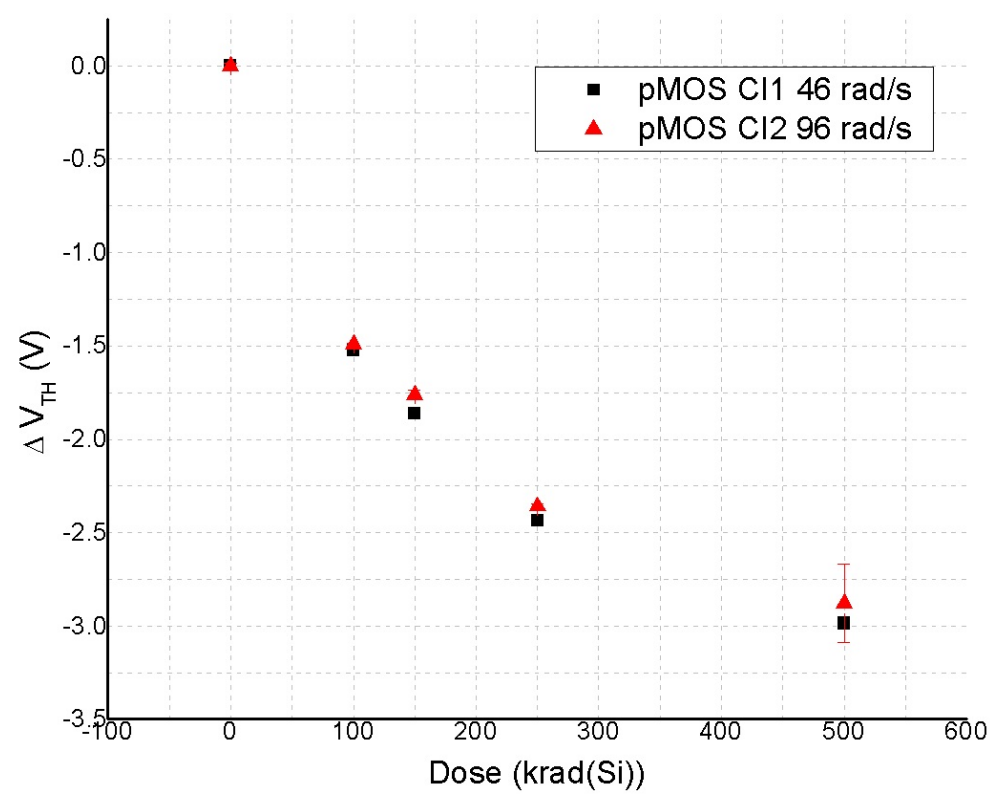

Fonte: Autor

A figura 32 mostra um gráfico da variação da tensão de limiar por dose para o nMOS para as duas taxas de dose utilizadas no estudo. A inversão na variação de tensão de limiar está relacionada com as cargas aprisionadas na interface. A densidade de cargas na interface entre o óxido e o canal começa a ter um efeito predominante em relação às cargas aprisionadas no óxido, fazendo com que a corrente de elétrons que flui entre dreno e fonte diminua. Esse efeito somente é observado em MOSFETs tipo N pelo fato dos portadores de carga que compõem a corrente elétrica serem elétrons.

Através da figura 33 nota-se o comportamento diferente do pMOS em comparação com o nMOS apresentado na figura 32. O pMOS apresenta sempre uma variação negativa na tensão de limiar e diferentemente do nMOS, o pMOS não apresenta uma inversão na sua variação de tensão de limiar. Os dispositivos apresentaram a mesma curva de tendência mesmo sendo expostos a taxas de dose diferentes, embora o dispositivo com taxa de dose maior apresentou uma variação menor na tensão de limiar (LEITE et al., 2014). 
Figura 34 - Variação da tensão de limiar em função do tempo para um dispositivo irradiado polarizado.

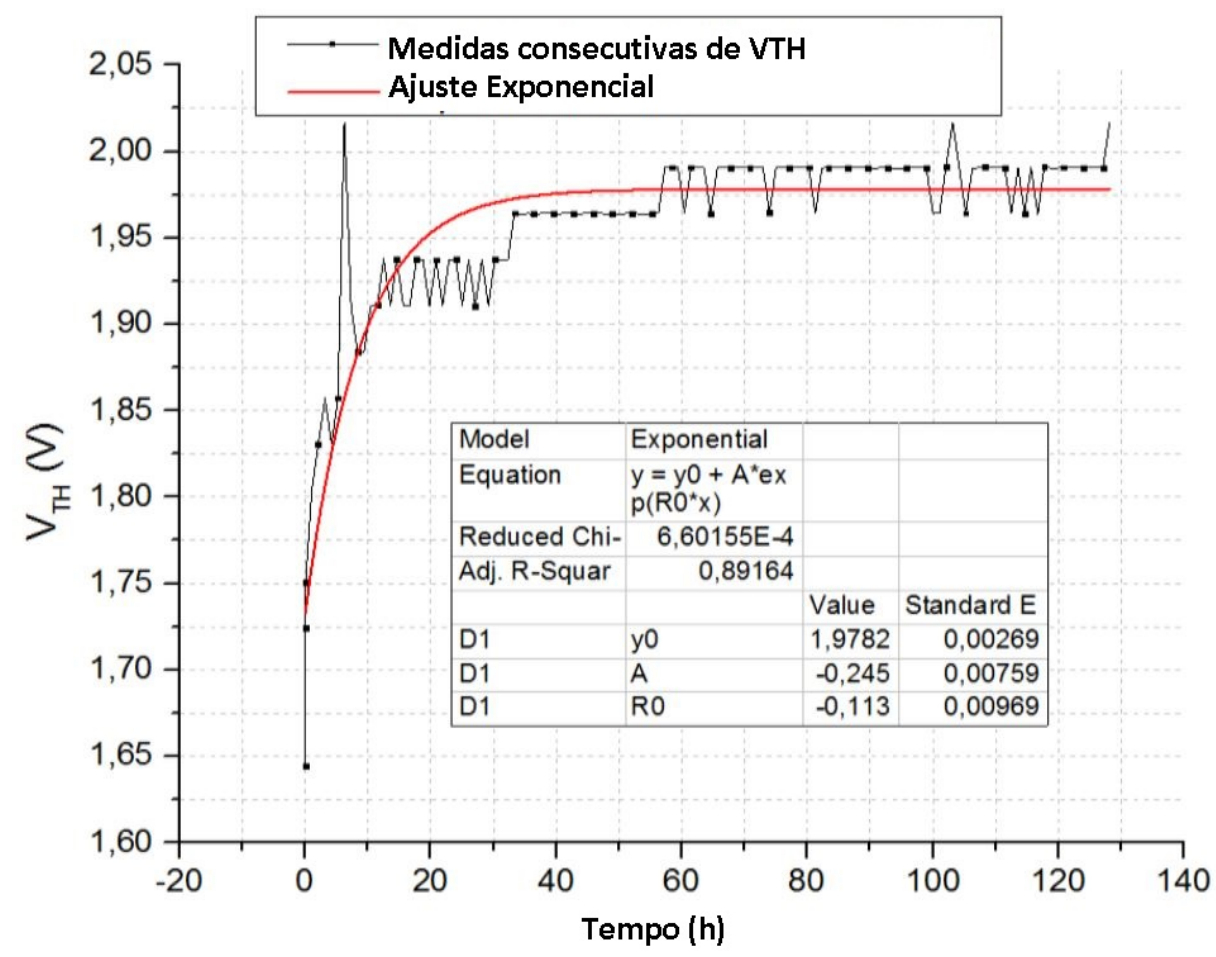

Fonte: Autor

A figura 34 mostra um outro detalhe que deve ser levado em consideração, e que é tão importante quanto os outros, é o efeito da polarização depois do dispositivo ser irradiado. $\mathrm{O}$ fato de realizar medidas consecutivas gera um campo elétrico resultante durante o tempo da medida. Esse campo elétrico rearranja as cargas aprisionadas no óxido e muda o efeito da radiação observado no dispositivo. Nessas medições, houve um equilíbrio após cerca de $36 \mathrm{~h}$ de polarização do dispositivo. Como todo circuito eletrônico digital é construído a partir de transistores, é esperado que as tensões de limiares e a característica I-V de todos os transistores que compõem o circuito se altere durante a irradiação, podendo causar aumentos na corrente de alimentação e faltas em seu funcionamento que podem levar a falhas do sistema (LEITE et al., 2015). Conhecer os efeitos da radiação ionizante que podem ocorrer no transistor é fundamental para entender o que acontece em um sistema mais complexo.

\subsubsection{Efeitos de Radiação em Memórias Flash}

A radiação ionizante pode afetar as memórias flash de diversas formas: alterando a tensão de limiar dos transistores de gate flutuante, danificando o circuito charge pump ou os circuitos decodificadores. Como a leitura é feita aplicando uma tensão determinada de leitura e o estado da célula é determinada se há ou não corrente elétrica, a alteração da tensão de limiar, 
através do TID, pode causar faltas na memória, fazendo com que a leitura do conteúdo das células estejam erradas. Além disso, a radiação ionizante pode degradar a tensão de saída do charge pump fazendo com que a tensão não seja suficiente para que os efeitos de tunelamento Fowler-Nordheim ou injeção de elétrons quentes ocorra e portanto, não sendo possível a leitura ou programação das células (GERARDIN et al., 2013). A seguir será exposto diversos resultados de experimentos com memórias flash ilustrando os efeitos de TID e SEE em memórias flash de alta capacidade ( maiores que 256 Mbit ) (GERARDIN et al., 2013).

Figura 35 - Efeito do TID nas células de gate flutuante.

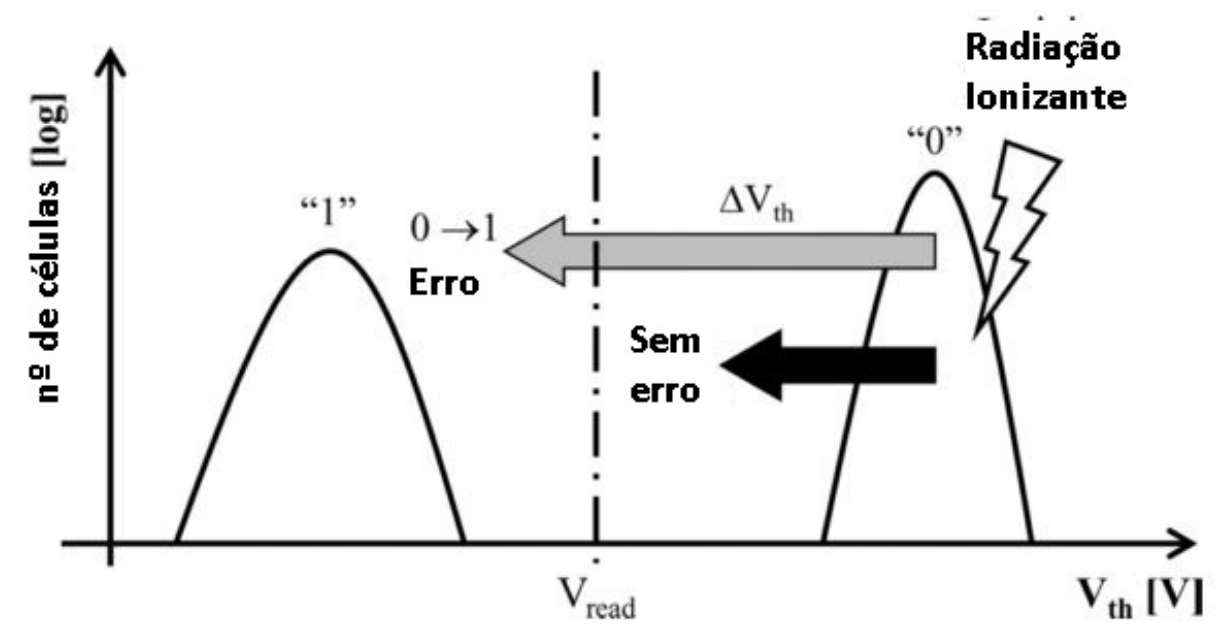

Fonte: (GERARDIN et al., 2013)

Figura 36 - Distribuições de tensão de limiar para células floating gate multi-níveis.

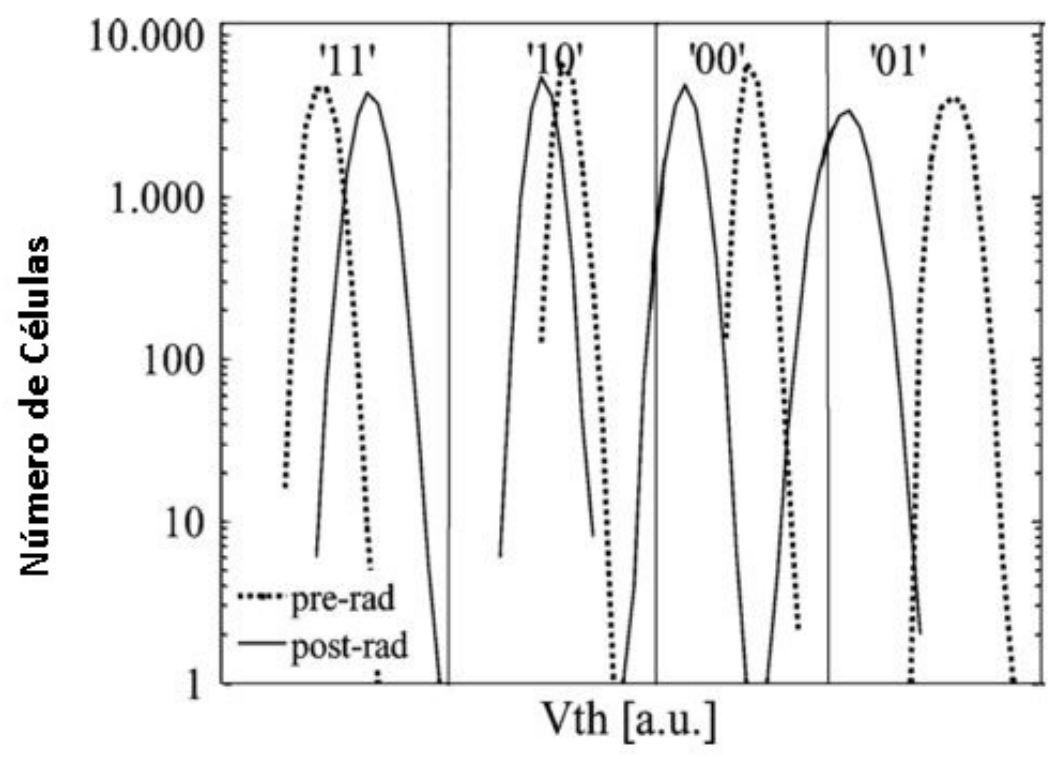

Fonte: (GERARDIN et al., 2013) 
As figuras 35 e 36 mostram a variação da tensão de limiar devido à radiação ionizante. Se a variação da tensão de limiar for grande suficiente para ultrapassar o nível definido pela tensão de leitura, ocorrerá um erro de leitura na célula. Esse efeito é muito mais crítico em células multi-níveis, em que há o armazenamento de um número maior de bits por célula (GERARDIN et al., 2013).

Figura 37 - Tensão de saída de um circuito charge pump em função da dose.

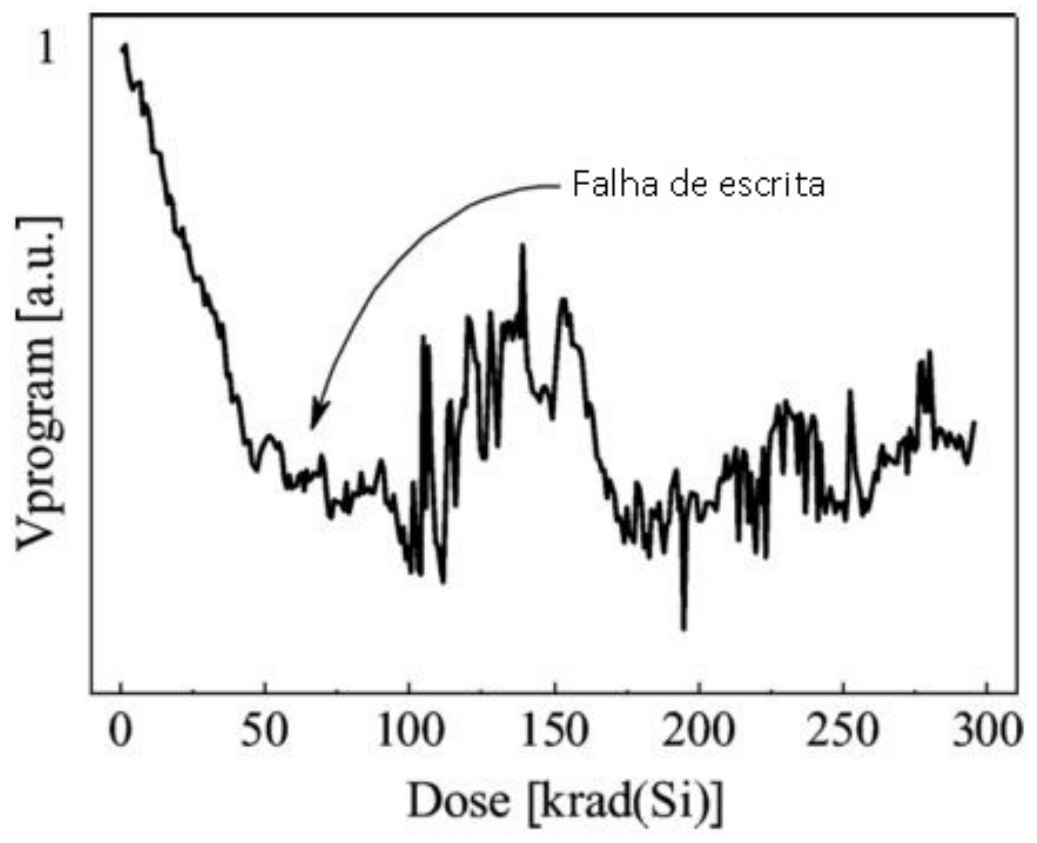

Fonte: (GERARDIN et al., 2013) 
Figura 38 - Número de erros de leitura em função da dose acumulada.

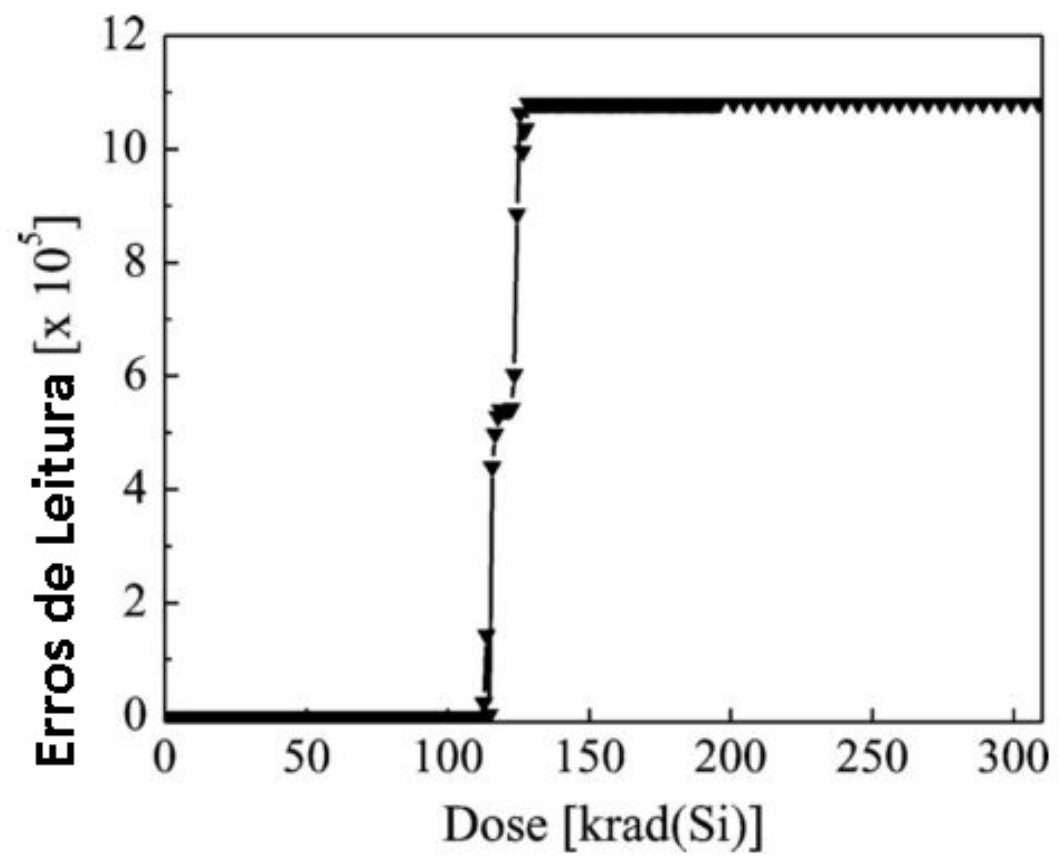

Fonte: (GERARDIN et al., 2013)

As figuras 37 e 38 mostram o efeito do TID no charge pump. A variação na tensão de programação gerada pelo charge pump causa um aumento abrupto no número de erros de leitura (GERARDIN et al., 2013).

Figura 39 - Seção de choque de SEUs para diferentes memórias.

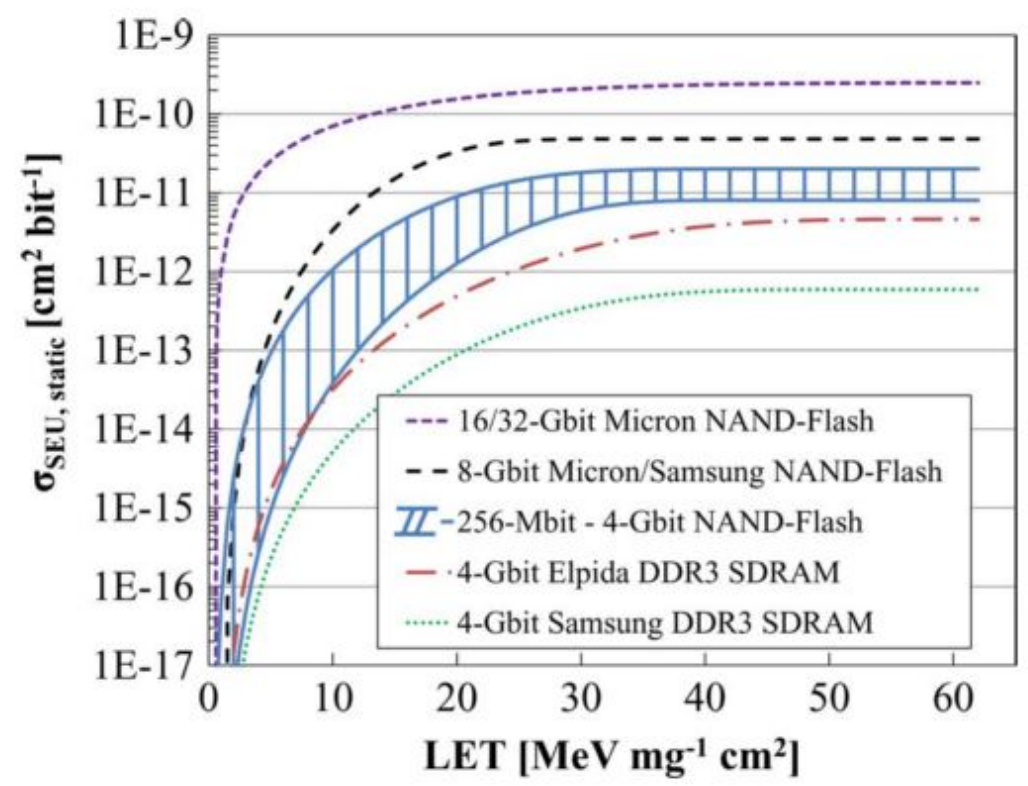

Fonte: (GERARDIN et al., 2013) 
Os efeitos do SEE também são observados nas memórias flash. As cargas geradas pelas interações das partículas no material podem modificar as cargas que estavam armazenadas no gate flutuante causando uma mudança na informação armazenada na célula. A figura 39 mostra o gráfico da seçao de choque de upsets em experimentos realizados com diversas memórias flash comerciais (GERARDIN et al., 2013).

\subsubsection{Efeitos de Radiação em Memórias SRAM}

As memórias SRAM tem um papel importante nos circuitos integrados modernos pois são capazes de serem construídos a partir do menor transistor possível para a tecnologia em que será fabricada, permitindo atingir uma grande densidade de memória no silício. Por esse motivo, a radiação ionizante afeta de maneira significativa esses dispositivos e, portanto, esses circuitos devem ser cuidadosamente testados. Pelo fato da memória ser construída a partir de dois inversores realimentados utilizando os menores transistores da tecnologia empregada, conforme descrito nas seções anteriores, esses dispositivos são fortemente sensíveis a SEE e também a TID.

O principal efeito do TID em memórias SRAM é a degradação dos parâmetros elétricos dos transistores que compõem as células de memória, por exemplo, os transistores de acesso de bit como abordado na seção 2.5.3. Essa degradação modifica a tensão de limiar dos transistores e, portanto, modifica a tensão de acionamento desses dispositivos modificando a margem de leitura e escrita, conforme ilustrado nas figuras abaixo, além de modificar a corrente de alimentação do circuito (SCHEICK; SWIFT; GUERTIN, 2000; YAO et al., 2008). 
Figura 40 - Corrente de alimentação de uma memória SRAM ao ser irradiada com $C o^{60}$.

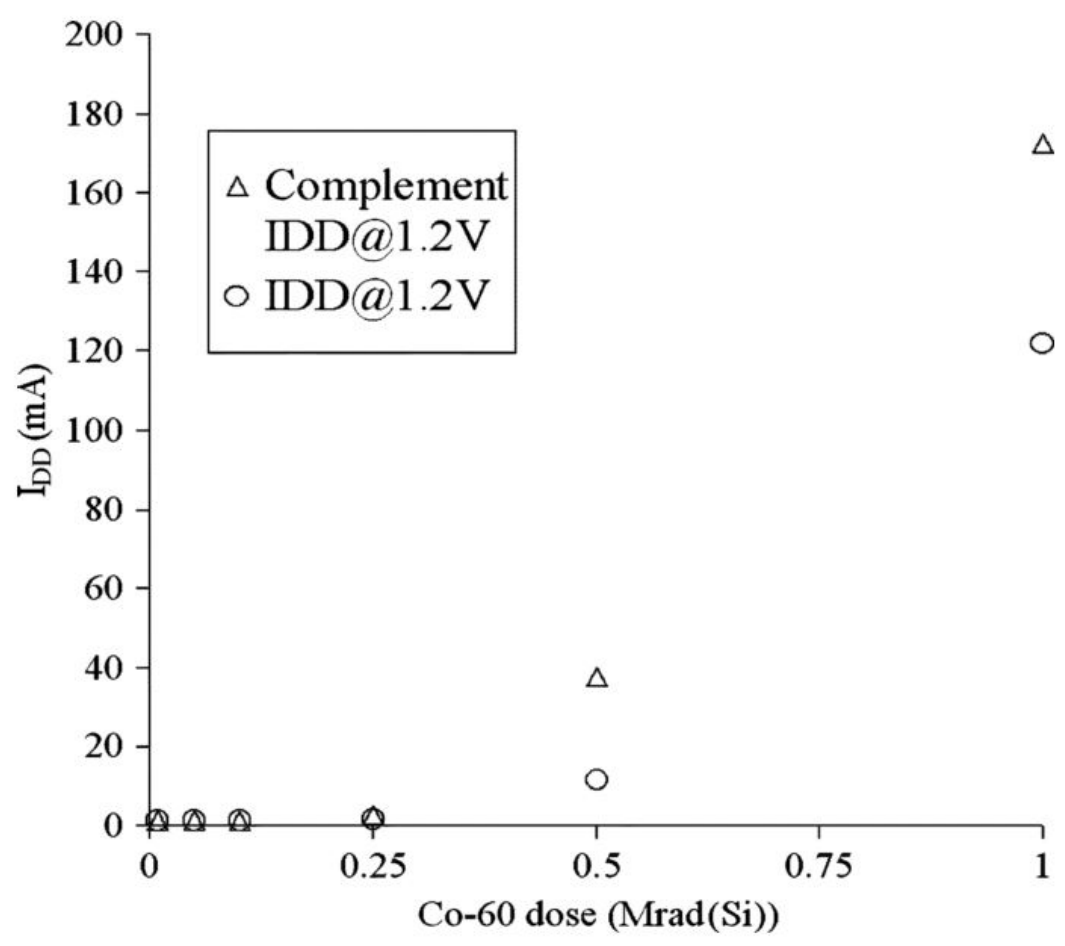

Fonte: (YAO et al., 2008)

A figura 40 mostra o aumento da corrente de alimentação de uma memória SRAM ao ser irradiada com $C o^{60}$ até uma dose de $1 \mathrm{Mrad}(\mathrm{Si})$.

Figura 41 - Ponto de acionamento dos transistores de acesso de escrita antes de serem irradiados.

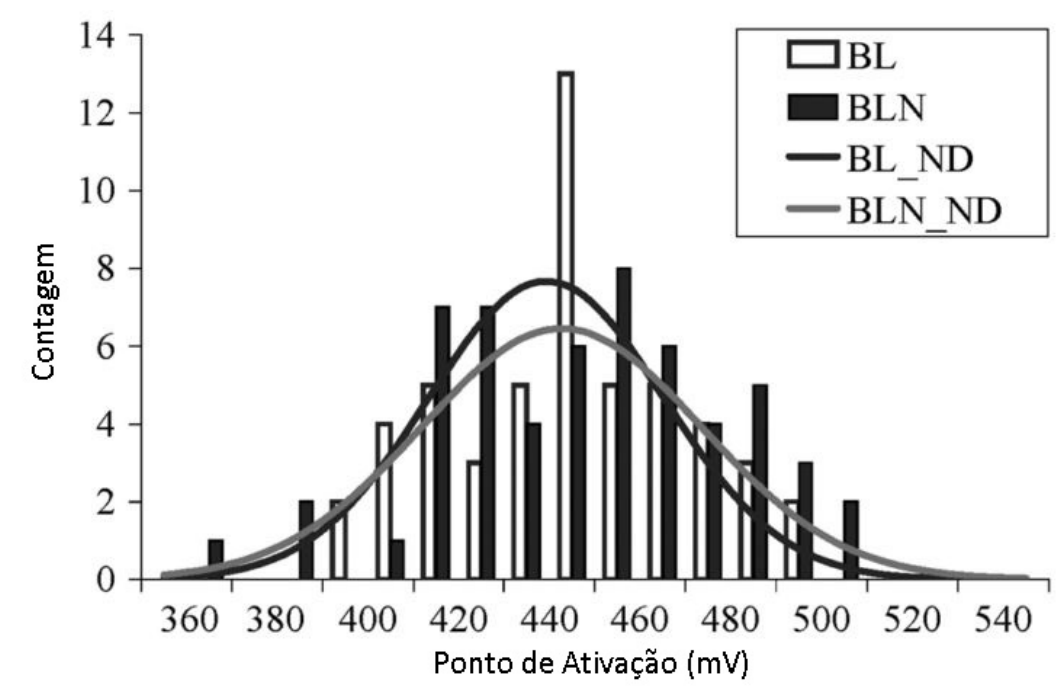

Fonte: (YAO et al., 2008) 
Figura 42 - Ponto de acionamento dos transistores de acesso de escrita após serem irradiados.

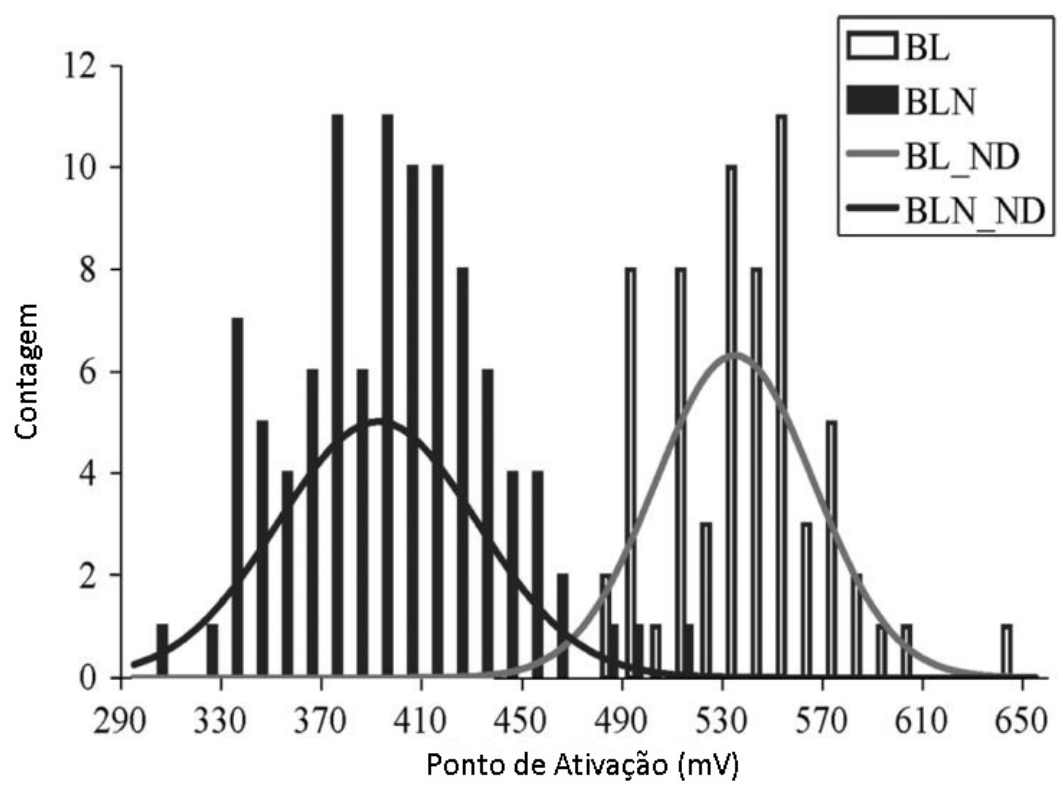

Fonte: (YAO et al., 2008)

A figura 41 e 42 mostra a variação das tensões de acionamento dos transistores de acesso ao bit que são responsáveis pela escrita e leitura da célula. Essa variação indica uma diminuição na margem de escrita e apresenta uma possível falha no dispositivo devido a TID (YAO et al., 2008). 
Figura 43 - Comparação entre a margem de ruído estático de leitura antes e após serem irradiados.

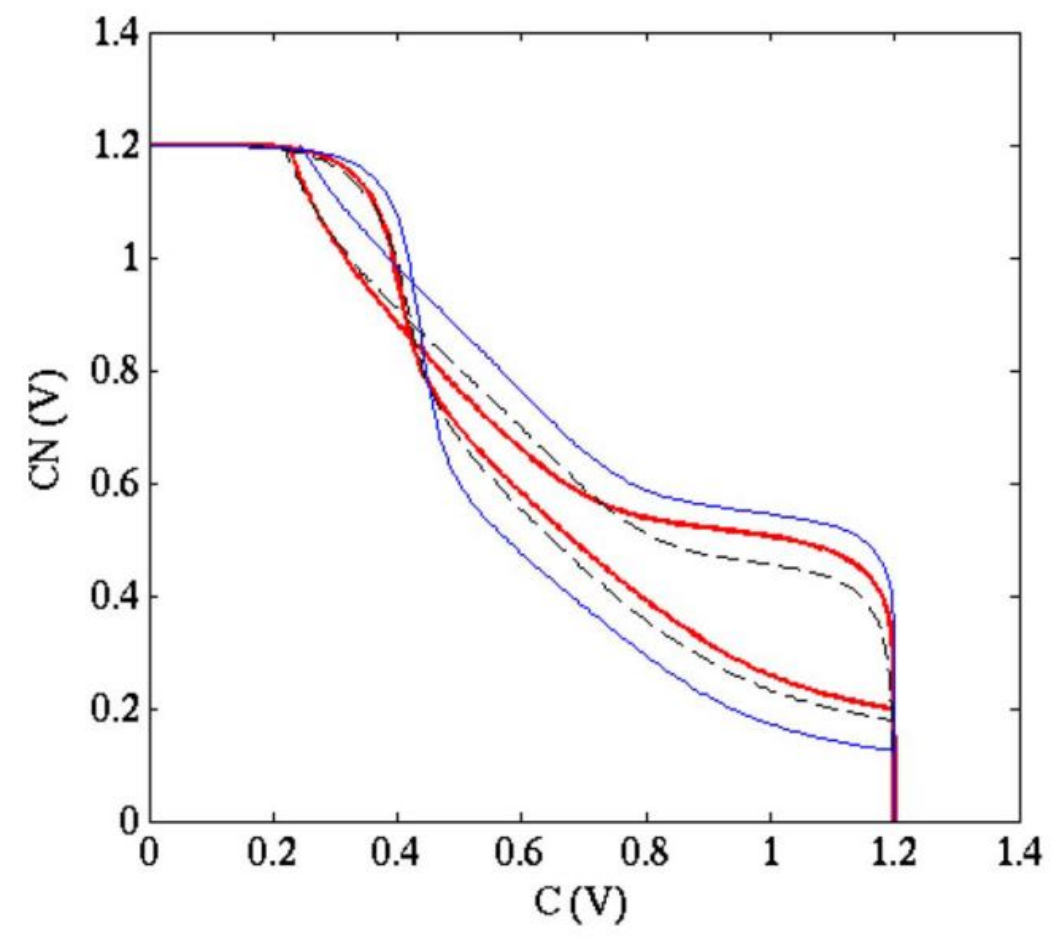

Fonte: (YAO et al., 2008)

A figura 43 mostra a margem de ruído estático para leitura antes e após a memória ser irradiada. Embora a figura se altere, o pior caso de leitura, ou seja, a "caixa"que é encaixada em cada "olho"da figura, que corresponde a margem de ruído estático, se mantém praticamente inalterada, indicando que o dispositivo pode suportar grandes níveis de dose acumulada sem comprometer sua performance de leitura (YAO et al., 2008). 
Figura 44 - Seção de choque de SEU de uma memória SRAM comercial.

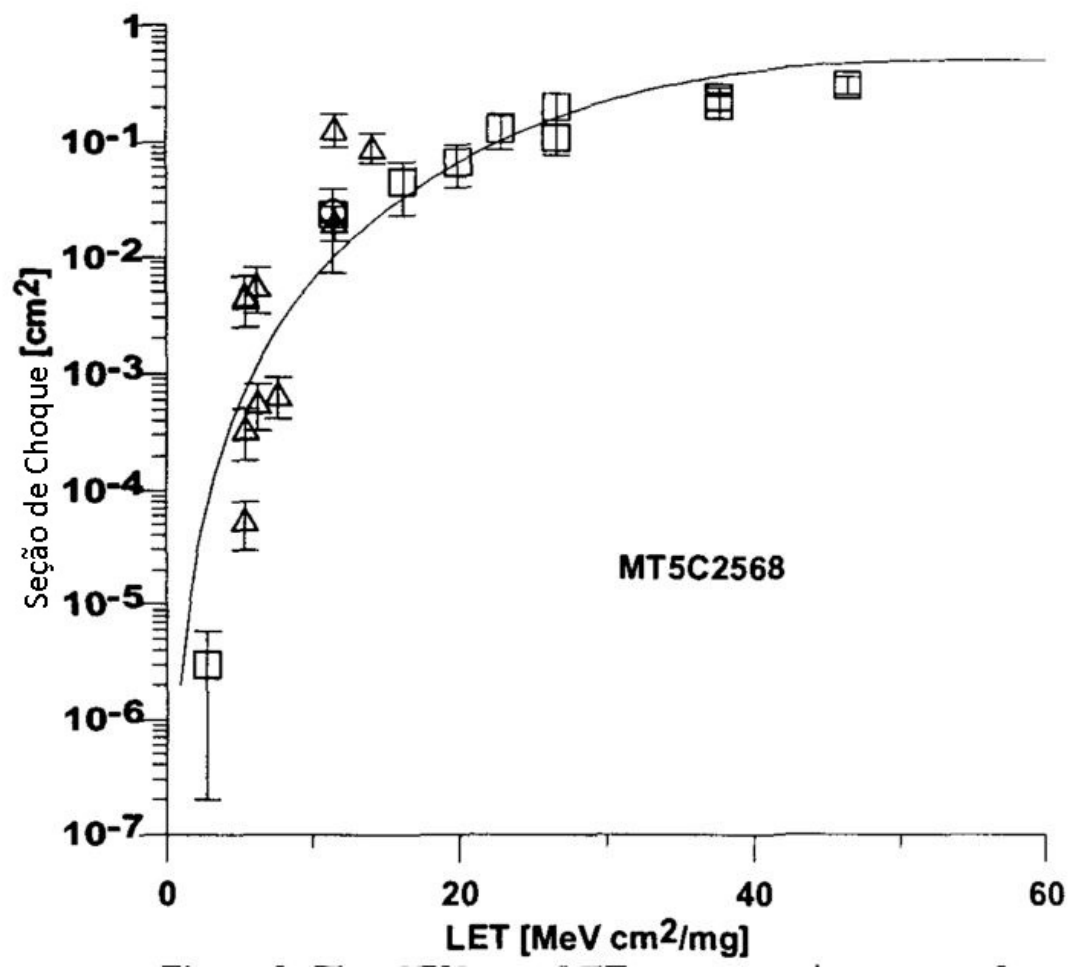

Fonte: (SCHEICK; SWIFT; GUERTIN, 2000)

A figura 44 mostra a seção de choque de SEU de uma memória SRAM comercial. É possível observar a grande uscetibilidade da SRAM à SEUs devido a SEE para LET maiores que $5 \mathrm{MeV}$ (SCHEICK; SWIFT; GUERTIN, 2000). 


\section{Procedimento Experimental}

Desenvolver sistemas eletrônicos com alta confiabilidade é uma tarefa desafiadora, na qual os testes devem ser cuidadosamente especificados e executados.

A caracterização da sensiblidade em relação ao TID de um dispositivo se dá com a análise dos efeitos da radiação nos parâmetros elétricos de interesse do dispositivo. Esses parâmetros devem ser definidos de acordo com o tipo de dispositivo e a aplicação e, por exemplo, os parâmetros podem ser corrente de polarização do circuito, temporização dos sinais elétricos, tensão de limiar de um transistor, entre outros. Todos esses parâmetros devem ser especificados cuidadosamente e caracterizados durante o teste.

A caracterização do sistema em relação a SEE deverá avaliar a quantidade de eventos únicos, a sua natureza e qual região, circuito ou dispositivo do sistema é mais sensível à radiação ionizante. O sistema deverá ser preparado de modo que possa ser contabilizada a quantidade de eventos ocorridos num determinado intervalo de tempo, se é temporário ou não, e calculada a seção de choque em função do LET, sendo esta a curva característica de sensibilidade de um dispositivo. Para executar esses testes, é necessário fontes de radiação bem caracterizadas e que possuam um bom controle para ser possível modificar os parâmetros referentes a radiação como taxa de dose, energia do feixe de partículas e LET.

Nesse capítulo serão descritas as fontes de radiação utilizadas nos experimentos e quais dispositivos foram testados, bem como as simulações da interação dos íons pesados com a matéria. Também será descrita a sequência de teste e as estratégias utilizadas tanto no teste estático, onde as memórias eram programadas e lidas sem a execução de um programa, quanto no teste dinâmico, onde as memórias eram programadas e lidas através de um firmware embarcado no sistema. Por fim, os testes serão repetidos em mais dois dispositivos com o objetivo de validar a repetibilidade dos testes.

\subsection{Fontes de Radiação}

Para os experimentos, os dispositivos foram irradiados com raios-X, íons pesados e partículas alfa. Os raios-X de $10 \mathrm{keV}$ são gerados a partir de um difratômetro Shimadzu XRD6100, localizado no Laboratório de Estudos de Radiação Ionizante (LERI) do Centro Universitário da FEI. Os testes com íons pesados e partículas alfa foram realizados nos laboratórios do Instituto de Física da USP. Os íons pesados são gerados pelo Acelerador Pelletron do LAFNUSP, o qual é o único acelerador de íons pesados no Brasil com tensão de operação de até 8 MV. As partículas alfa foram geradas a partir de uma amostra de Amerício-241. 


\subsubsection{Raios-X}

Nos testes para tolerância à TID foi utilizado um difratrômetro Shimadzu XRD-6100 (vide figura 45) configurado para gerar raios- $X$ com energia efetiva de $10-\mathrm{keV}$. Os raios- $\mathrm{X}$ são emissões eletromagnéticas provenientes de uma fonte segura de cobre, onde é emitido raios$\mathrm{X}$ característico de cobre. A energia efetiva foi medida através da camada semirredutora do alumínio obtendo aproximadamente $(10 \pm 1) \mathrm{keV}$. A dose foi determinada a partir do uso de uma câmara de ionização considerando a medida de exposição e transformada em dose absorvida em silício. Raios-X de energia efetiva de $10-\mathrm{keV}$ é um método muito popular de caracterização de TID de circuitos integrados pois o principal efeito causado devido a raios-X de $10-\mathrm{keV}$ é o efeito fotoelétrico. O efeito fotoelétrico gera pares elétron-lacuna no material, que podem ser armadilhados em íveis de energia e contribuir para mudanças nos parâmetros elétricos dos dispositivos. $\mathrm{O}$ raios- $\mathrm{X}$ de $10-\mathrm{keV}$ apresenta um rendimento comparável com o cobalto $\left(C_{o}^{60}\right)$ e, ao mesmo tempo, é uma fonte segura e de fácil controle. Além disso, os raios-X de 10-keV apresentam uma taxa de perda de energia no material na mesma ordem dos prótons de 20 até $100 \mathrm{MeV}$, o que torna essa energia interessante para simular efeitos de prótons encontrados no espaço (SCHWANK; SHANEYFELT; DODD, 2013). A figura 46 mostra diversos rendimentos de lacunas armadilhadas para diferentes partículas em função do campo elétrico.

Figura 45 - Difratômetro de raios-X Shimadzu XRD-6100

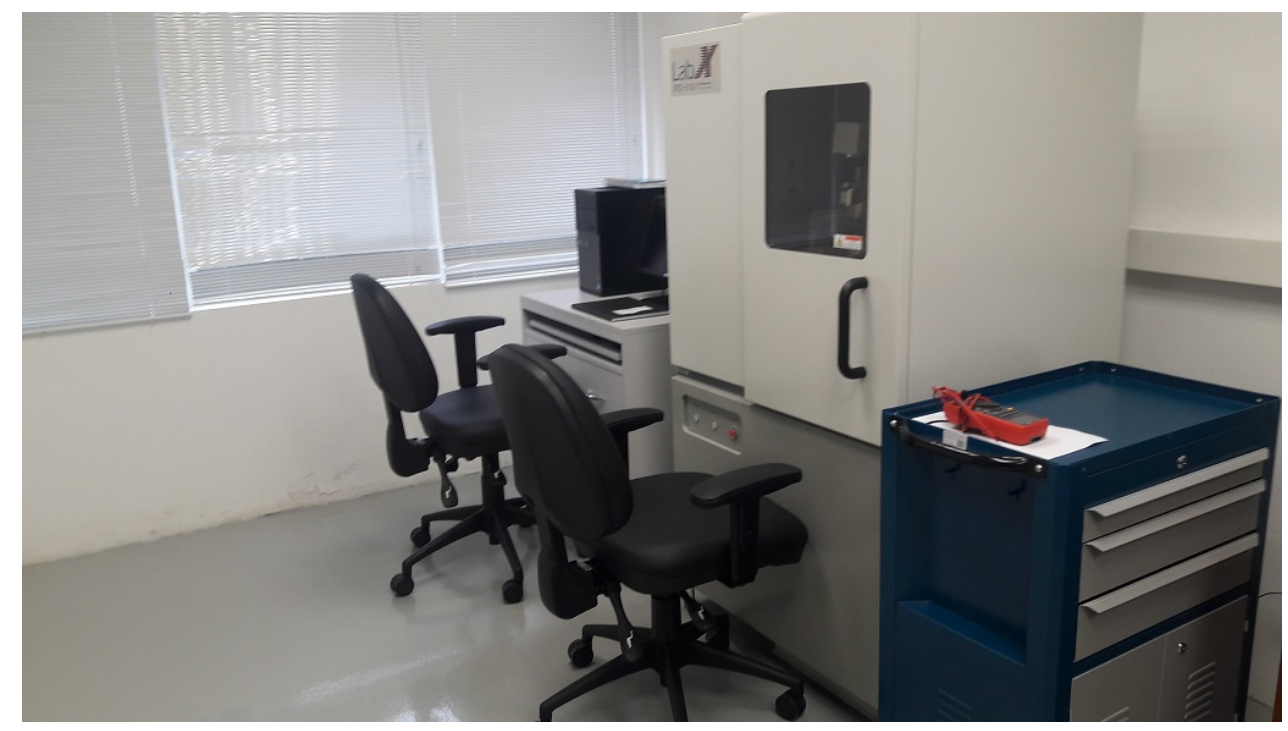

Fonte: Autor 
Figura 46 - Rendimento de lacunas armadilhados obtido experimentalmente para diferentes partículas.

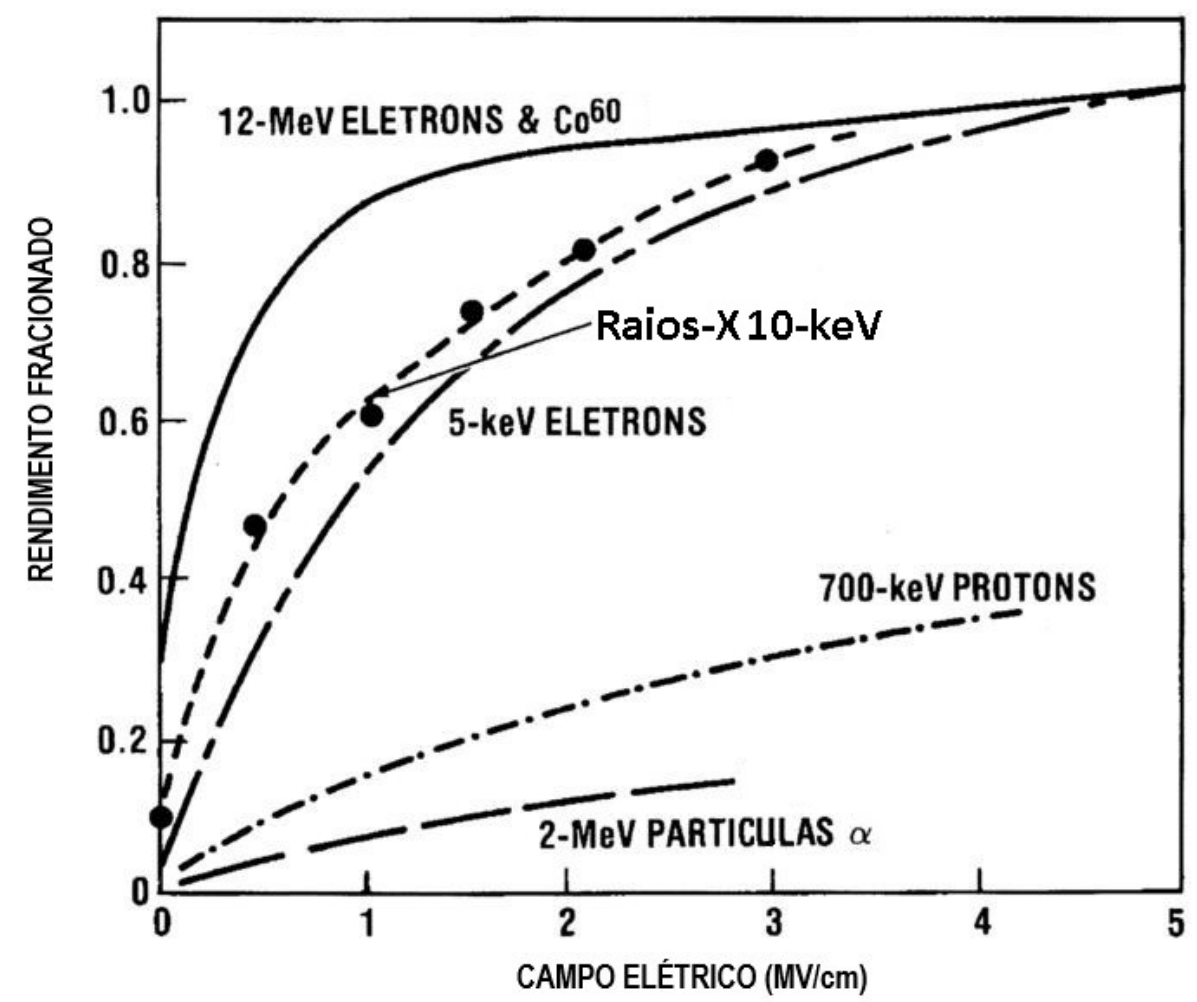

Fonte: (OLDHAM; MCLEAN, 2003)

\subsubsection{Prótons}

Para o experimento de irradiação por prótons foi utilizado um acelerador de partículas do tipo Pelletron-Tandem, disponibilizado pelo Laboratório de Análise de Materiais por Feixes Iônicos (LAMFI) no Instituto de Física da USP. O equipamento Pelletron-Tandem consiste em um acelerador eletrostático, modelo 5SDH, com “stripper” gasoso (Nitrogênio), construído pela National Electrostatics Corporation e pode alcançar até 1,7 MV de tensão terminal gerando prótons com uma energia máxima de $3,4 \mathrm{MeV}$.

A fonte utilizada neste trabalho foi Source of Negative Ions by Cesium Sputtering (SNICS), sendo capaz de gerar íons negativos de uma grande parcela de elementos da tabela periódica. Este princípio de funcionamento da fonte SNICS consiste em aquecer uma quantidade de Césio metálico obtendo-se vapor a uma temperatura aproximada de $120^{\circ} \mathrm{C}$, fazendo com que uma parte deste vapor seja depositada em um ionizador de Tântalo aquecido em uma temperatura acima de $1200^{\circ} \mathrm{C}$, gerando íons Cs+ na qual são atraídos ao cátodo através de uma diferença de potencial. No cátodo, que nada mais é do que um cadinho de material metálico, está contido o pó de onde serão extraídos os íons negativos e o césio não só é depositado sobre o material contido no cadinho como também o pulveriza. Sendo pulverizado, o material atravessa 
a fina camada de césio, favorecendo uma troca de carga tornando-o negativo. A partir disto, o material é repelido e extraído da fonte, colimado e focado no ímã seletor de massa.

\subsubsection{Fonte Alfa}

A irradiação com partículas alfa foi realizada utilizando uma fonte alfa composta de um isótopo de amerício $\left({ }^{241} \mathrm{Am}\right)$, cuja meia-vida é de 432,2 anos. O isótopo ${ }^{241} \mathrm{Am}$ decai principalmente através de decaimento alfa junto com a emissão de um fraco raio gama. Para cada transição entre núcleo final e inicial, uma diferença fixa de energia (ou valor $\mathrm{Q}$ ) caracteriza o decaimento. Há uma forte correlação entre a energia da partícula alfa e a meia-vida do isótopo pai e aqueles com maior energia são os que possuem menores meia-vida. Na prática, partículas alfa com energias maiores que $6,5 \mathrm{MeV}$ possuem meia-vida de alguns dias e não há muita utilidade. Por outro lado, quando a energia é menor que $4 \mathrm{MeV}$, o poder de penetração da partícula se torna muito pequena e portanto, também não muito útil (KNOLL, 1989). Por esse motivo, as partículas alfa mais comuns tem energia entre 4 e $6 \mathrm{MeV}$. No caso do ${ }^{241} \mathrm{Am}$, a transição com maior probabilidade de ocorrência é de 5,486 MeV (cerca de 85\%), seguida da transição com energia de 5,443 MeV (13\%) e 5,388 (2\%). Devido ao fato de partículas alfa perderem energia rapidamente em materiais, a fonte foi preparada em uma camada muito fina para apresentar um espectro praticamente monoenergético.

\subsection{4 Íons Pesados}

Feixes iônicos podem ser gerados de diversas formas, por exemplo, por meio de fontes de plasma ou fontes de sputtering. No caso do acelerador Pelletron utilizado, a fonte utilizada é uma fonte Multi-Cathode Source of Negative Ions by Cesium Sputtering (MC-SNICS). Uma visão do acelerador Pelletron pode ser observada na figura 47. A fonte de íons comporta até 32 cátodos diferentes, originando o nome multi-catodo. No processo de sputtering, os átomos arrancados passam através da fina camada de césio depositada sobre a superfície. Devido à sua eletropositividade, ocorre o fenômeno de ionização superficial. Os íons negativos (carga -e) gerados neste processo são repelidos e acelerados pelo potencial positivo de $20 \mathrm{kV}$ aplicado ao extrator e passam através de um furo no ionizador. Após a passagem pelo extrator, o feixe negativo é acelerado por uma tensão de $90 \mathrm{kV}$, além de ser focalizado, direcionado e colimado em direção ao primeiro eletroímã seletor. Após a produção de íons, o feixe passa através de um eletroímã seletor de massa onde o íon é deflexionado em 90 (SALA; SPALEK, 1974). A deflexão em $90^{\circ}$ é responsável pela seleção de massa dos íons de interesse, uma vez que o campo magnético é ajustado de forma que só sejam defletidos com trajetória central os íons com rigidez magnética. Após a seleção de massas, o feixe entra no acelerador propriamente dito. $\mathrm{O}$ acelerador consiste de colunas com divisores resistivos e anéis metálicos para a distribuição suave e uniforme de campo elétrico. No centro do acelerador está o terminal, onde a tensão 
de aceleração (positiva de até $8 \mathrm{MV}$ ) é aplicada. Após essa etapa, o feixe deve passar entre duas fendas que fazem o controle fino da energia do acelerador e após as fendas, o feixe passa por um último eletroímã, cuja função é desviá-lo para uma das 7 canalizações disponíveis no Acelerador Pelletron. Na figura 48 é possível observar detalhes da linhas de feixe da sala experimental.

Figura 47 - Visão geral do acelerador Pelletron.

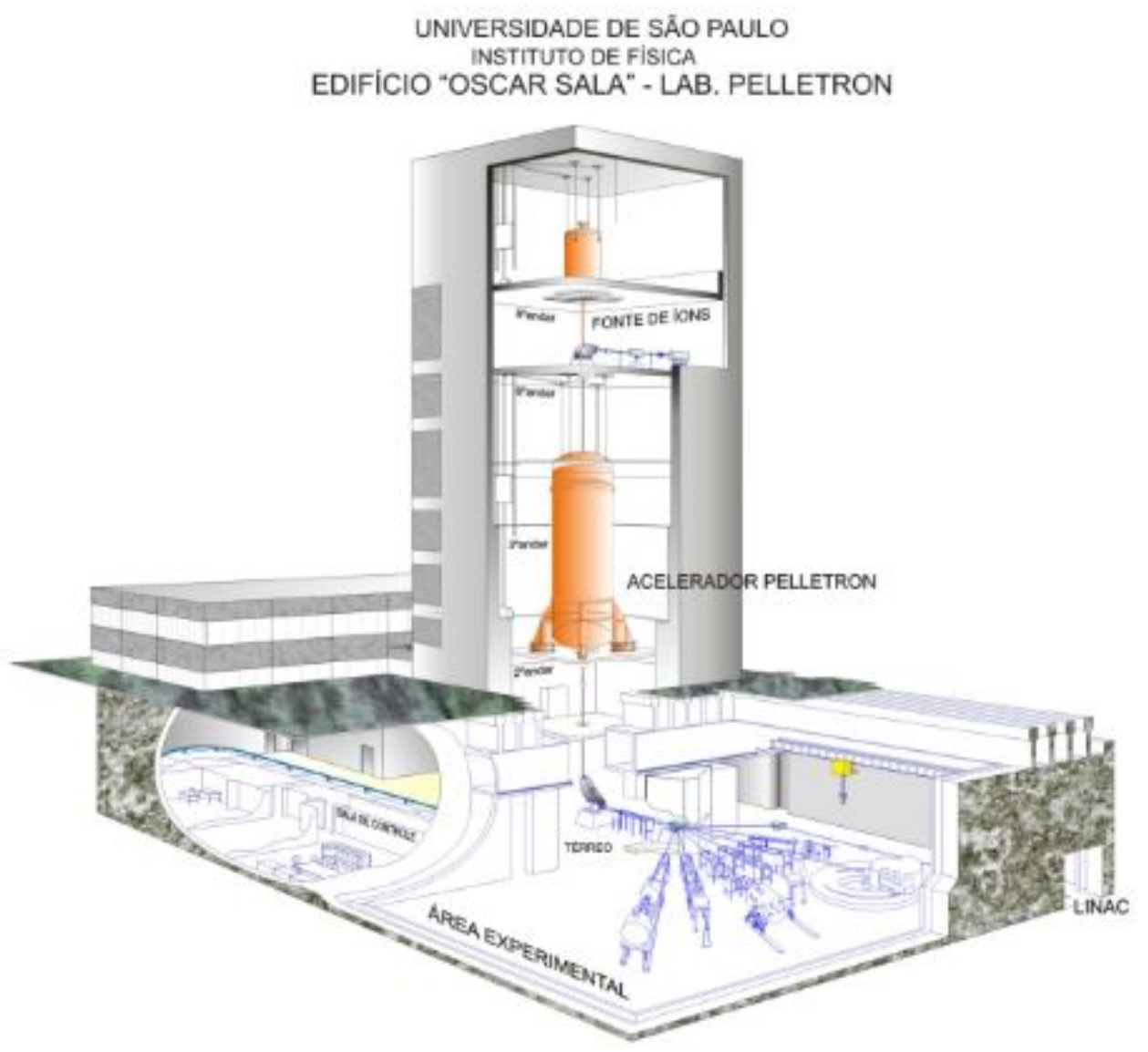

Fonte: (AGUIAR, 2014) 
Figura 48 - Detalhe da sala experimental.

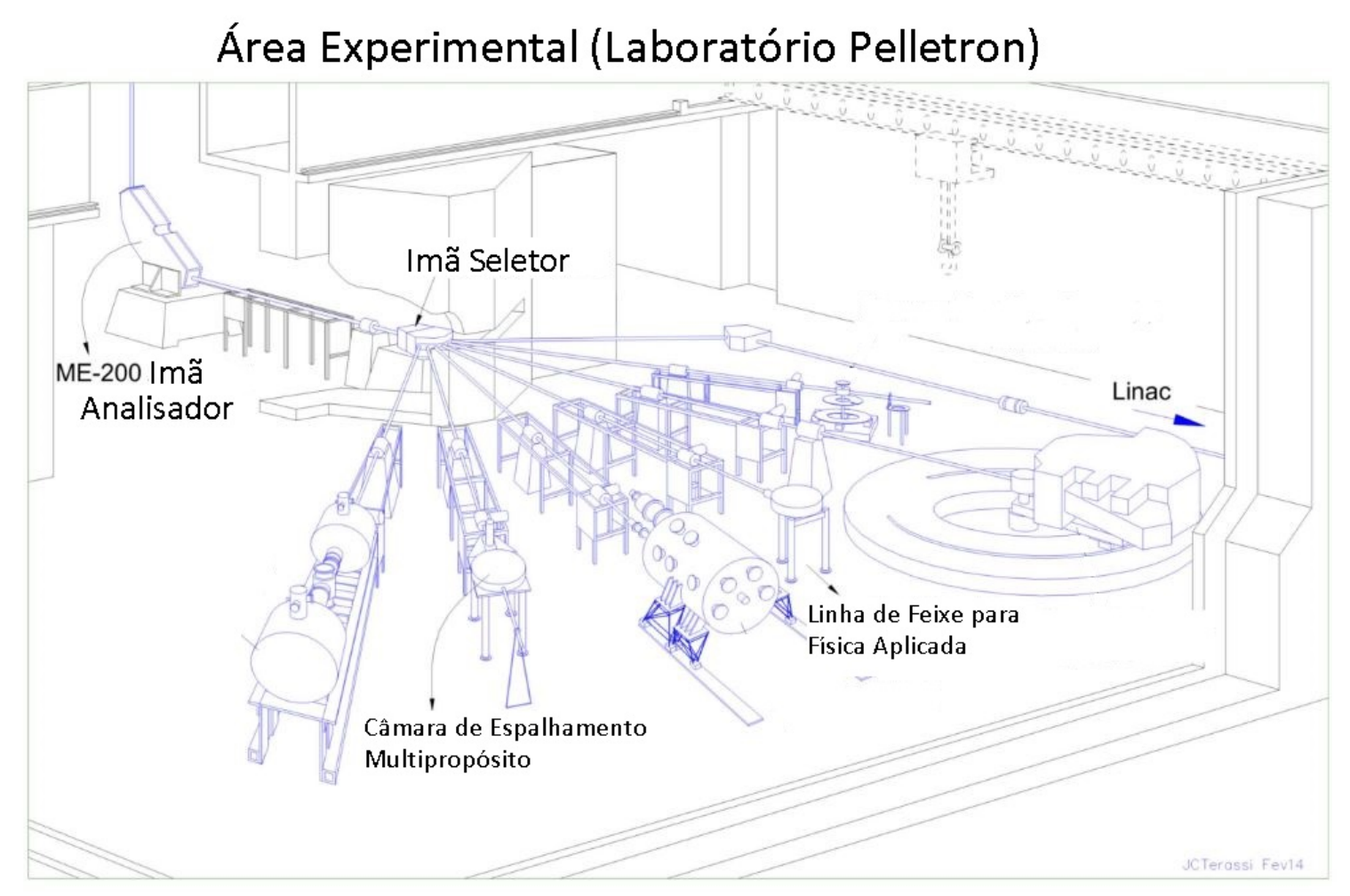

Fonte: (AGUIAR, 2014)

Os experimentos foram conduzidos na canalização $30^{\circ} \mathrm{B}$ da área experimental. Esta linha possui uma câmara de espalhamento de uso geral de 1 metro de diâmetro e cerca de 30 centímetros de altura, duas bombas turbo-moleculares para mantê-la numa pressão da ordem de $10^{-} 6$ Torr e um prolongamento que pode ser utilizado para feixe externo. Para atender os requisitos, a linha utiliza uma montagem tradicional de espalhamento Rutherford, de modo que no centro da câmara já alvos de ouro com diferentes espessuras. Essas diferentes espessuras permitem uma rápida mudança no fluxo de feixe espalhado apenas pela mudança da espessura do meio espalhador, embora com prejuízo em relação a energia do feixe. A linha foi projetada de modo que dispositivos, mesmo com dimensões superestimadas, tenham a variação da fluência menor que 10\%. A figura 49 demonstra o LET e alcance em silício para diversos feixes, possibilitando a escolha dos feixes de interesse para os testes (AGUIAR, 2014). 
Figura 49 - LET médio em função do alcance em silício para diversos feixes, energias e janelas.

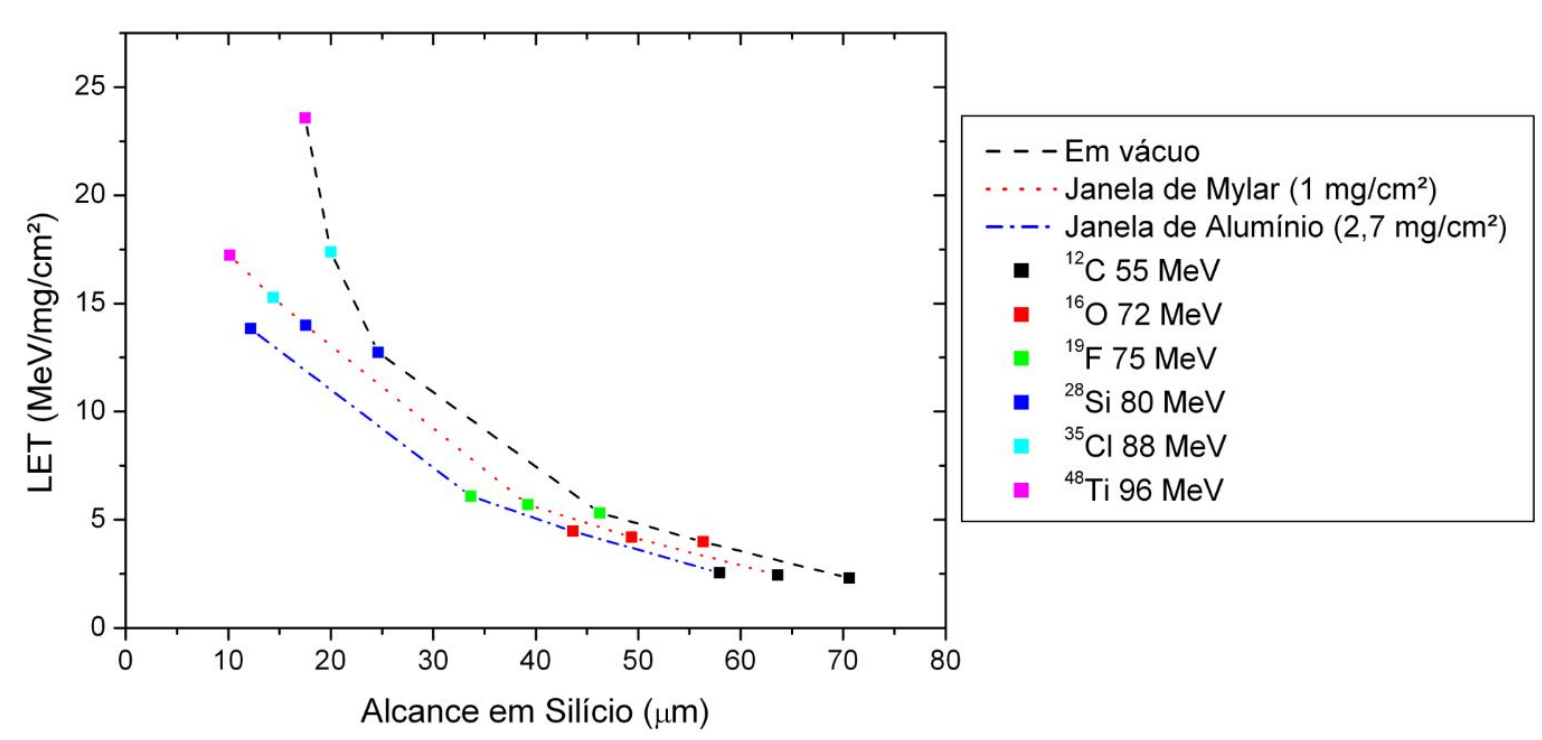

Fonte: (AGUIAR, 2014)

\subsection{Dispositivos sob Teste}

Para os experimentos foram utilizados dois microcontroladores comerciais de prateleira:

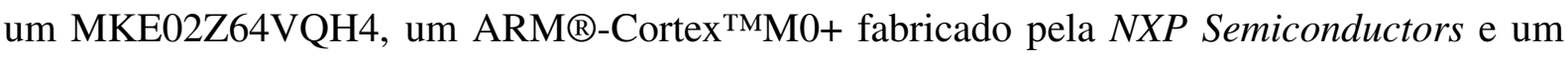
RM42L432, um ARM®-Cortex ${ }^{\mathrm{TM}} \mathrm{R} 4$ fabricado pela Texas Instruments. Os testes iniciais que exploraram os efeitos da radiação ionizante em microcontroladores foram todos executados utilizando o MKE02Z64VQH4 da NXP. Os testes de verificação foram executados novamente com outro dispositivo MKE02Z64VQH4 além do RM42L432, da Texas Instruments.

\subsubsection{MKE02Z}

Um dos dispositivos escolhidos para os testes foi o MKE02Z64VQH4, um microcon-

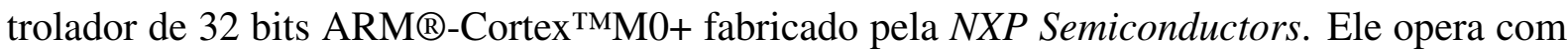
frequência de clock de até $20 \mathrm{MHz}$. Suporta uma tensão de alimentação de $2.7 \mathrm{~V}$ até $5.5 \mathrm{~V}$ e consegue operar em temperaturas que vão desde $-40{ }^{\circ} \mathrm{C}$ até $105^{\circ} \mathrm{C}$. A fabricação de processadores utilizando núcleo ARM já utilizam tecnologias de até $55 \mathrm{~nm}$, porém, esse dispositivo foi estimado em ser fabricado na tecnologia entre 130 a $180 \mathrm{~nm}$. O dispositivo tem uma memória flash com 64 kB de capacidade para armazenamento de código e 4 kB de SRAM para armazenamento de variáveis e dados voláteis do programa. O dispositivo conta com vários periféricos dentro do chip, por exemplo, Universal Asynchronous Receiver/Trasmitter (UART), Serial Peripheral Interface (SPI), entradas e saídas de propósito geral (GPIO), saídas com modulação por largura de pulso (PWM), conversores analógico-digital (ADC). A memória flash 
conta com um algoritmo de correção de erro (ECC) embarcado na própria memória que é capaz de corrigir erros simples, onde ocorre erro em apenas um bit da posição de memória, ou detectar duplo erro de bit (SEMICONDUCTOR, 2013). O dispositivo está montado em uma placa de desenvolvimento (vide figura 50) que possui headers de I/O, sensores, botões, LED e um adaptador de depuração e comunicação serial (openSDA). O firmware que implementa a função do openSDA está gravado em um segundo microcontrolador da série Kinetis K, da NXP Semiconductors, cujo partnumber é o K20DX128VFM5 e através dele é possível depurar aplicações, escrever e ler nas memórias além de estabelecer uma comunicação serial com o microcontrolador alvo da placa (KE02Z64VQH4). A figura 51 exemplifica o uso do openSDA durante os testes, onde o USB Host é o PC onde a placa é conectada através de uma porta USB. A aplicação executada pelo PC, envia comandos via USB para a aplicação openSDA que está sendo executada no microcontrolador secundário da placa de desenvolvimento onde é decodificado. A partir da decodificação dos comandos, o microcontrolador openSDA controla os sinais da interface JTAG do dispositivo alvo, onde acessa a porta de acesso a depuração (Debug Access Port - DAP).

Figura 50 - Detalhe da placa de desenvolvimento FRDM-KE02Z utilizada nos testes.

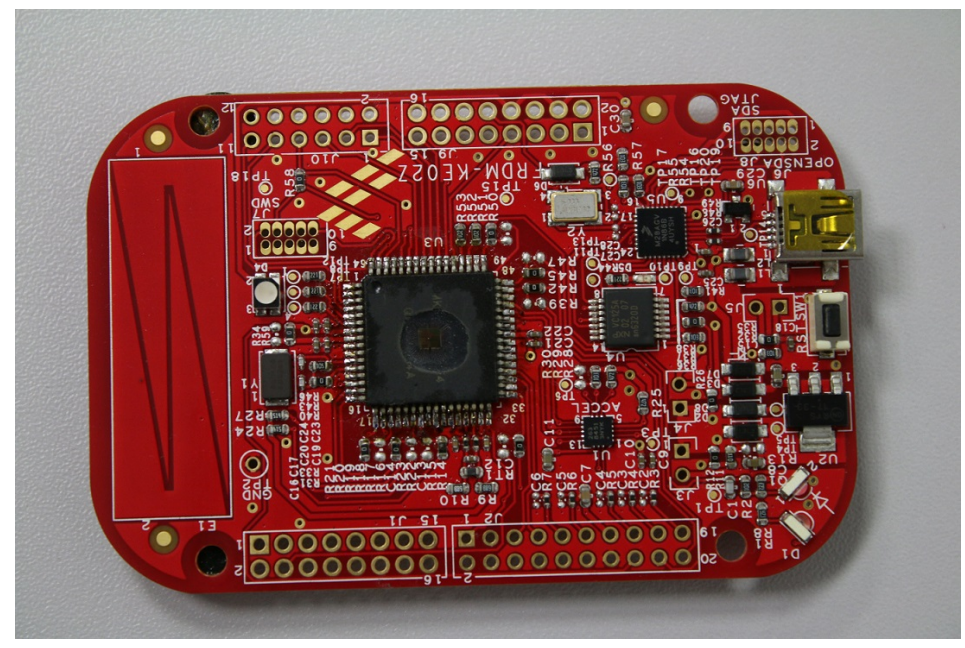

Fonte: Autor 
Figura 51 - Diagrama exemplificando o uso do openSDA.

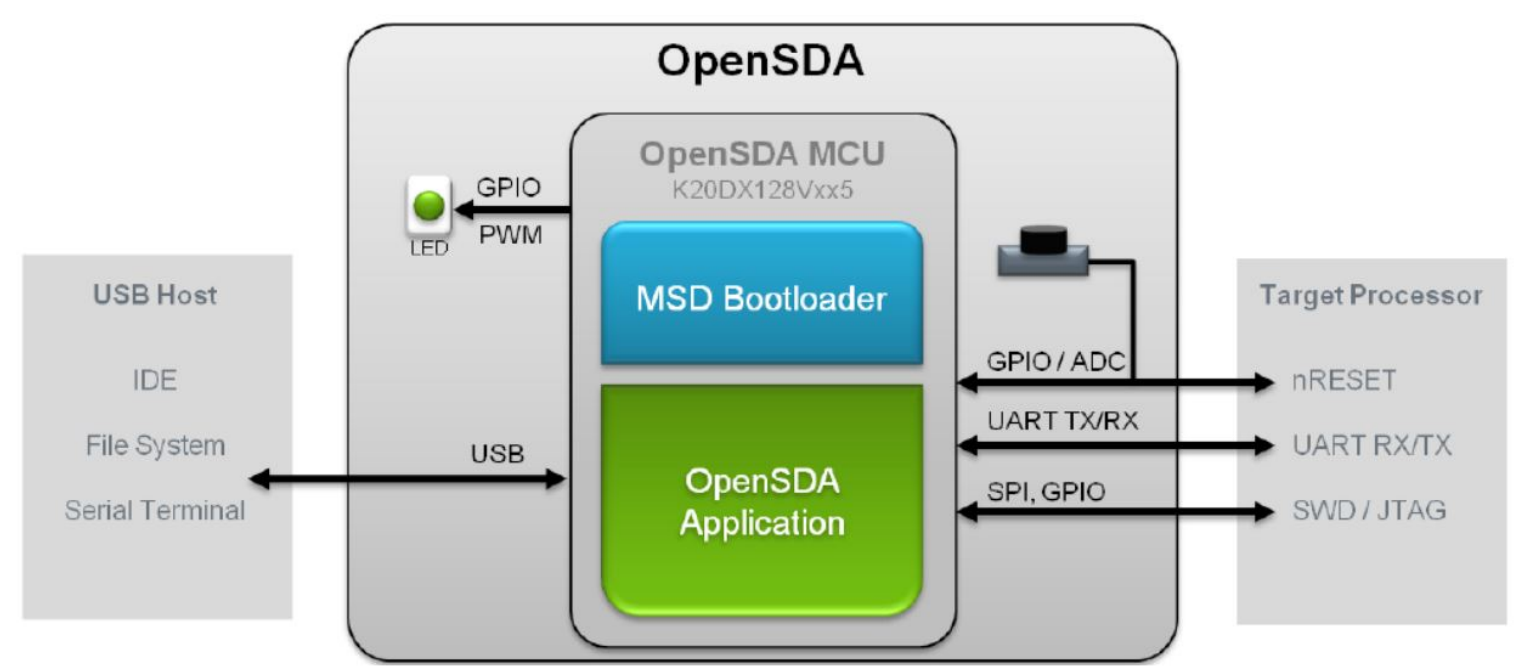

Fonte: Autor

\subsubsection{RM42L432}

O segundo dispositivo utilizado nos testes é o RM42L432, um microcontrolador de 32 bits ARM®-Cortex ${ }^{\mathrm{TM}} 4$ fabricado pela Texas Instruments. Ele opera com frequência de clock de até $100 \mathrm{MHz}$ e é alimentado através de duas tensões: 1,2 e 3,3 volts. Opera em temperaturas de -40 até $105^{\circ} \mathrm{C}$ e possui $400 \mathrm{kB}$ de flash e $32 \mathrm{kB}$ de RAM. O dispositivo está montado em uma placa de desenvolvimento onde possui um circuito JTAG para depuração e gravação de programas, além de possibilitar a comunicação serial com o microcontrolador. Esse dispositivo é um microcontrolador de alta performance projetado para sistemas seguros. Ele possui duas CPUs que executam as mesmas instruções em paralelo e são capazes de detectar erros. Além das CPUs redundantes, o dispositivo possui ECC tanto na memória flash quando na memória RAM.

Figura 52 - Detalhe da placa de desenvolvimento LaunchPad-RM42x utilizada nos testes.

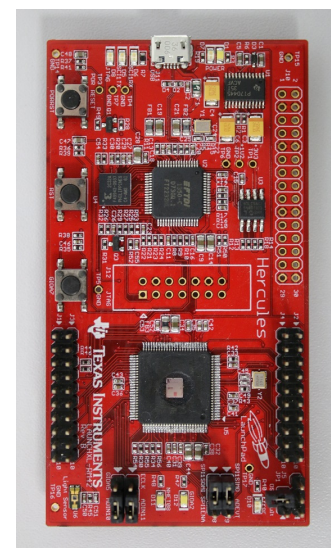

Fonte: Autor 


\subsubsection{Preparo das Amostras}

Os circuitos integrados comerciais possuem em sua grande maioria um encapsulamento feito de epóxi por apresentar boas propriedades em termos de custo, proteção mecânica e temperatura de operação (ARDEBILI; WONG; PECHT, 2003). Para facilitar os cálculos e conseguir estimar com melhor precisão a dose de radiação absorvida, o dispositivo foi desencapsulado através de um processo químico de corrosão. A corrosão foi feita cuidadosamente de modo que apenas a lâmina de silício ficasse exposto sem danos aos wire bondings que conectam a lâminas aos terminais do CI. O método de remoção do encapsulamento epóxi é descrito a seguir: Primeiramente, é necessário posicionar o dispositivo em uma placa aquecedora, onde utilizou-se uma temperatura em um intervalo de $70^{\circ} \mathrm{C}$ e $80^{\circ} \mathrm{C}$ para que a eficiência da reação química seja maior. Após o aquecimento, é possível iniciar o procedimento de corrosão. Este processo foi realizado com a solução $5 \mathrm{ml}$ de ácido nítrico $\left(\mathrm{H}_{2} \mathrm{NO}_{3}\right)$ para o ataque corrosivo aplicado com uma pipeta manual. Após o primeiro ataque, forma-se um líquido viscoso acima da amostra, sendo necessária sua remoção. Para interromper este processo, necessita-se de uma solução de acetona, neste caso, foi utilizado $100 \mathrm{ml}$ de acetona. A amostra é retirada da placa aquecedora com uma pinça e mergulhada na acetona até que se retire toda camada atacada. Após este procedimento o dispositivo pode ser recolocado na placa aquecedora para uma próxima aplicação de ácido. Ao término do desencapsulamento, deve-se mergulhar o dispositivo em um banho de bicarbonato de sódio (aproximadamente $100 \mathrm{ml}$ ) em um intervalo de 3 a 5 minutos para que interrompa completamente o processo corrosivo. Caso não seja interrompido de forma correta, após alguns dias, a peça vai sendo corroída aos poucos, apresentando variação de espessura no próprio chip a ser analisado. Este processo deve ser cíclico até que a parte sensível do chip seja exposta. A figura 53 mostra uma fotografia feita com um microscópio eletrônico de varredura na qual pode ser observada a superfície do chip e a figura 54 mostra a seção transversal do dispositivo onde é possível observar as camadas sensíveis do dispositivo localizada em uma profundidade de até $10 \mu m$ (PASCHOAL, 2017). 
Figura 53 - Fotografia realizada com um microscópio eletrônico de varredura (MEV) da lâmina de silício do microcontrolador MKE02Z.

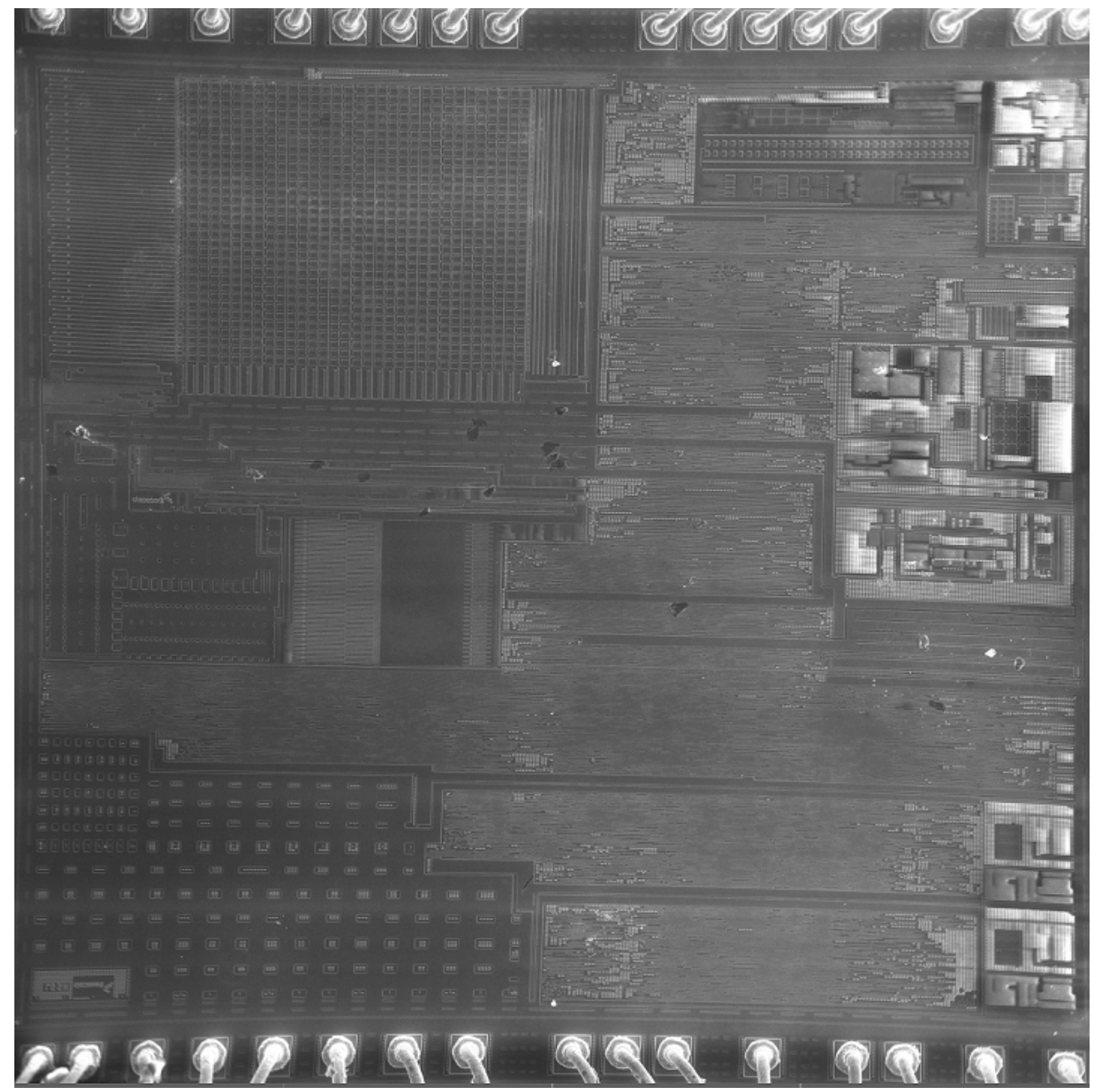

Fonte: Autor 
Figura 54 - Imagem de microscopia eletrônica de varredura do corte transversal do microcontrolador MKE02Z.

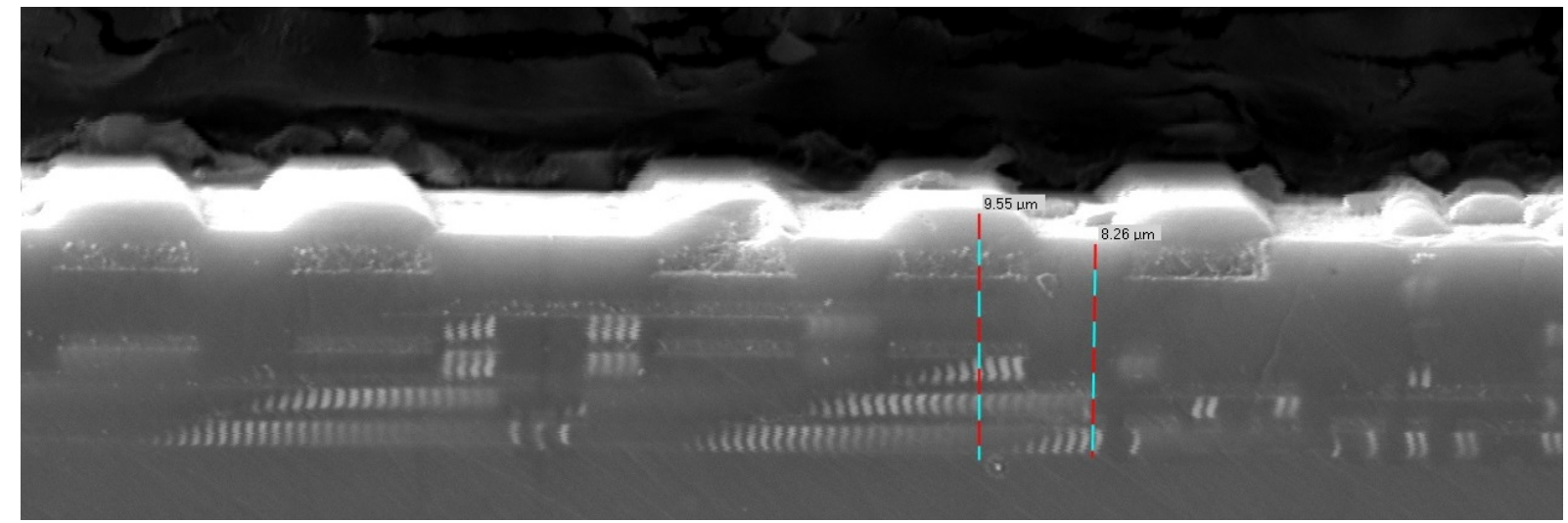

Fonte: Autor

Figura 55 - Fotografia realizada com um microscópio digital da lâmina de silício do microcontrolador RM42L432.

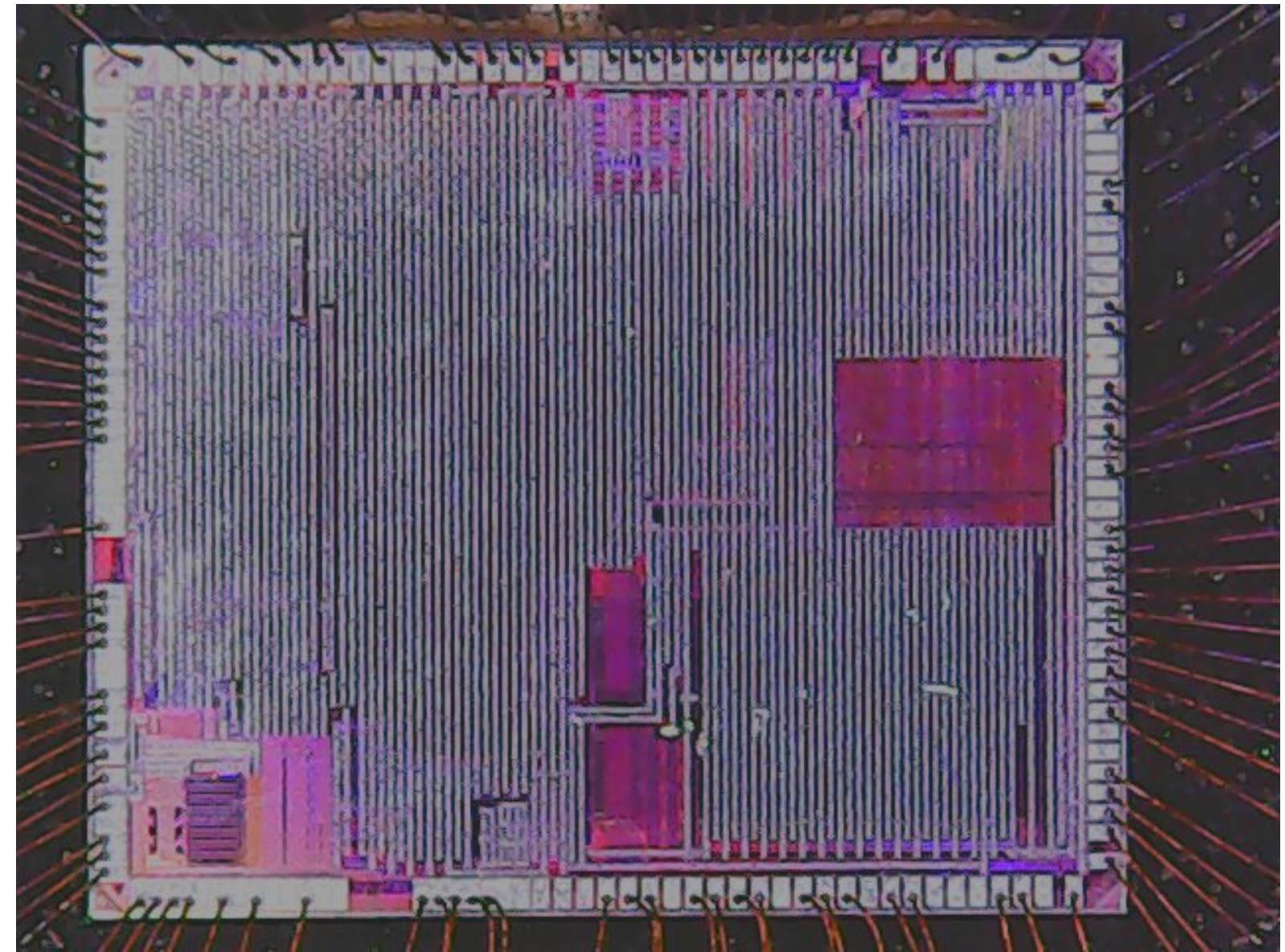

Fonte: Autor 
Com o CI desencapsulado, não é necessário considerar as interações que a radiação ionizante terá com o material do encapsulamento. Desta forma, estima-se com uma maior precisão os parâmetros de irradiação do dispositivo.

\subsubsection{Simulações SRIM}

Para estimar o alcance das partículas nos materiais, simulações foram realizadas utilizando o software Stopping and Range of Ions in Matter (SRIM) no qual é possível especificar as espessuras dos materiais dos dispositivos, as partículas incidentes e obter parâmetros de ionização em função da profundidade do material, entre outros resultados importantes. A figura 56 abaixo ilustra simulações para o feixe de ${ }^{12} C$ com energia de $26,6 \mathrm{MeV}$ e 47,7 MeV. É possível observar um aumento abrupto do valor de LET e então uma queda brusca, o qual é caracterizado como pico de Bragg. A distância onde ocorre o pico de Bragg é adotado como sendo o alcance da partícula no material.

Figura 56 - Simulação de feixe de ${ }^{12} C$ para energia de $26,6 \mathrm{MeV}$ e 47,7 MeV.

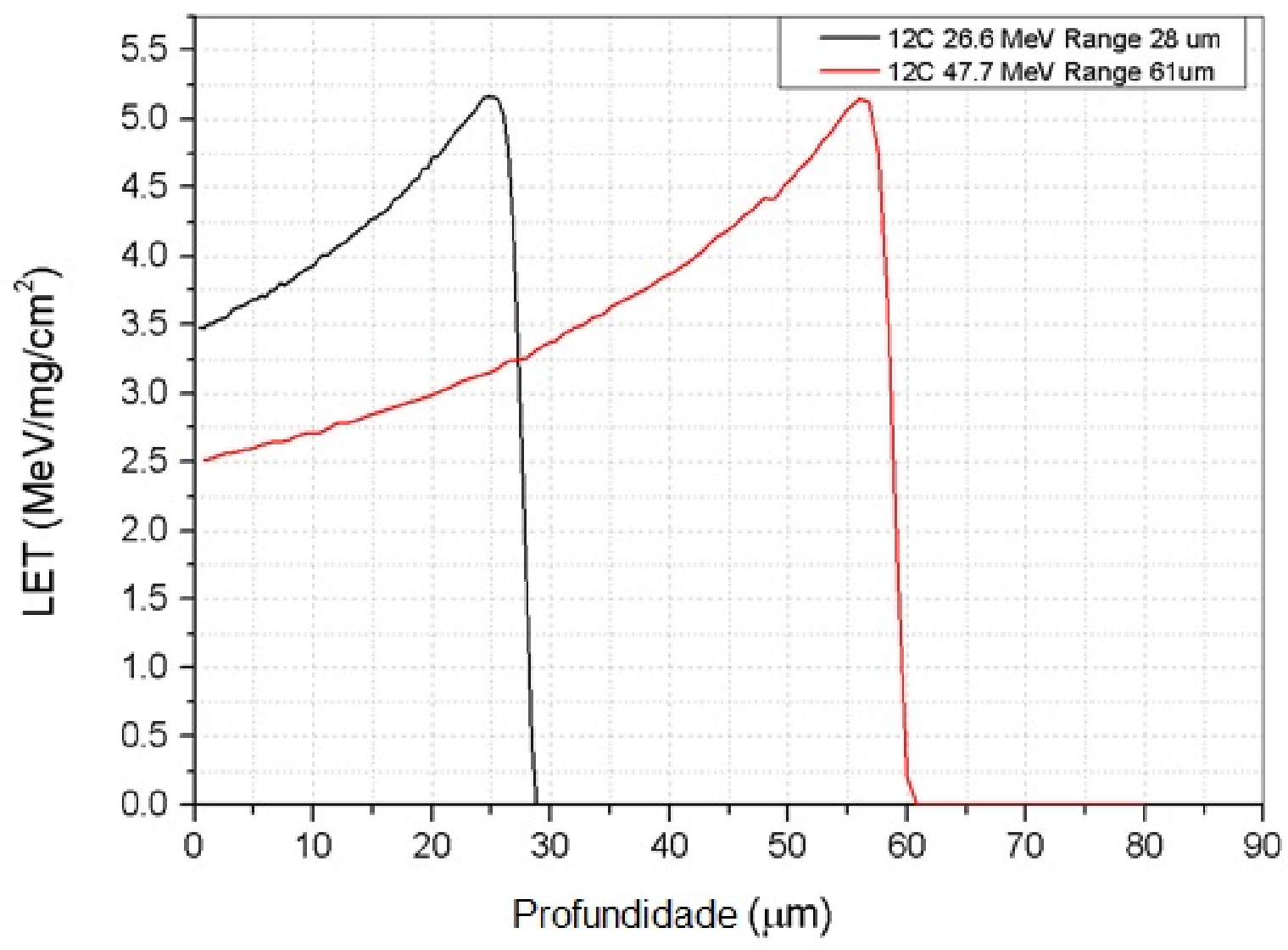

Fonte: Autor 
Figura 57 - Simulação de feixe de ${ }^{12} C$ atravessando uma lâmina de $40 \mu m$ de silício.

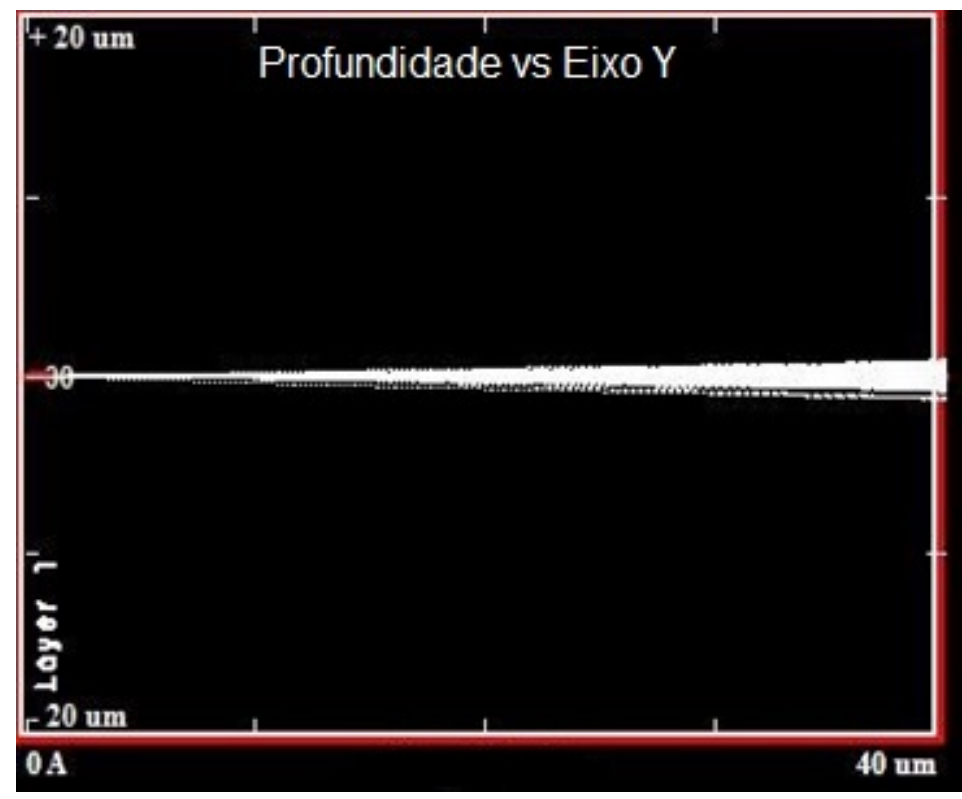

Fonte: Autor

A figura 57 ilustra a trajetória das partículas em uma lâmina de silício de $40 \mu \mathrm{m}$. Nessa simulação já foi descontado a perda de energia da partícula ao atravessar o ar.

\subsubsection{Sequência de Testes}

Inicialmente, apenas o MKE02Z foi testado com o objetivo de definir uma sequência razoável de testes para ser possível propor uma metodologia de testes para microcontroladores, portanto, nessa parte do trabalho apenas um dos dispositivos foi testado. É importante ressaltar que, nesse momento, havia duas amostras do dispositivo MKE02Z: uma usada nos testes de raios-X e outra usada nos testes de íons pesados, prótons e partículas alfa. Isso é necessário pois a suscetibilidade à SEE de um dispositivo pode ser alterada caso ele já tenha sido afetado por TID. A sequência adotada nos testes foi definida de acordo com os resultados que foram sendo obtidos durante a realização do trabalho. Portanto, num primeiro momento, foi realizado uma investigação de como o dispositivo seria afetado pela radiação ionizante. Foram realizados testes utilizando raios- $\mathrm{X}$ e íons pesados (utilizando o acelerador Pelletron), onde não havia nenhum programa sendo executado com o objetivo de avaliar as memórias flash e SRAM, assim como os registradores do dispositivo. Com o resultado desses testes, a sequência lógica seria verificar qual a sensibilidade do dispositivo, ou seja, qual o máximo valor de LET em que não ocorria efeitos observáveis no dispositivo ou qual a máxima dose acumulada em que o dispositivo continuaria a operar normalmente. Para atingir os níveis estimados de LET, foi necessário utilizar outros tipos de fontes de radiação além do acelerador Pelletron, de modo que fosse possível variar de modo seguro e com precisão os níveis de energia dos íons de modo 
a atingir os valores de LET necessários. Por esse motivo, foram realizados testes utilizando prótons e partículas alfa. Os resultados dos testes serão discutidos a seguir.

É importante ressaltar que os encapsulamentos dos outros componentes montados na placa não haviam sido removidos e eram suficientes para bloquear tanto a irradiação por feixe iônico quanto a irradiação por partículas alfa. Para o raios-X, o feixe era direcionado ao dispositivo sob teste e possuía uma área de cerca de $1 \mathrm{~cm}^{2}$, de modo que o restante da placa não sofria os efeitos por raios-X.

\subsubsection{Estratégia de Testes}

No início, foi identificada qual parte do dispositivo era mais suscetível a eventos únicos e danos induzidos pela radiação ionizante. Para isso, foi elaborada uma estratégia de teste que utiliza a interface de depuração e controle do núcleo do microcontrolador, o qual permite escrever e ler as memórias sem que o núcleo esteja de fato executando alguma instrução. Isso reduz o tempo morto onde não é possível identificar se houve alguma falha no microcontrolador além de tornar o teste mais robusto e controlado. Utilizando essa estratégia, foram feitos dois testes no dispositivo: um teste utilizando raios- $\mathrm{X}$ como fonte de radiação ionizante e o outro teste utilizando íons pesados. Após esses testes, identificou-se que a memória SRAM era mais sensível à SEE e que não houve nenhum SEU observado na memória flash. Essa maior sensibilidade da SRAM deve-se à sua arquitetura que emprega realimentação de inversores, na qual um transiente em um nó sensível da memória pode facilmente inverter o valor do bit que estava armazenado (AZAMBUJA; KASTENSMIDT; BECKER, 2014). Considerando esse cenário, foi desenvolvido um programa específico para o teste da SRAM, chamado de Dynamic Ram Test (DRT).

\subsubsection{Setup do teste com raios- $X$}

A figura 58 ilustra o posicionamento do dispositivo durante a irradiação por raios-X. O feixe está perpendicular em relação a superfície do dispositivo e está posicionado a uma distância de $10 \mathrm{~cm}$, garantindo que toda a área do dispositivo está sendo irradiado com uma taxa de dose de $96 \pm 5 \mathrm{rad}(\mathrm{Si}) / \mathrm{s}$. A taxa de dose, segundo a norma MIL-STD-883, deve estar entre 50 e $300 \mathrm{rad}(\mathrm{Si}) / \mathrm{s}$ para um teste padrão. Por esse motivo, foi escolhido uma taxa de dose que estivesse dentro dessa faixa. 
Figura 58 - Detalhe do setup do dispositivo durante a irradiação por raios-X, mostrando o dispositivo posicionado perpendicularmente ao feixe.

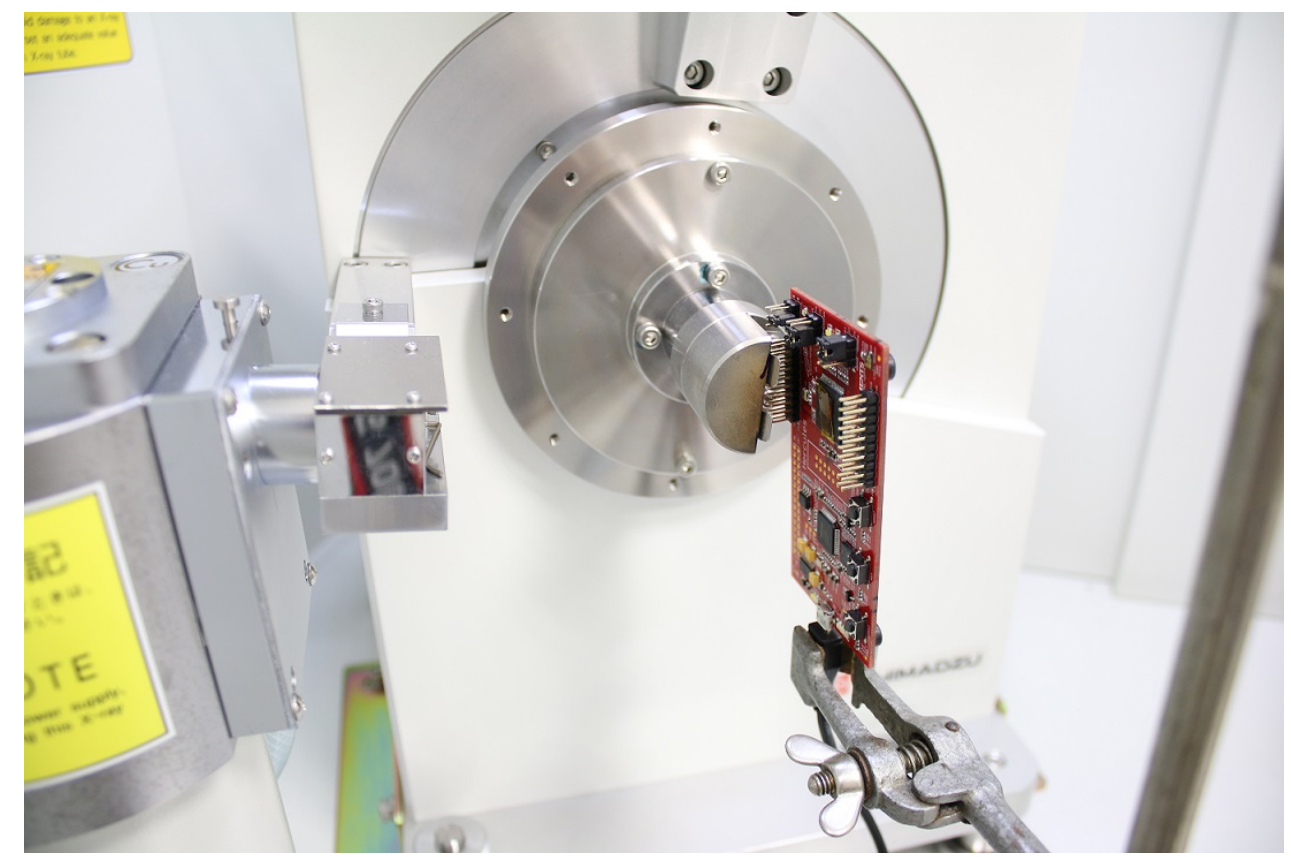

Fonte: Autor

\subsubsection{Setup do teste com íons pesados no Acelerador Pelletron}

O dispositivo foi posicionado dentro de uma câmara de espalhamento e fixado em uma grade plástica formando um ângulo de aproximadamente $30^{\circ}$ em relação a canalização da linha do feixe de partículas, como visto na figura 59. Um detetor foi posicionado também a $30^{\circ}$ na direção oposta para contabilizar o fluxo de partículas e tornar possível o cálculo da seção de choque de bit-flips do dispositivo. O dispositivo foi irradiado com feixes de ${ }^{12} \mathrm{C},{ }^{16} \mathrm{O},{ }^{19} \mathrm{~F}$ e ${ }^{28} \mathrm{Si}$ 
Figura 59 - Detalhe do setup do dispositivo na câmara de espalhamento.

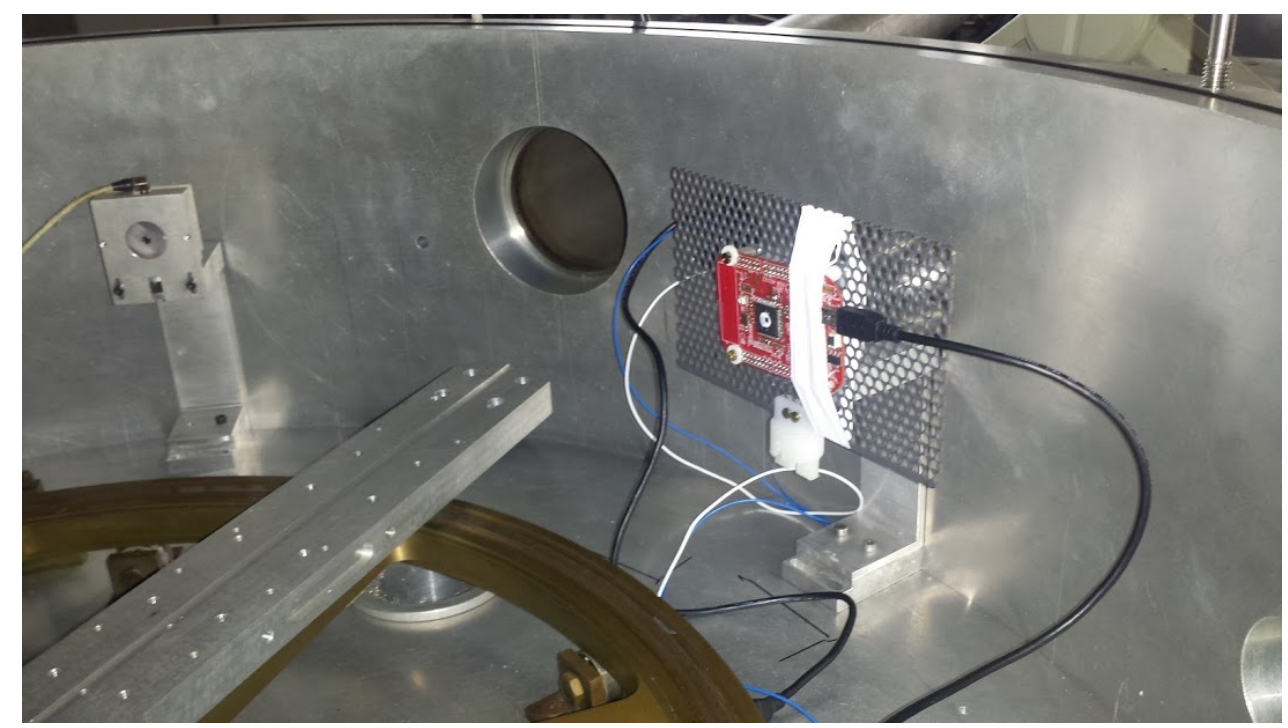

Fonte: Autor

\subsubsection{Setup do teste com íons pesados no Acelerador LAMFI}

O dispositivo foi posicionado dentro da câmara de espalhamento e fixado em uma grade plástica formando um ângulo de aproximadamente $30^{\circ}$ em relação a canalização da linha, vide figura 60 . Um detetor foi posicionado a quase $180^{\circ}$ em relação ao feixe de modo a contabilizar o fluxo de partículas na direção do detetor. Sendo conhecido o ângulo onde o detetor está posicionado e o ângulo onde o dispositivo está posicionado, é possível estimar o fluxo que atinge o dispositivo. 
Figura 60 - Detalhe do setup do dispositivo na câmara de espalhamento.

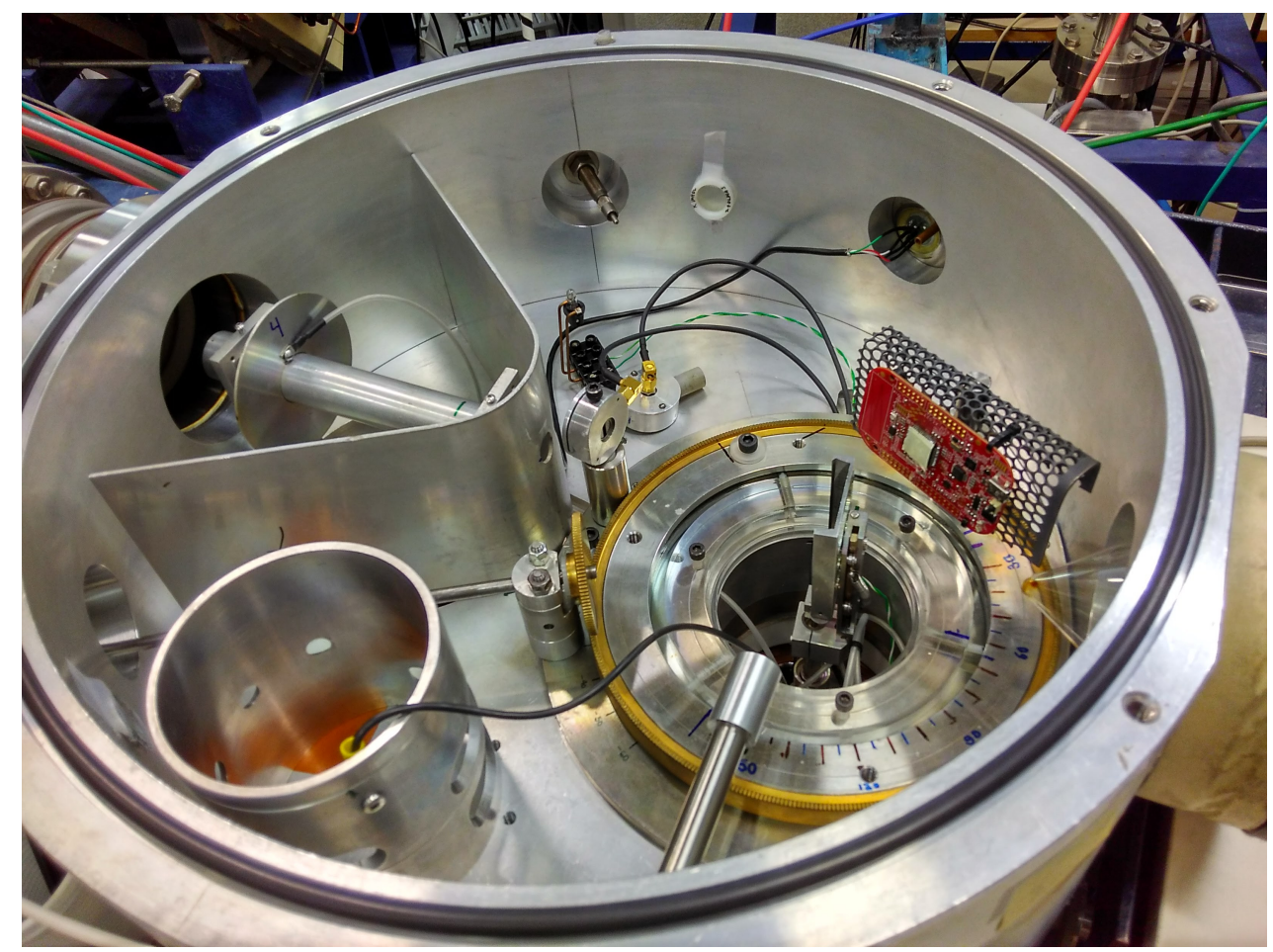

Fonte: Autor

\subsubsection{Setup do teste com partículas alfa com fonte ${ }^{241} \mathrm{Am}$}

A figura 61 ilustra o posicionamento do dispositivo durante a irradiação por partículas alfa. O dispositivo está posicionado a $15 \mathrm{~mm}$ da fonte alfa. A atividade da fonte foi estimada em 13,7 contagens/s/msr a uma distância de $20 \mathrm{~mm}$ e a energia das partículas é aproximadamente 5,5 MeV. O LET da partícula no dispositivo variou de 0,61 $\mathrm{MeV} / \mathrm{mg} / \mathrm{cm}^{2}$ até 1,48 $\mathrm{MeV} / \mathrm{mg} / \mathrm{cm}^{2}$ através da mudança da pressão do gás de argônio da câmara. 
Figura 61 - Detalhe do setup do dispositivo durante a irradiação por partículas alfa.

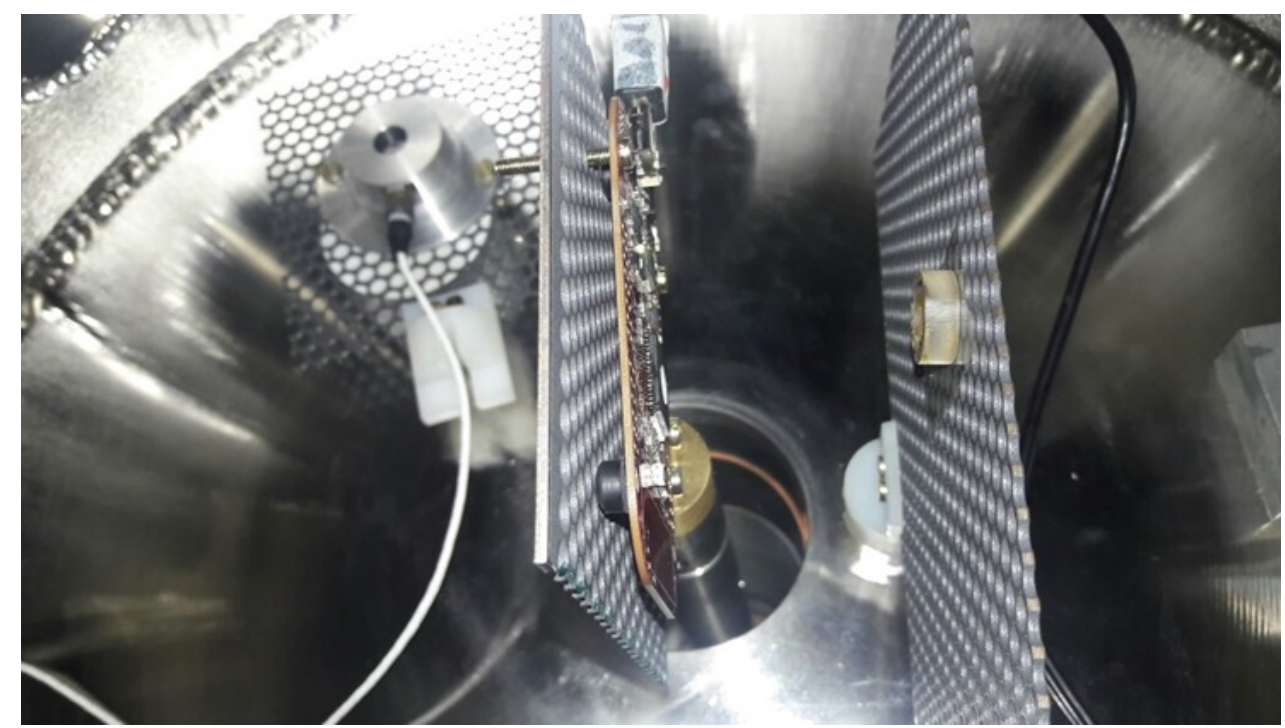

Fonte: Autor

\subsubsection{Teste Estático via Depurador}

Atualmente é cada vez mais comum os circuitos integrados possuírem um circuito lógico específico para teste. Essa lógica é normatizada pelo IEEE através do padrão IEEE 1149.7 e ficou conhecido como interface JTAG (Joint Test Action Group) e foi originada com o propósito de estabelecer um padrão para testes funcionais de um circuito integrado quando este estivesse montado numa placa de circuito impresso. Os testes funcionais eram feitos através de uma configuração em daisy-chain onde a saída de um CI fosse ligado a entrada de outro e um padrão de teste era injetado nesse caminho de dados a fim de garantir que todas as entradas e saídas estavam funcionais e conectadas. Com a popularização dos microcontroladores e dispositivos programáveis, se tornou necessário aumentar a capacidade dessa interface de teste para gravação e depuração de programas. Porém, para dispositivos de baixo custo ou com uma quantidade de pinos limitada, utilizar a interface JTAG pode ser impeditivo, uma vez que essa interface é definida com 5 terminais. Em microcontroladores ARM®isso é resolvido utilizando o Serial Wire JTAG - Debug Port (SWJ-DP), que implementa uma interface JTAG baseado no padrão IEEE com interface ao Debug Access Port, além de uma interface de dois pinos específica para o DAP, chamada de Serial Wire Debug. Essa interface conta com uma lógica de detecção automática entre JTAG e SWD, possibilitando o uso do JTAG e SWD nos mesmos pinos, vide figura 62 (ARM, 2017). 
Figura 62 - Estrutura da interface SWJ-DP.

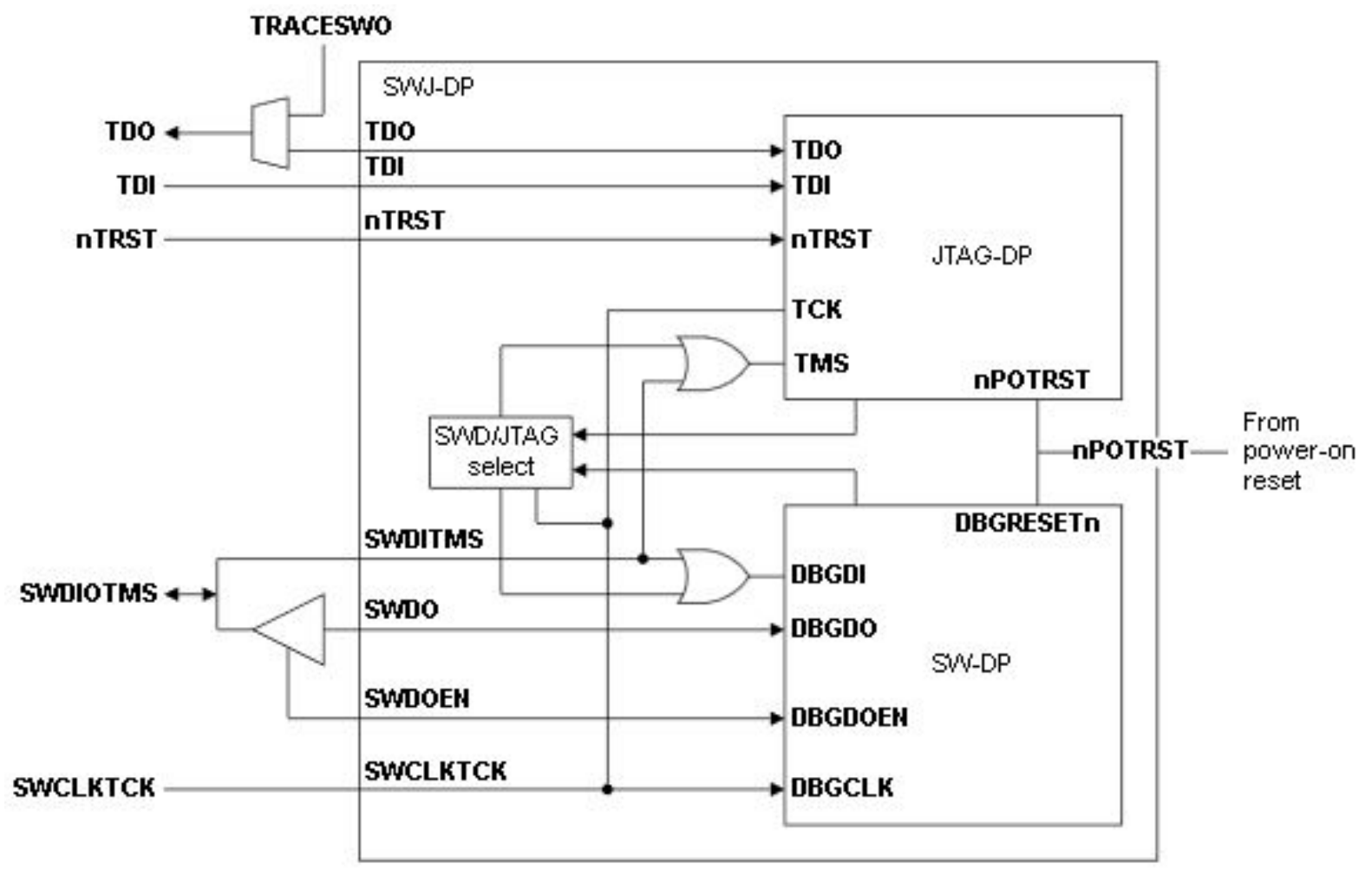

Fonte: (ARM, 2017) 
O DAP age como um componente para traduzir transferências de dados de um tipo de interface para outra, por exemplo, de depuradores externos para transações nos barramentos internos ao chip. A figura 63 exemplifica o acesso que a interface SWJ-DP fornece ao barramento de periféricos (Advanced Peripheral Bus, APB). Tudo isso permite que o dispositivo seja controlado sem, de fato, ter um programa sendo executado e é dessa forma que a gravação e leitura das memórias foi realizada durante os testes.

Figura 63 - Fluxo de controle da interface DAP.

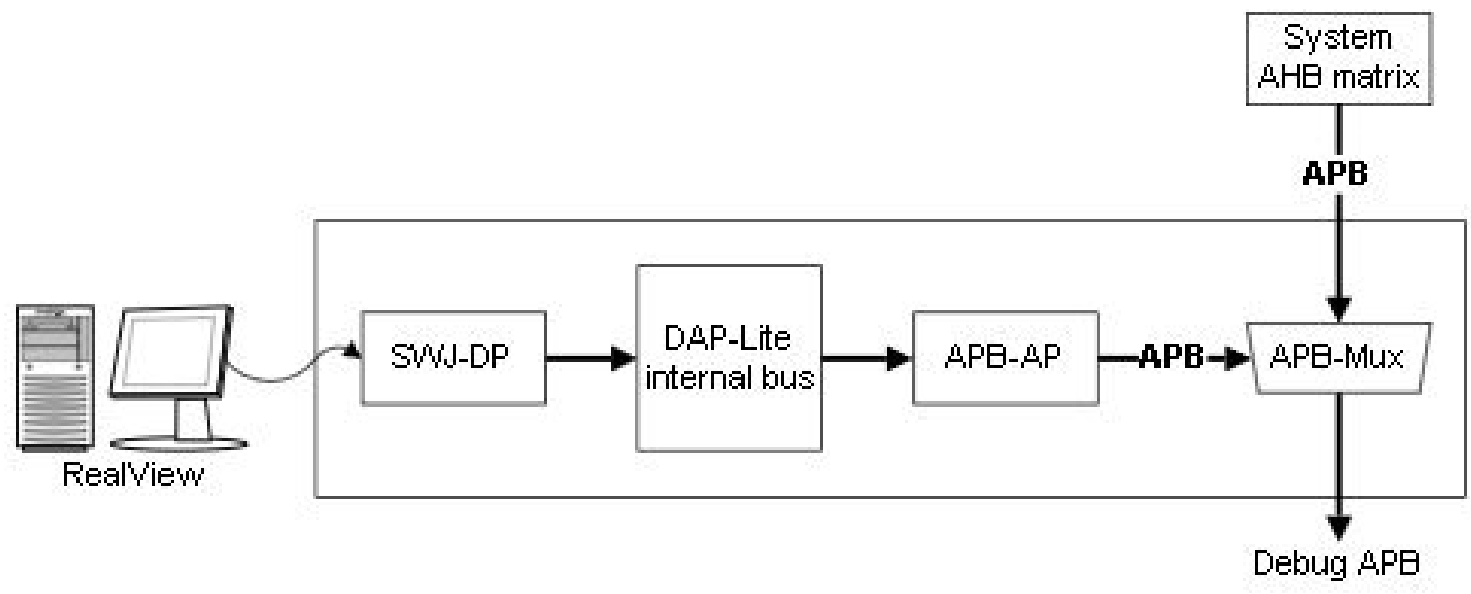

Fonte: (ARM, 2017) 
Figura 64 - Fluxograma do teste via JTAG.

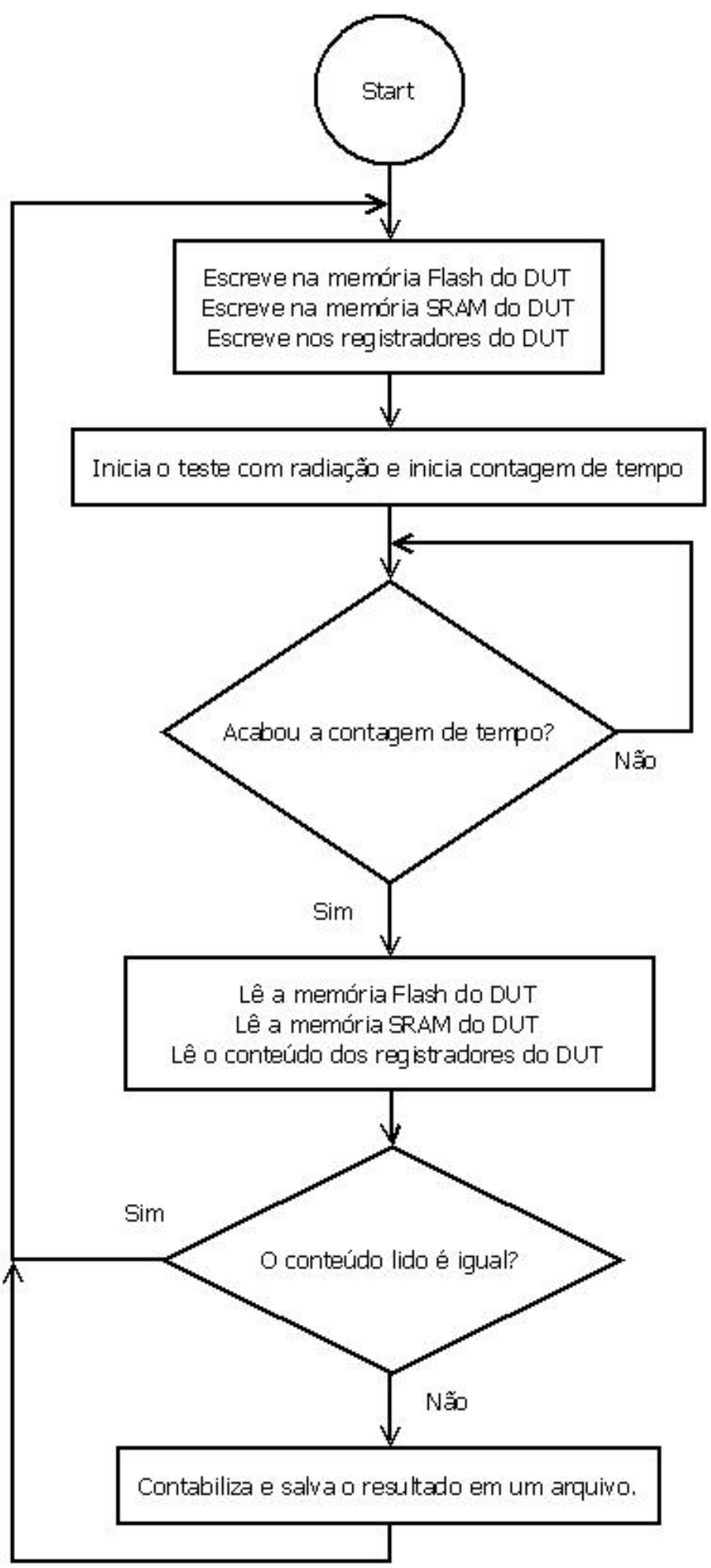

Fonte: Autor 


\subsubsection{Resultados do Teste Estático}

O teste estático foi realizado com íons pesados, no Acelerador Pelletron, e com raios$\mathrm{X}$, utilizando o difratômetro de raios-X. Durante os testes no Acelerador Pelletron, utilizando feixes de ${ }^{28} \mathrm{Si}$ e ${ }^{16} \mathrm{O}$ foram observados SEL causando uma falha no funcionamento do circuito lógico de debug, impossibilitando a leitura das memórias do dispositivo em teste, o que indica que esse dispositivo não tolera valores de LET maiores que $5.0 \mathrm{MeV} / \mathrm{mg} / \mathrm{cm}^{2}$. Uma vez que os íons pesados causavam falhas no dispositivo, a reinicialização do sistema após cada SEL já era suficiente para recuperar sua funcionalidade. Em contra-partida, feixes de ${ }^{12} C$ com valores de LET maiores que $3.2 \mathrm{MeV} / \mathrm{mg} / \mathrm{cm}^{2}$, o circuito de debug não apresentava problemas de funcionalidade e bit-flips puderam ser observados na SRAM. Durante a irradiação $\operatorname{com}^{12} C$, nenhum SEL foi observado e o número de SEU na memória SRAM e na memória flash puderam ser medidos. Os dados da seção de choque de bit da SRAM em função do LET são mostrados na tabela 2. Diferentes valores de LET foram obtidos usando diferentes energias para o mesmo feixe de ${ }^{12} C$. Os dados sugerem que a seção de choque do dispositivo está praticamente constante. O fato da seção de choque ser praticamente constante indica que o feixe de íons atravessou completamente o volume sensível do dispositivo mesmo com um range menor de 28,4 $\mu \mathrm{m}$. Isso sugere que a memória SRAM é mais sensível à SEE do que a memória flash.

Tabela 2 - Seção de choque de bit para memória flash e SRAM em função do LET do feixe ${ }^{12} \mathrm{C}$ e do range do íons no dispositivo.

Fonte: Autor

\begin{tabular}{c|c|c|c}
\hline$L E T\left(M e V / m g / \mathrm{cm}^{2}\right)$ & flash $\left(\mathrm{cm}^{2} /\right.$ bit $)$ & SRAM $\sigma\left(\mathrm{cm}^{2} /\right.$ bit $)$ & Range $(\mu \mathrm{m})$ \\
\hline $2,36\left({ }^{12} \mathrm{C}\right)$ & 0 & $1,20(4) \cdot 10^{-} 8$ & 61,0 \\
\hline $2,88\left({ }^{12} \mathrm{C}\right)$ & 0 & $1,16(5) \cdot 10^{-} 8$ & 38,2 \\
\hline $3,24\left({ }^{12} \mathrm{C}\right)$ & 0 & $9,51(14) \cdot 10^{-} 9$ & 28,4 \\
\hline
\end{tabular}


Figura 65 - Seção de choque de bit para memória SRAM em função do LET do feixe ${ }^{12} C$.

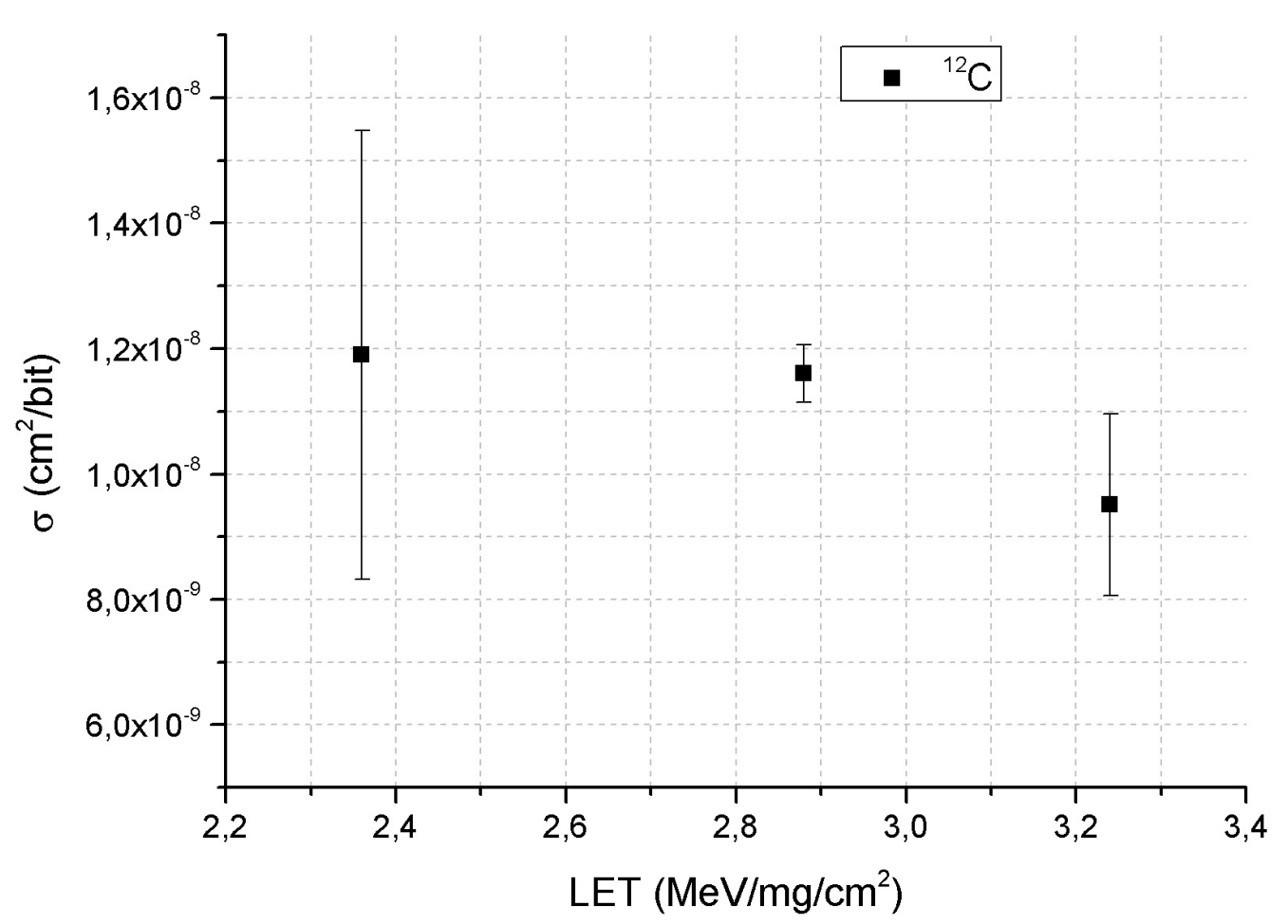

Fonte: Autor

A figura 65 mostra a seção de choque da memória SRAM para diversos LETs do feixe de ${ }^{12} C$ onde é possível observar que a seção de choque, dentro das incertezas, se manteve praticamente constante. Para a irradiação com raios-X, não foi observado nenhuma interrupção funcional do dispositivo até $30 \mathrm{krad}(\mathrm{Si})$. Em contrapartida, após $60 \mathrm{krad}(\mathrm{Si})$ de dose acumulada o dispositivo entrou em modo de dispositivo seguro, modo no qual é impossível realizar a leitura das memórias. O módulo da memória flash do dispositivo tem um mecanismo de segurança no qual é configurado pelos dois primeiros bits do registro Flash Security. Isso sugere que esses bits foram influenciados pelo acúmulo de dose devido a raios-X. A corrente de alimentação do dispositivo foi monitorado durante o teste e é apresentado na figura 66. Durante toda a irradiação para acumular $60 \mathrm{krad}(\mathrm{Si})$ não foi observado nenhuma mudança significativa na corrente de alimentação a não ser nos momentos onde a memória estava sendo programada. Sendo assim, não foi observado mudança significativa na corrente de alimentação devido a cargas aprisionadas (SEMICONDUCTORS, 2011). 
Figura 66 - Corrente de alimentação em função do tempo durante a irradiação com raios-X.

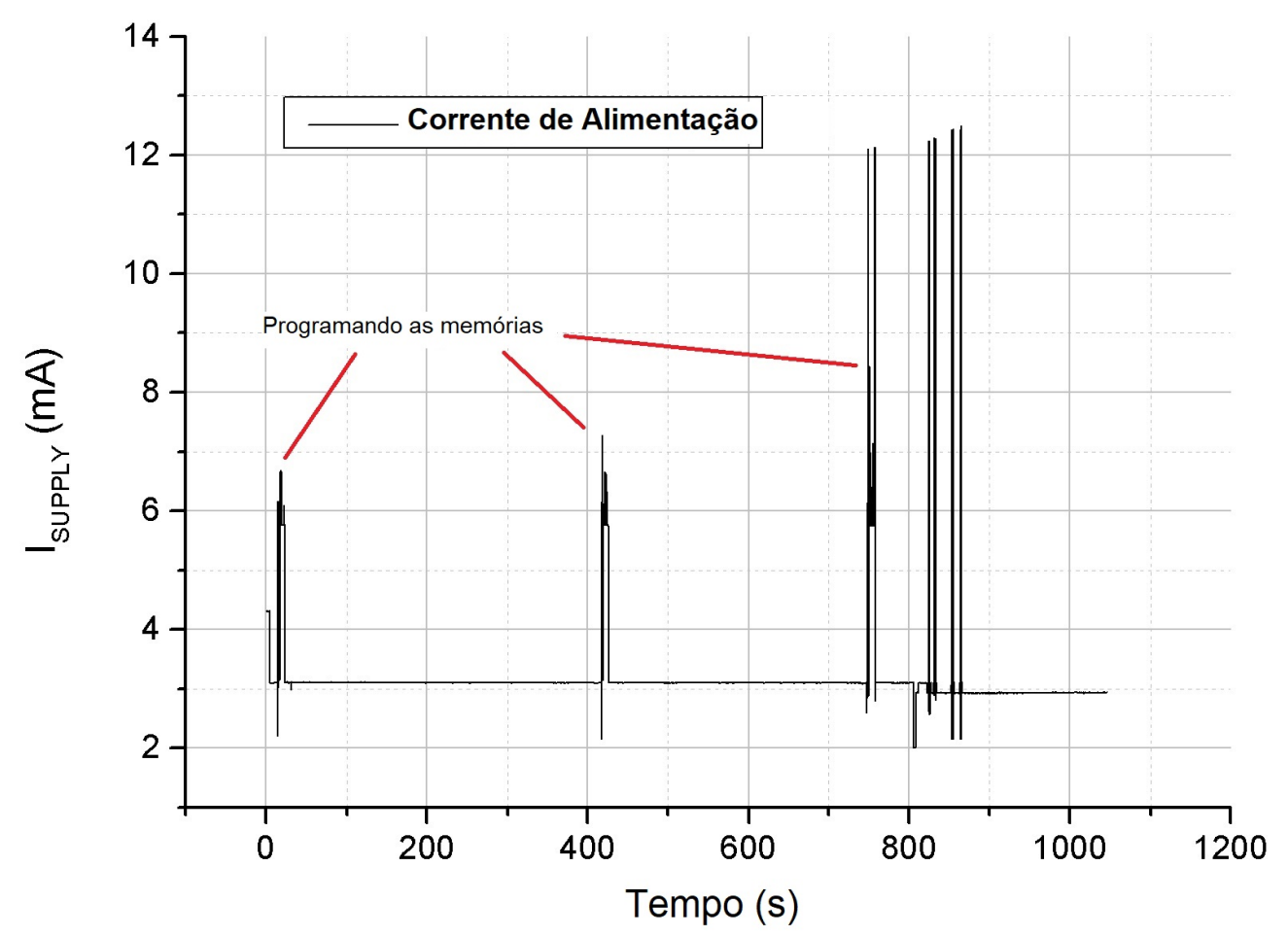

Fonte: Autor

\subsubsection{Teste Dinâmico via Programa}

Com os resultados do teste estático, nota-se que para o dispositivo em teste a memória SRAM é a mais sensível em relação à radiação ionizante e como nenhum efeito foi observado na memória flash, torna-se possível realizar testes em tempo real executando programas no microcontrolador. Para isso, foi desenvolvido um software específico para esse teste. Através de uma interface de comunicação serial, um PC envia comandos ao microcontrolador que decodifica os comandos e os executa. Dessa forma, é possível controlar todo o teste remotamente pelo PC e elaborar scripts de teste. A figura 67 mostra a arquitetura do software utilizado no teste. Para aumentar a robustez da comunicação, foi implementado um simples protocolo. Esse protocolo adiciona alguns bytes na mensagem a ser enviada da seguinte maneira:

$$
<\text { startbyte }><\text { tamanho }><\text { mensagem }><\text { checksum }><\text { endbyte }>
$$


Figura 67 - Arquitetura de software utilizado nos testes.

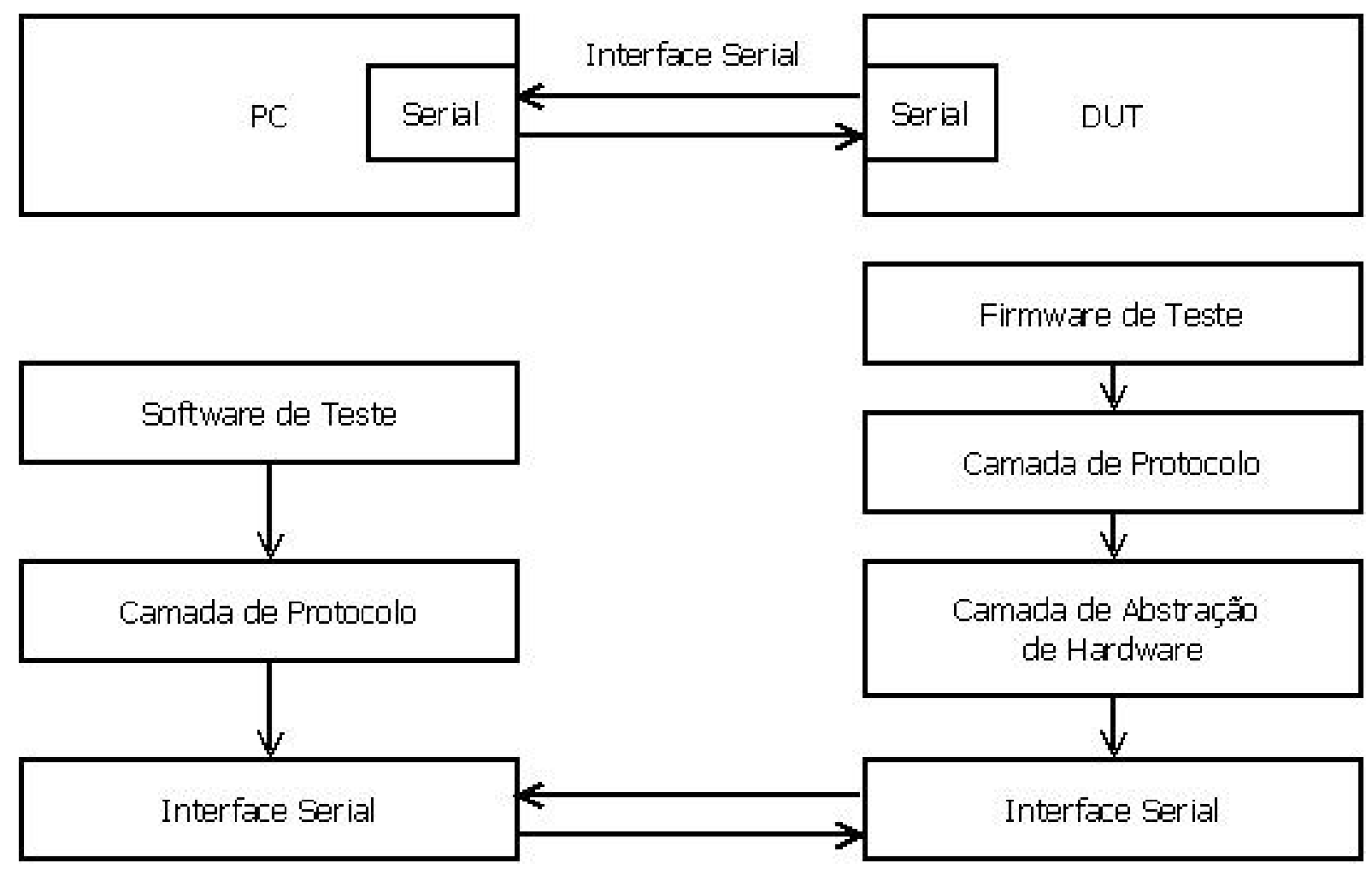

Fonte: Autor

Desse modo, apenas comandos que foram recebidos com sucesso serão processados. $\mathrm{O}$ software de teste, executado no PC (vide figura 68), apresenta algumas funções pré-definidas como preenchimento da SRAM com alguns padrões e comando para checar o número de erros na memória. Esses comandos são enviados através da interface serial e uma vez que toda a mensagem for recebida pelo DUT, este irá verificar se há erros na mensagem, se não houver erros, o DUT processará o comando. Para implementar o firmware de teste no DUT, responsável pela execução dos comandos recebidos do PC, é necessário uma certa quantidade de memória SRAM. Por esse motivo, 512 bytes da SRAM foram reservados para a execução do programa e os 3584 bytes restantes foram utilizados para o teste. O firmware foi desenvolvido de modo que erros na SRAM reservada ao programa não impactasse no funcionamento do teste. 
Figura 68 - Interface gráfica do software de teste.

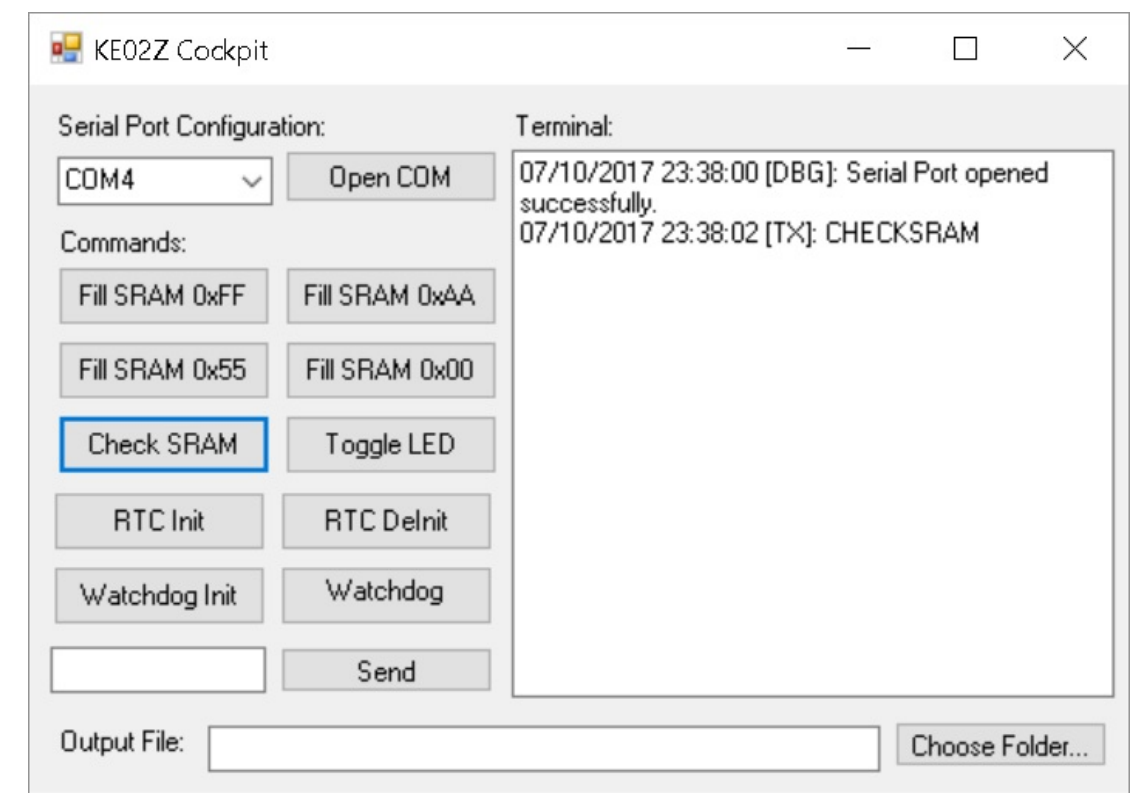

Fonte: Autor

Os códigos-fonte dos programas utilizados para o teste dinâmico estão disponíveis no github do autor desse trabalho: https://github.com/felipeghleite.

\subsubsection{Resultados do Teste Dinâmico}

Utilizando essa estratégia de teste, foram realizados experimentos com prótons, utilizando o LAMFI, e com partículas alfa, utilizando uma fonte de ${ }^{241} \mathrm{Am}$. A energia dos prótons, durante o experimento no LAMFI, variou de 1,0 MeV até 3,4 MeV e não foi observado nenhum evento, indicando que o valor do LET dos prótons estavam abaixo do limiar. Por este motivo, foi realizado testes com partículas alfa utilizando uma fonte alfa de ${ }^{241} \mathrm{Am}$. A fonte emite partículas alfa com energias na ordem de 5,5 MeV. Todo o sistema de teste, composto pela placa de desenvolvimento, um detector de estado sólido de silício e um suporte para a placa, ficou dentro de uma câmara de vácuo. Para estimar o fluxo de partículas alfa que atingia o dispositivo, o detector foi colocado a uma distância de $20 \mathrm{~mm}$ da fonte, resultando em um fluxo de 13,7 cont/s/msr. Para determinar o fluxo de partículas, é necessário calcular o ângulo sólido entre a fonte e o dispositivo sob teste, utilizando a equação 4 considerando $1 \mathrm{~cm}^{2}$ para a área (uma área padrão do dispositivo a ser irradiado) e considerando $2 \mathrm{~cm}$ como o raio. O fluxo obtido para esses valores é de 3425 contagens por segundo. A fluência é determinada multiplicando esse fluxo pelo tempo de experimento (em segundos) onde o dispositivo foi irradiado.

Considerando a espessura da fonte alfa e a auto-absorção apresentada pela própria amostra, o espectro da partícula apresenta uma energia efetiva de cerca de $E=5296 \pm 14 \mathrm{keV}$, correspondendo a um valor de LET de $0,61 \mathrm{MeV} / \mathrm{mg} / \mathrm{cm}^{2}$ até $1,48 \mathrm{MeV} / \mathrm{mg} / \mathrm{cm}^{2}$ no dispositivo em teste. As partículas alfa atingiam o dispositivo perpendicularmente e a fonte alfa estava à 
uma distância de $15 \mathrm{~mm}$ do dispositivo. O tempo de aquisição foi escolhido de modo a obter um número de contagens alta o suficiente para efetivamente testar os quatro padrões gravados na memória. A seção de choque é calculada a partir do número de erros e fluência utilizando a equação 12. A tabela 3 mostra valores da seção de choque de SEE de partículas alfa para o dispositivo em vácuo.

Tabela 3 - Seção de choque de SEE de partículas- $\alpha$ no teste em vácuo

Fonte: Autor

\begin{tabular}{c|c}
\hline Padrão & $\sigma\left(\mathrm{cm}^{2}\right)$ em vácuo \\
\hline 0x00 & $2.05(47) \times 10^{-6}$ \\
0xFF & $3.77(82) \times 10^{-6}$ \\
0xAA & $2.60(67) \times 10^{-6}$ \\
0x55 & $3.48(80) \times 10^{-6}$ \\
\hline
\end{tabular}

Foi observado um número maior de bit-flips (aproxidamente uma ordem de magnitude maior) quando o sistema foi colocado na câmara com ar. Esse aumento foi observado devido a menor energia cinética das partículas alfa quando atingem o dispositivo após a perda de energia ao atravessar o ar, uma vez que a artícula alfa perde aproximadamente $1 \mathrm{MeV}$ de sua energia cinética ao atravessar $1 \mathrm{~cm}$ em ar em condições normais de temperatura e pressão (CNTP). Com menor energia, o range das partículas é reduzido, e o máximo de sua ionização (pico de Bragg) se desloca mais próximo da superfície do dispositivo, o que ocorre dentro ou muito próximo do volume sensível do dispositivo. Os resultados preliminares de um teste de 15 minutos, com o dispositivo à uma distância de $15 \mathrm{~mm}$ da fonte alfa, estão na tabela 4.

Tabela 4 - Seção de choque de SEE de partículas- $\alpha$ no teste em ar

Fonte: Autor

\begin{tabular}{c|c}
\hline Padrão & $\sigma\left(\mathrm{cm}^{2}\right) \mathrm{em} \mathrm{ar}$ \\
\hline 0x00 & $1.82(31) \times 10^{-5}$ \\
0xFF & $1.70(29) \times 10^{-5}$ \\
0xAA & $1.58(29) \times 10^{-5}$ \\
0x55 & $2.07(44) \times 10^{-5}$ \\
\hline
\end{tabular}

Como a seção de choque depende do range da partícula alfa, foi realizado experimentos para explorar o efeito da ionização máxima da partícula no volume sensível do dispositivo com partículas alfa de diferentes energias. O sistema foi colocado na câmara de vácuo (figura 73) e a energia da partícula alfa foi controlada através da injeção de gás argônio. A pressão do gás argônio foi controlada de $10^{-} 1$ Torr até 830 Torr utilizando uma bomba de vácuo, mudando a densidade do gás. A densidade do gás pode ser calculado através da teoria de gases ideias e os resultados são mostrados na tabela 5 .

Esses valores de densidade foram inseridos no simulador SRIM, como mostrado na figura 69, onde foi simulado a perda de energia no ar e a ionização da partícula em silício. 
Tabela 5 - Densidade da atmosfera de argônio para diferentes pressões

Fonte: Autor

\begin{tabular}{c|c}
\hline Pressão (Torr) & Densidade $(\mathrm{g} / \mathrm{ml})$ \\
\hline 100 & 0,00021485823082619 \\
200 & 0,00042971646165239 \\
300 & 0,00064457469247859 \\
400 & 0,00085943292330478 \\
500 & 0,00107429115413097 \\
600 & 0,00128914938495717 \\
700 & 0,00150400761578337 \\
\hline
\end{tabular}

Figura 69 - Interface gráfica do software SRIM mostrando onde inserir os valores de densidade.

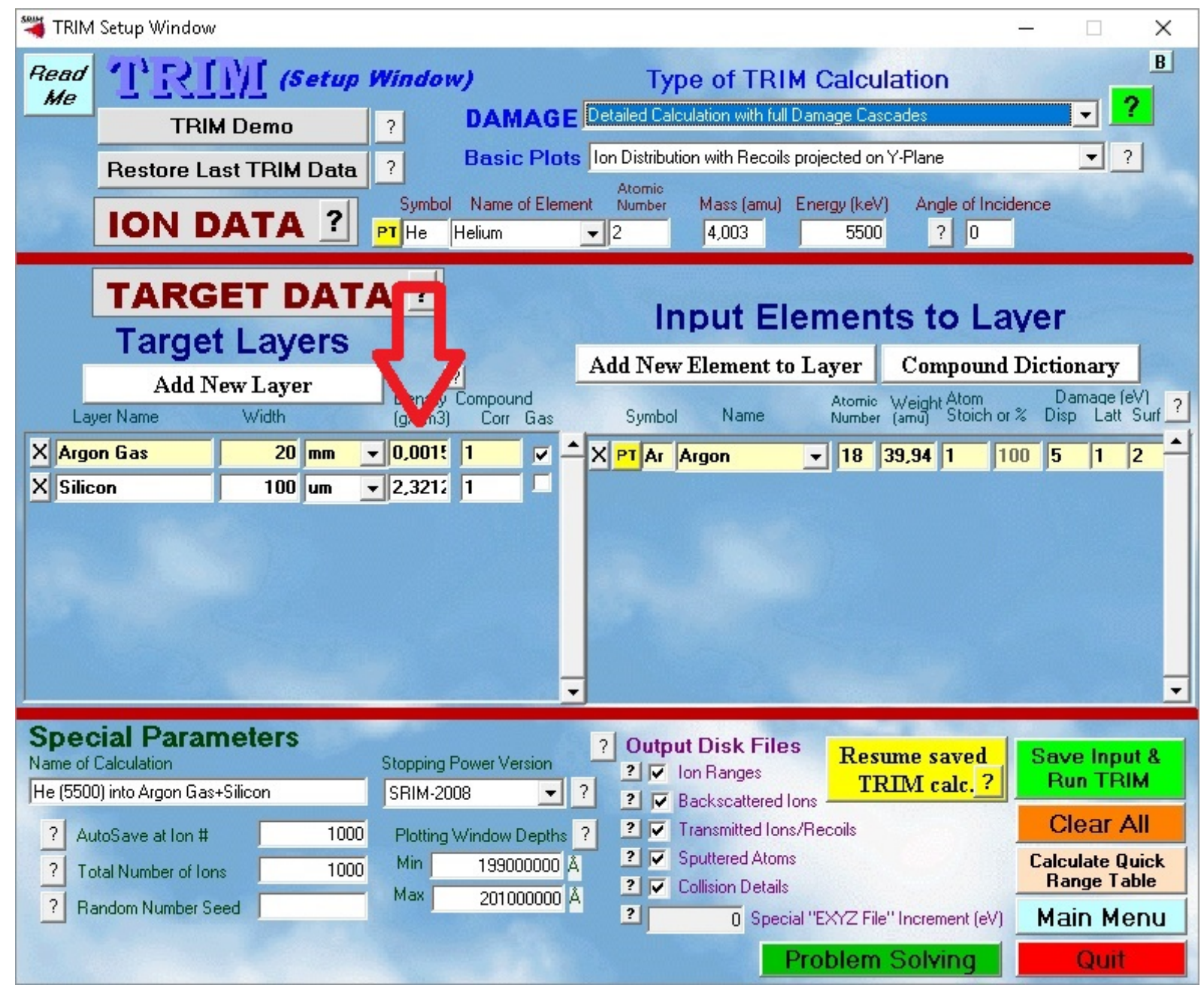

Fonte: Autor

A energia perdida no trajeto da partícula na atmosfera de argônio até o dispositivo foi estimado através do software SRIM e através do software, foi possível calcular o LET efetivo das partículas no dispositivo, estimando a perda de energia no ar, sob diferentes pressões. O range 
da partícula alfa no silício diminuiu de $26,5 \mu \mathrm{m}$ até $16 \mu \mathrm{m}$, causando uma maior ionização no volume sensível do dispositivo em um ponto aproximadamente 9,5 $\mu \mathrm{m}$ abaixo da superfície do microcontrolador, como mostrado na figura 54. A figura 70 mostra os resultados das simulações realizadas para observar a perda de energia das partículas sob diferentes pressões da atmosfera de argônio, demonstrando que o alcance da partícula e a posição do pico de Bragg diminui para pressões maiores. A figura 71 mostra as trajetórias das partículas na região da interface entre o gás argônio e o silício. Na tabela 6 a energia média da partícula alfa e o range em silício para diferentes pressões da atmosfera de argônio é apresentado (ZIEGLER, J. F.; ZIEGLER, M.; BIERSACK, 2010). A figura 72 mostra os valores da seção de choque em função da pressão da atmosfera de argônio.

Figura 70 - Perda de energia das partículas alfa no silício ao atravessar 15 mm de gás argônio em diferentes pressões.

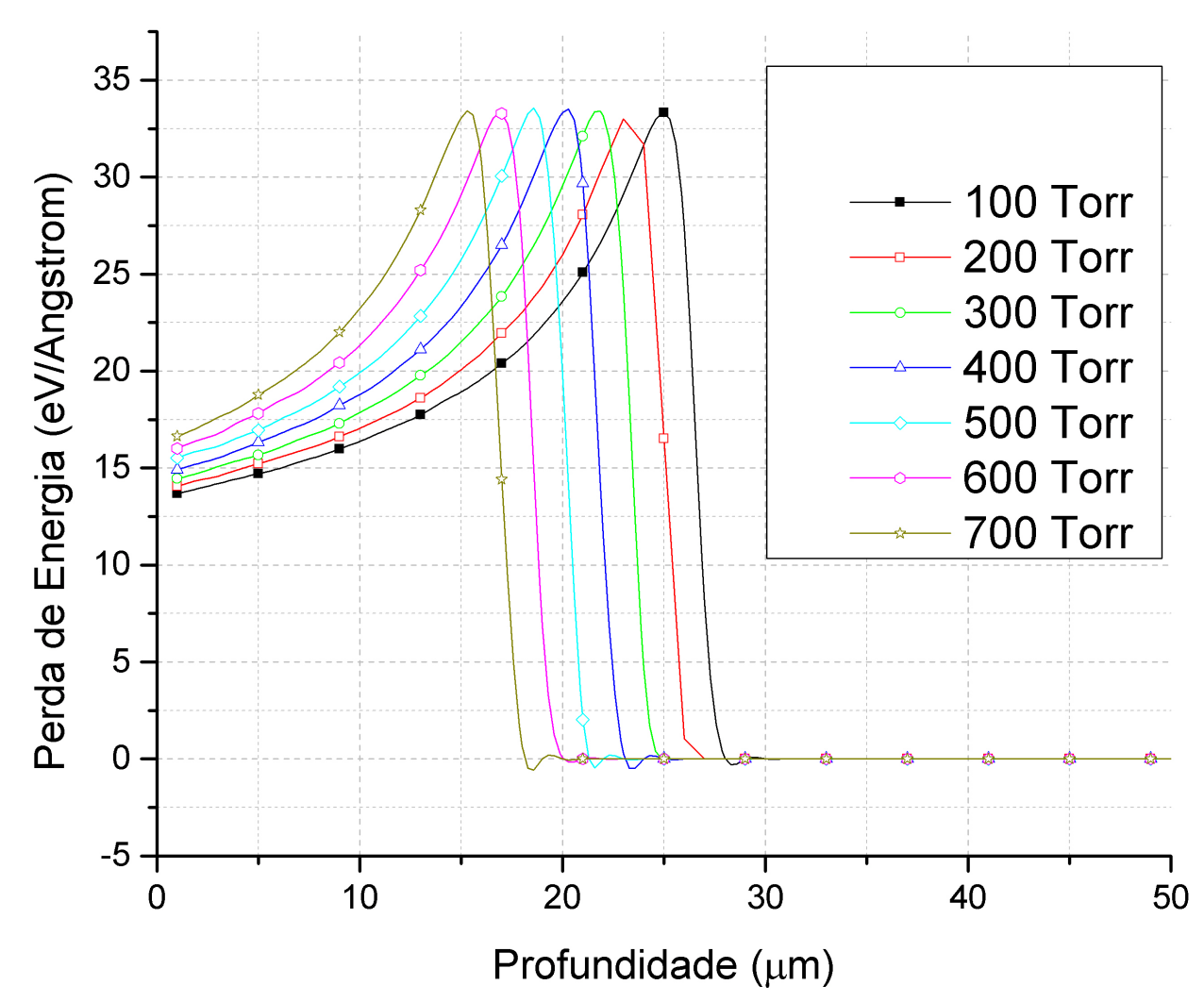

Fonte: Autor 
Figura 71 - Simulações das trajetórias das partículas entre o gás argônio e silício.

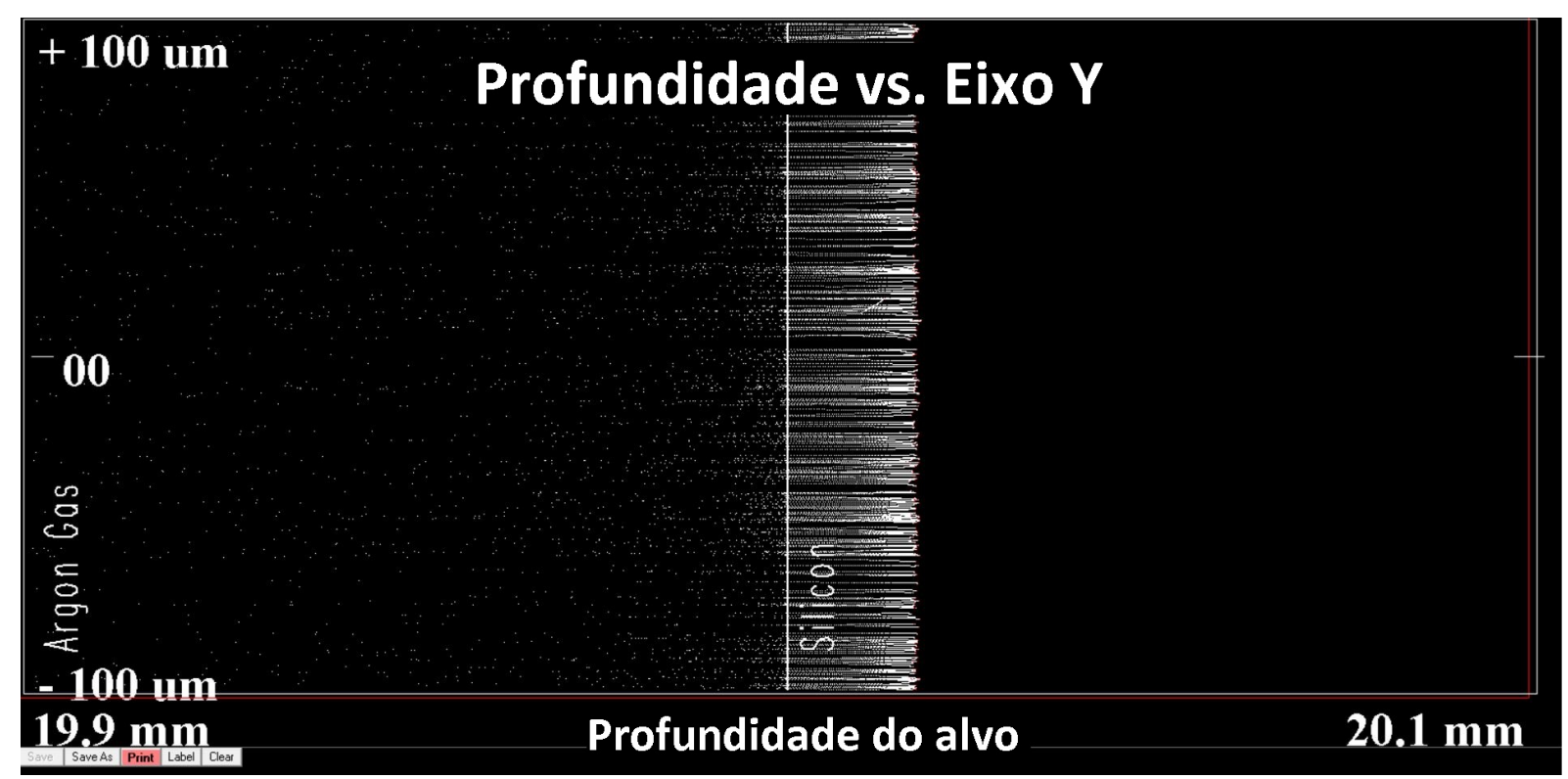

Fonte: Autor

Tabela 6 - Energia na superfície do dispositivo e alcance em silício das partículas $\alpha$ após atravessar $20 \mathrm{~mm}$ em uma atmosfera de argônio com pressão controlada.

\begin{tabular}{c|c|c}
\hline Pressão Argônio (Torr) & Energia $(\mathrm{MeV})$ & Penetração em Silício $(\mu \mathrm{m})$ \\
\hline $10^{-1}$ & 5.3 & 26.5 \\
400 & 4.6 & 21.5 \\
600 & 4.2 & 19.0 \\
750 & 3.9 & 17.0 \\
830 & 3.7 & 16.0 \\
\hline
\end{tabular}

Fonte: Autor 
Figura 72 - Seção de choque em função da pressão da atmosfera de argônio.

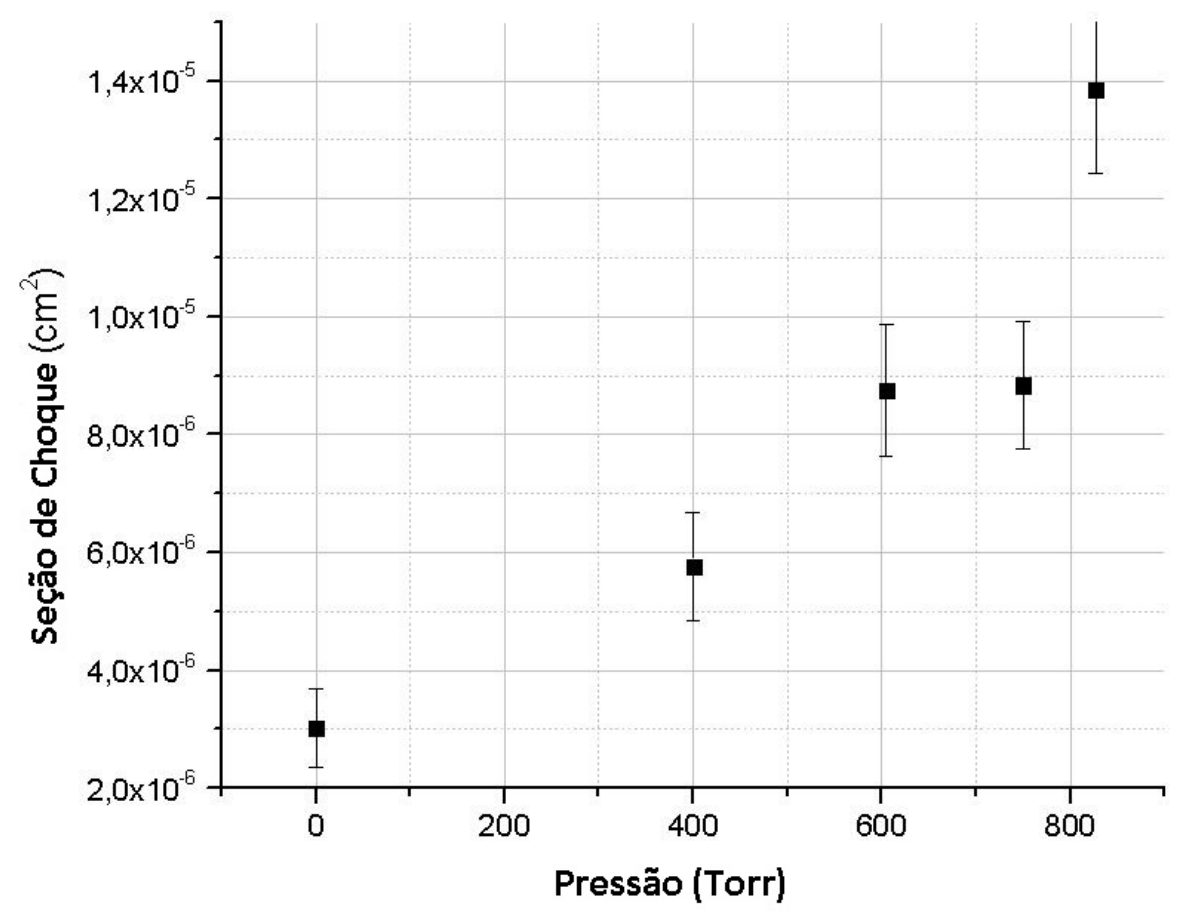

Fonte: Autor

Figura 73 - Detalhe do setup na câmara.

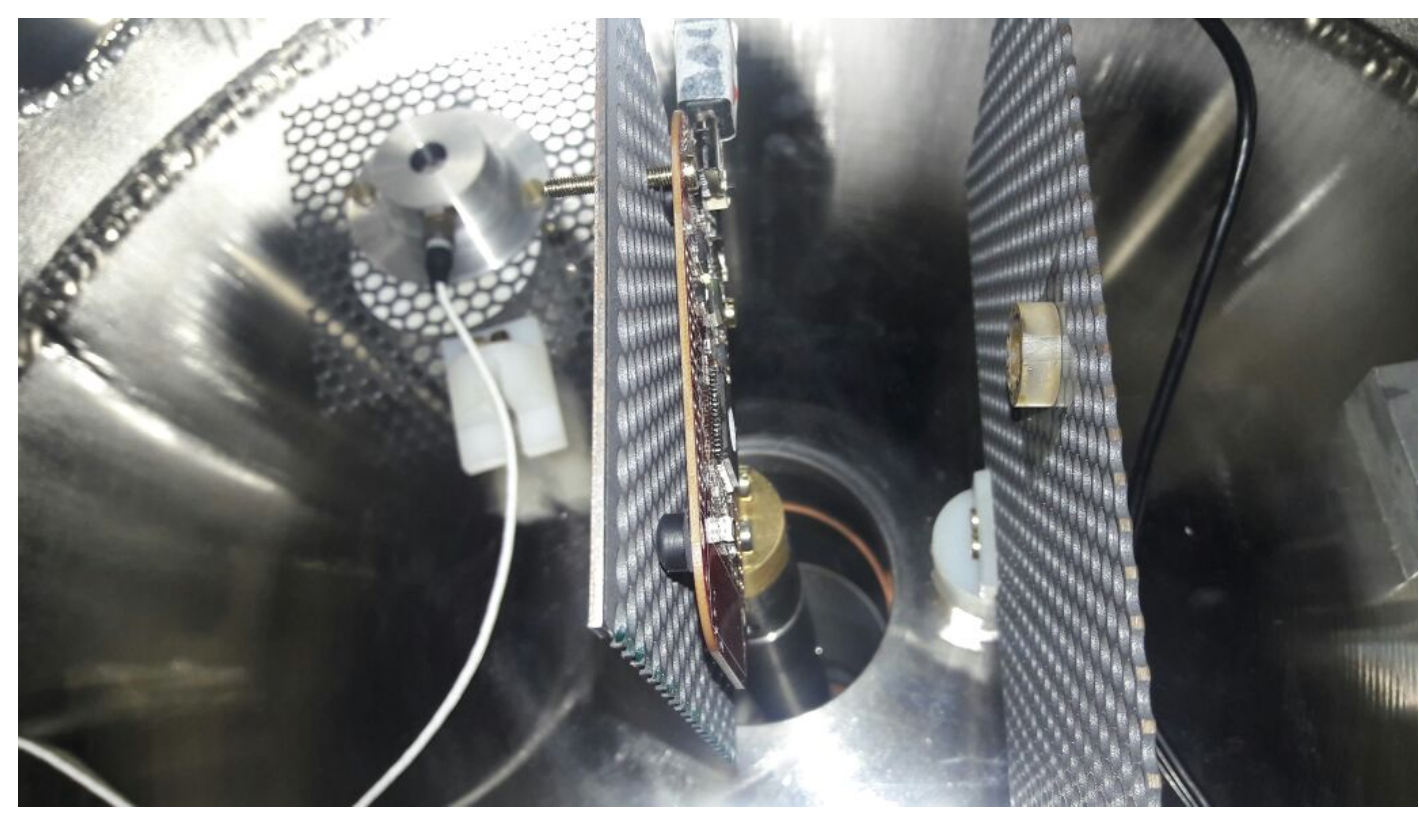

Fonte: Autor 


\subsection{Verificação dos Testes}

Após essa sequência de testes é possível concluir que o microcontrolador não tolera partículas com LET maior que $5 \mathrm{MeV} / \mathrm{mg} / \mathrm{cm}^{2}$, apresenta SEUs apenas na memória SRAM e perde sua funcionalidade com doses próximas de $60 \mathrm{krad}(\mathrm{Si})$. Para verificar essas informações e a repetibilidade dos resultados, os testes foram realizados novamente com mais duas amostras sendo a primeira amostra um dispositivo MKE02Z e a segunda amostra um dispositivo RM42L432.

\subsubsection{Testes com Raios-X}

Os dispositivos foram submetidos a raios-X utilizando o mesmo setup já descrito nas seções anteriores. Os dispositivos estavam executando o teste dinâmico, a corrente de alimentação dos dispositivos estava sendo monitorada durante o teste e a cada $10 \mathrm{krad}(\mathrm{Si})$ de dose acumulada havia uma verificação da capacidade de escrita/leitura da memória flash através da regravação do firmware de teste. A execução do teste dinâmico permite que a memória SRAM também fosse verificada durante o experimento.

Figura 74 - Corrente de alimentação versus tempo para teste de raios-X do dispositivo MKE02Z.

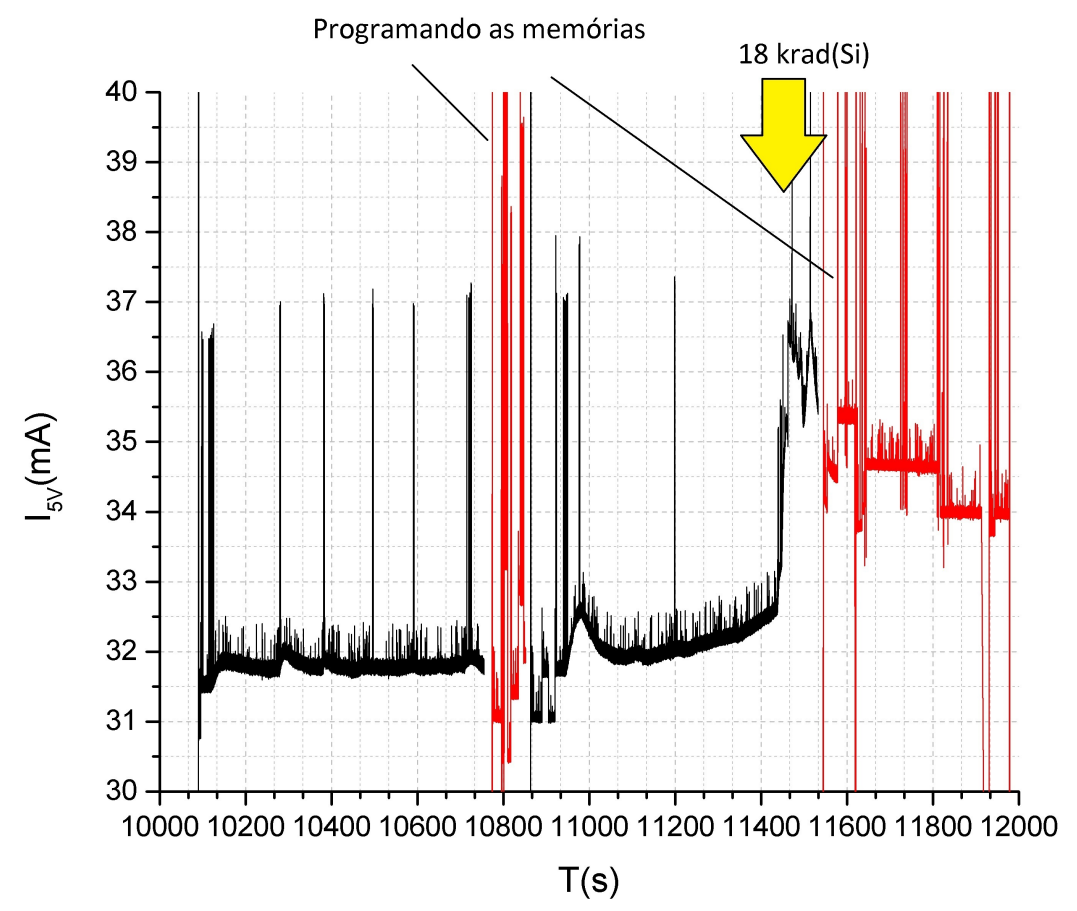

Fonte: Autor 
Figura 75 - Corrente de alimentação versus tempo para teste de raios-X do dispositivo RM42L432.

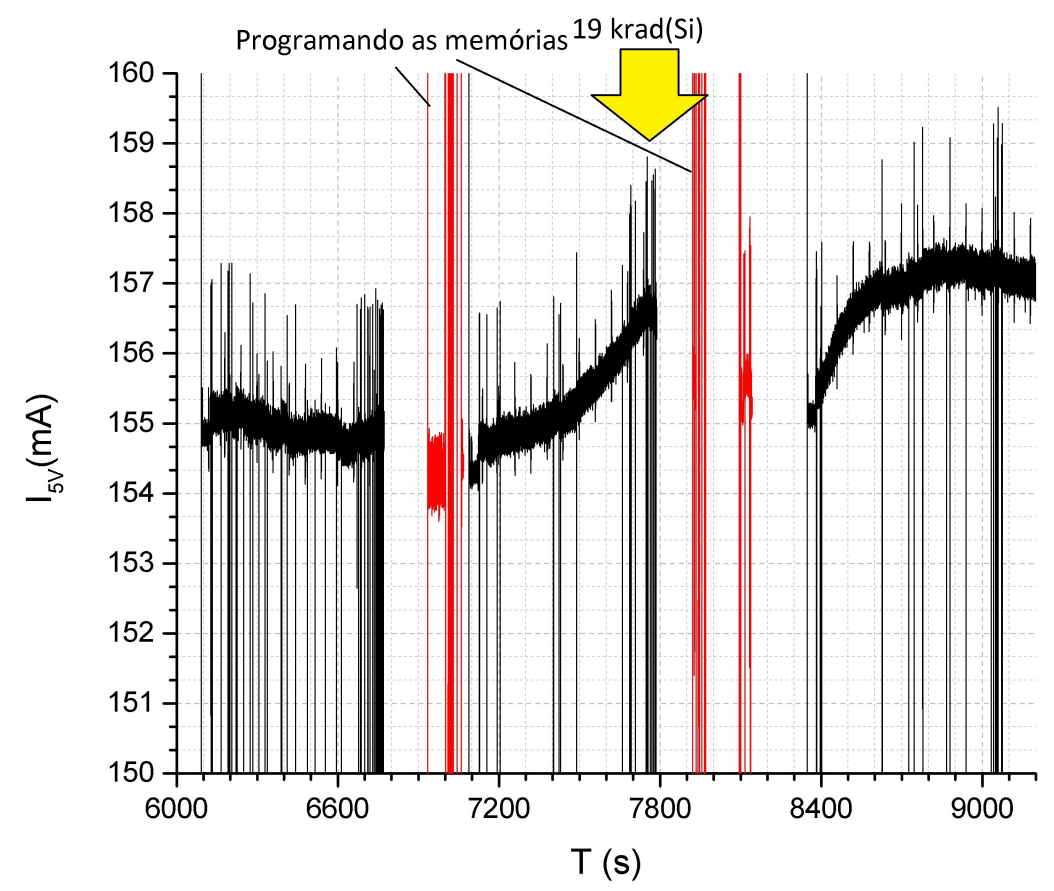

Fonte: Autor

A figura 74 e 75 mostra a corrente de alimentação dos dispositivos durante o teste. Em ambos os casos, a corrente apresentou uma variação abrupta quando a dose acumulada se aproximou de $18 \mathrm{krad}(\mathrm{Si})$. Até essa dose, a corrente não havia apresentado mudanças significativas em seu valor e o dispositivo apresentava uma perfeita capacidade de leitura e escrita em suas memórias. Após essa variação da corrente de alimentação, os dois dispositivos ficaram totalmente incapazes de escrever em suas memórias flash, possivelmente devido a algum problema no circuito charge pump de suas memórias flash. Entretanto, a amostra do dispositivo RM42L432 ainda era capaz de ler a memória flash e, portanto, era capaz de executar o programa, enquanto que a amostra do dispositivo MKE02Z perdeu totalmente a capacidade de leitura da memória, inutilizando o dispositivo e caracterizando uma falha no sistema. Pelo fato do dispositivo RM42L432 continuar executando o firmware, embora incapaz de reprogramá-lo, indica que esse dispositivo é mais tolerante à TID em comparação ao dispositivo MKE02Z. Embora a dose em que houve as faltas não seja igual ao observado no teste descrito na seção anterior, foi possível observar os efeitos similares em ambos os dispositivos e determinar qual dispositivo é mais tolerante à TID, o qual é o propósito da metodologia que será proposta nesse trabalho. 


\subsubsection{Testes com Partículas Alfa}

Os dispositivos foram submetidos ao mesmo experimento com partículas alfa descritos anteriormente. Os dispositivos estavam executando o teste dinâmico e apenas a memória SRAM estava sendo monitorada. O dispositivo MKE02Z apresentou o mesmo comportamento dos testes iniciais e o resultado está apresentado a seguir:

Figura 76 - Seção de choque em função da pressão do gás argônio para o dispositivo MKE02Z.

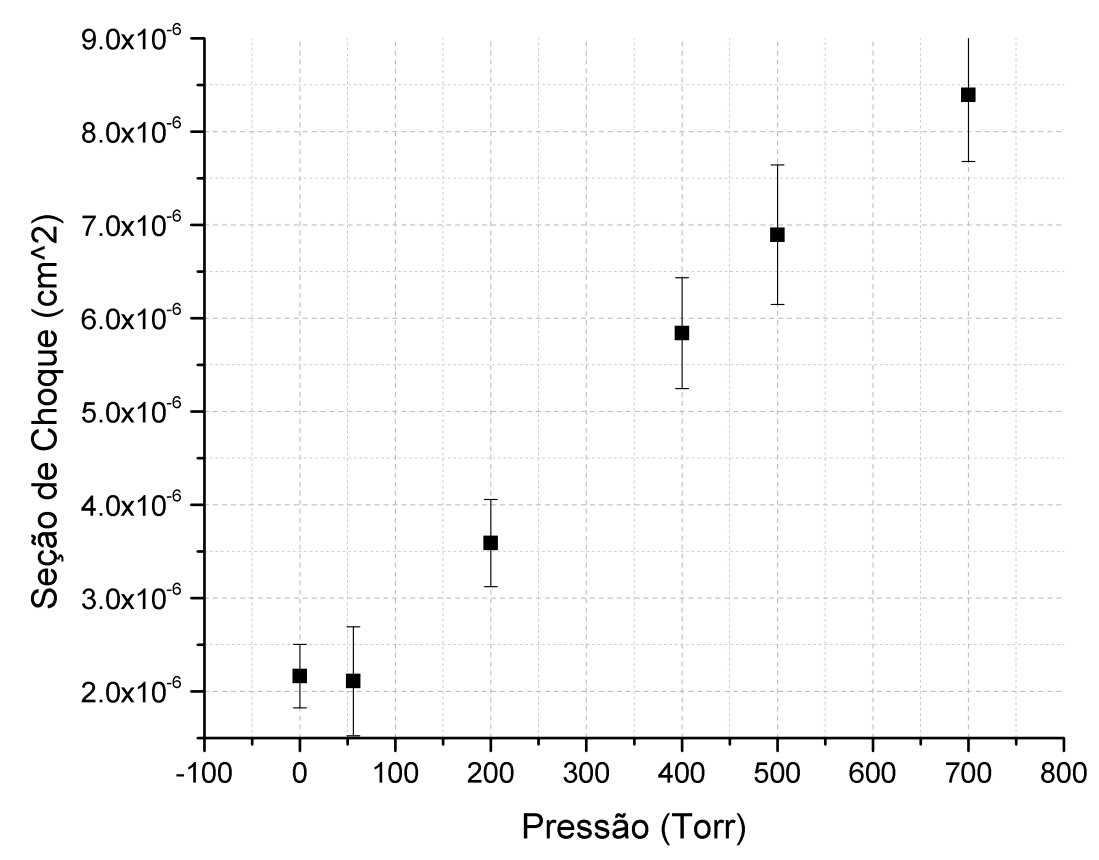

Fonte: Autor 
Figura 77 - Seção de choque em função do LET para o dispositivo MKE02Z.

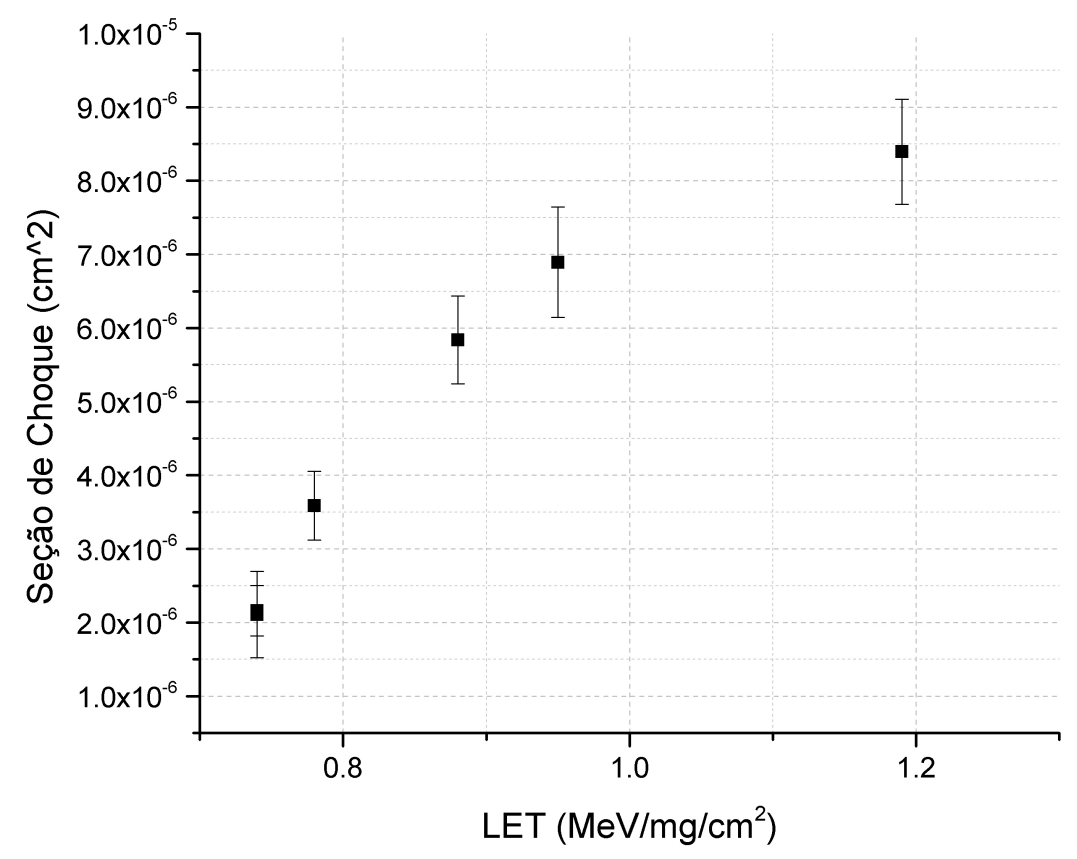

Fonte: Autor

Já o dispositivo RM42L432 não apresentou nenhum SEU, mesmo variando a distância entre o dispositivo e a fonte, sugerindo que o LET mínimo não foi alcançado com a fonte alfa. 


\section{Proposta de Metodologia}

Essa metodologia não tem a proposta de substituir os padrões de medidas e testes definidos por agências como o Departamento de Defesa americano e Agência Espacial Europeia, e sim complementar, de modo que componentes possam ser testados e qualificados de maneira mais simples e rápida, entretanto, assim que possíveis componentes forem selecionados é necessário a execução total dos testes especificados nesses padrões de medidas.

Com o resultado dos experimentos e a verificação da repetibilidade dos testes descritos nesse trabalho, é possível sugerir uma sequência de testes para qualificação de microcontroladores e sistemas eletrônicos. É interessante realizar os testes de qualificação em dispositivos do mesmo lote de fabricação do dispositivo que será usado no sistema. Se isso não for possível, é importante ter em mente que diferenças durante o processo de fabricação do dispositivo pode afetar a resposta à radiação dos dispositivos. De uma maneira geral, quanto maior o número de dispositivos testados, mais confiável é o resultado dos testes. Todavia, obter um grande número de dispositivos não é sempre possível. Para os casos de apenas uma amostra ser disponível, os testes devem ser planejados de modo que os testes com íons pesados, partículas $\alpha$ ou prótons sejam realizados antes dos testes de TID. Se duas amostras forem disponíveis, uma deve ser reservada para os testes de TID e a outra para testes de SEE.

Com as amostras separadas, o dispositivo deve ser submetido à testes preliminares para verificar quais componentes que compõem o dispositivo é mais suscetível à radiação ionizante. Para isso, o teste deve ser projetado para que os componentes de interesse possam ser testados. No caso desse trabalho, foi realizado um teste estático onde foi possível verificar todos os elementos de memória (memória flash, SRAM e registradores de uso geral), além do funcionamento geral do dispositivo. Esse teste pode, e deve, ser modificado para abranger mais ou menos componentes, por exemplo interfaces de comunicação ou pinos de entrada/saída, dependendo dos requisitos do projeto.

Com o resultado da etapa anterior, já é possível observar, de maneira qualitativa, se um dispositivo é mais sensível do que outro e os que apresentaram falhas graves e que não poderão ser usados na aplicação podem ser descartados do teste. A partir desse momento, os dispositivos restantes podem ser submetidos à testes mais elaborados de modo a levantar a curva de sensibilidade dos dispositivos. No caso desse trabalho, foi possível desenvolver um firmware de teste para levantamento da curva de sensibilidade da memória SRAM, uma vez que não foi observado erros na memória flash e registradores. Para o levantamento da curva de sensibilidade, é necessário atingir determinados valores de energia, LET e range do feixe iônico, por esse motivo, o tipo de feixe utilizado para irradiação do dispositivo deve ser cuidadosamente especificado. No caso desse trabalho, o dispositivo MKE02Z foi totalmente verificado utilizando apenas a fonte de partículas alfa, enquanto para o dispositivo RM42L432 nenhum SEU foi observado para as partículas alfa, sendo necessário os testes utilizando feixes de íons pesados. 
Figura 78 - Fluxograma da metodologia proposta.

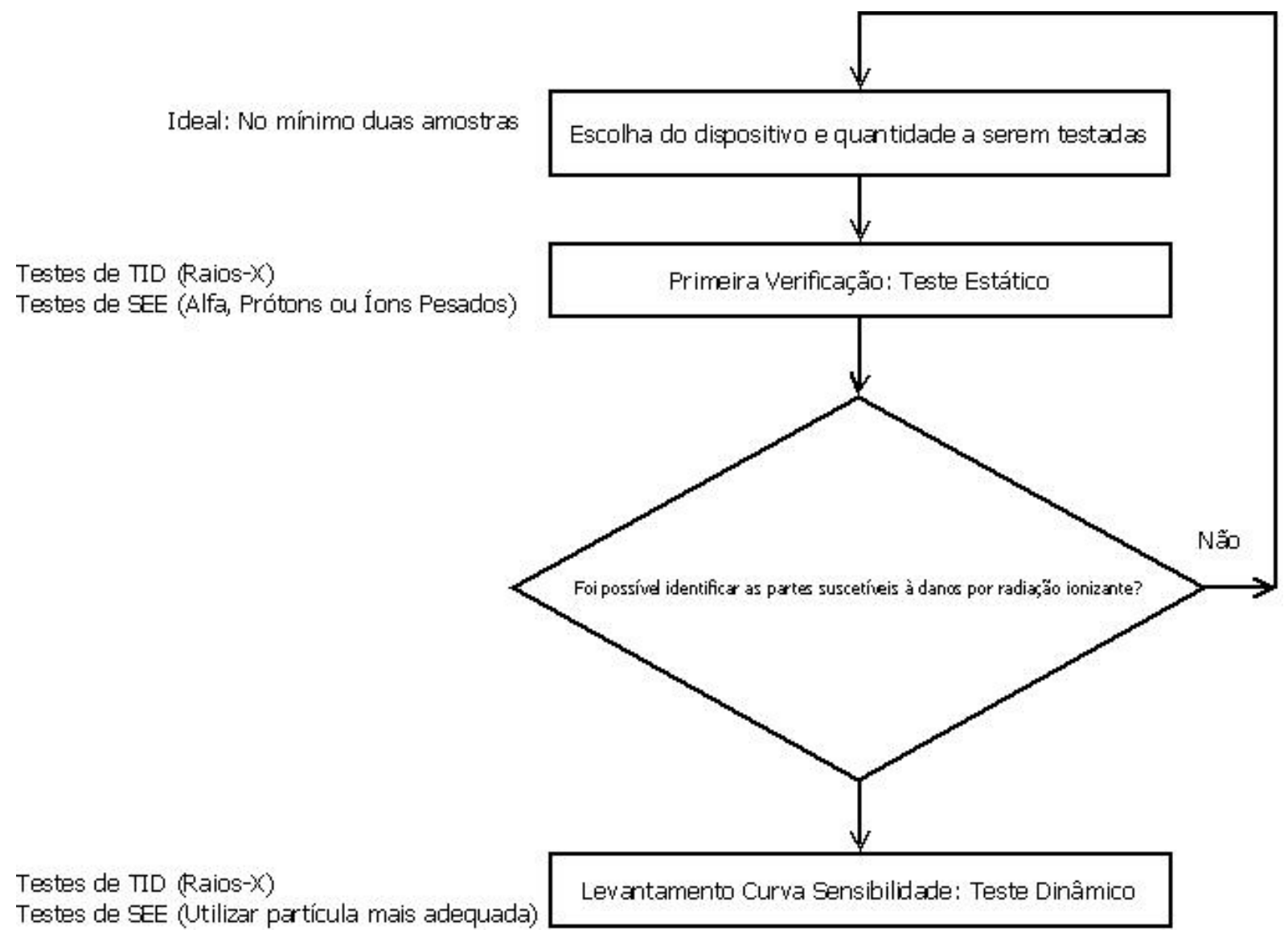

Fonte: Autor

A figura 78 resume a metodologia proposta. Qualquer dispositivo microcontrolado pode ser submetido a essa sequência de testes e poderá ser avaliado e comparado com outros dispositivos, como realizado nesse trabalho. 


\section{Conclusões}

O trabalhou possibilitou o estudo e o desenvolvimento de uma metodologia para qualificação de sistemas microcontrolados expostos à radiação ionizante. Os efeitos que podem ocorrer quando um dispositivo eletrônico for exposto à ambientes radiativos, como ambiente espacial, podem ser simulados em laboratório através de vários métodos. Os danos causados por interações de fótons nos dispositivos podem ser simulados em laboratório através de raios$\mathrm{X}$, gerados através de um equipamento específico para esse fim, ou raios gama, utilizando fontes radiativas que emitem radiação gama como o $C o^{60}$. Já as interações de partículas podem ser simuladas utilizando aceleradores de partículas, onde é possível obter feixes iônicos compostos por prótons até por íons pesados, ou por fontes radiativas, como fontes que emitem partículas alfa, por exemplo o ${ }^{241} \mathrm{Am}$.

Uma primeira verificação foi realizada com uma amostra do dispositivo MKE02Z onde foi possível determinar quais circuitos são mais sensíveis à radiação ionizante e assim propor uma estratégia de testes de tolerância de dispositivos digitais à radiação ionizante. A verificação foi separada em duas etapas: teste estático, onde não havia execução de um firmware de teste, e teste dinâmico, onde havia a execução de um firmware de teste. Com os resultados preliminares dos testes estáticos, onde cada memória foi avaliada individualmente, foi possível perceber a maior sensibilidade da memória SRAM à radiação ionizante em relação a memória flash. As falhas do dispositivo observadas sugerem que o dispositivo não tolera valores de LET maiores que $5,0 \mathrm{MeV} / \mathrm{mg} / \mathrm{cm}^{2}$ e dose acumulada superior a $60 \mathrm{krad}(\mathrm{Si})$. A memória SRAM apresentou uma seção de choque de bit na ordem de $3,89.10^{-4} \mathrm{~cm}^{2}$ quando foi irradiado pelo feixe de ${ }^{12} \mathrm{C}$ cujo LET era $2,36 \mathrm{MeV} / \mathrm{mg} / \mathrm{cm}^{2}$, enquanto não foram observados nenhum SEU para a memória flash. Para extrair a curva de sensibilidade do dispositivo, o dispositivo foi irradiado com duas fontes que apresentavam valores de LET menores do que os obtidos na irradiação por íons pesados: prótons e partículas alfa. Essas irradiações foram realizadas com execução do teste dinâmico onde foi possível monitorar a SRAM em tempo real. Não foi observado nenhum SEU devido a irradiação de prótons, sugerindo que o LET obtido com essas partículas estava abaixo do LET mínimo para gerar eventos observáveis. Por sua vez, as partículas alfa, emitidos por uma lâmina de ${ }^{241} \mathrm{Am}$, causavam SEU e foram feitos testes em vácuo e em ar. A seção de choque apresentou um maior valor quando o dispositivo foi irradiado em ar, devido ao fato do máximo valor de ionização ocorrer mais próximo a superfície do dispositivo, gerando mais cargas dentro do volume sensível do dispositivo. O dispositivo apresentou uma seção de choque de bit na ordem de $2 \cdot 10^{-6} \mathrm{~cm}^{2}$ quando irradiado em vácuo e $2 \cdot 10^{-5} \mathrm{~cm}^{2}$ quando irradiado em ar. Por esse comportamento, a câmara foi preenchida com atmosfera de argônio e variando apenas a pressão do gás dentro da câmara de teste foi possível variar a energia e LET do feixe e determinar o LET mínimo desse dispositivo que ficou em torno de $0,7 \mathrm{MeV} / \mathrm{mg} / \mathrm{cm}^{2}$.

Para verificar essas informações, novos testes foram realizados com mais duas amostras: um novo MKE02Z e um RM42L432. Para os testes de TID, ambos os dispositivos ficaram 
incapaz de escrever em suas memórias flash com dose acumulada de $18 \mathrm{krad}(\mathrm{Si})$. Apenas o RM42L432 ainda era capaz de ler o conteúdo da memória flash, indicando que esse dispositivo é mais robusto comparando com o MKE02Z e poderia ser considerado em uma aplicação onde não fosse necessário a escrita na memória. Já os testes de SEE do dispositivo MKE02Z tiveram resultados similares aos resultados obtidos anteriormente, enquanto não foram observados SEU para o RM42L432 quando irradiados com partículas alfa.

Com esses resultados, é possível sugerir uma metodologia de teste para qualificação de microcontroladores utilizando os métodos estudados nesse trabalho. Qualquer microcontrolador pode ser avaliado e comparado se for submetido a sequência de testes realizadas nesse trabalho: Verificação inicial das partes sensíveis à TID e à SEE e a execução de um teste mais elaborado para determinar os níveis mínimos de LET e doses máximas que o dispositivo suporta. 


\section{REFERÊNCIAS}

AGUIAR, V.A.P. Efeitos de Radiação em dispositivos eletrônicos com feixes de íons pesados. 2014. p. 109. Dissertação (Mestrado em Física) - Universidade de São Paulo, São Paulo, 2014.

ALATI, D. M. Estudo do Comportamento Elétrico de Estruturas MOSFETs não Convencionais e do MOSFET diamante em Ambientes Radioativos. 2012. p. 199. Dissertação (Mestrado em Engenharia Elétrica) - Centro Universitário da FEI, São Bernardo do Campo, 2012.

ARDEBILI, H.; WONG, E. H.; PECHT, M. Hygroscopic swelling and sorption characteristics of epoxy molding compounds used in electronic packaging. IEEE Transactions on Components and Packaging Technologies, v. 26, n. 1, p. 206-214, 2003.

ARM. CoreSight DAP-Lite Technical Reference Manual. Nov. 2017. Disponível em: $<$ http://infocenter.arm.com/help/index.jsp?topic=/com.arm.doc.ddi0316d/Chdiaihc.htm>. Acesso em: 9 nov. 2017.

ATTIX, F. H.; TOCHILIN, E.; ROESCH, W. C. Radiation dosimetry. 2nd ed. New York: Academic New York, 1966. 3 v. :

AZAMBUJA, J.R.; KASTENSMIDT, F.; BECKER, J. Hybrid Fault Tolerance Techniques to Detect Transient Faults in Embedded Processors. [S.1.]: Springer International Publishing, 2014. (SpringerLink : Bücher).

BARNABY, H. J. Total-Ionizing-Dose Effects in Modern CMOS Technologies. IEEE Transactions on Nuclear Science, v. 53, n. 6, p. 3103-3121, dez. 2006.

BAUMANN, R. C. Soft errors in advanced semiconductor devices-part I: the three radiation sources. IEEE Transactions on Device and Materials Reliability, v. 1, n. 1, p. 17-22, mar. 2001.

BELLOTTI, G. et al. A radiation hardened by design charge pump for flash memories. In: 2013 14th European Conference on Radiation and Its Effects on Components and Systems (RADECS). Oxford, U.K: Anais..., set. 2013. p. 1-4.

BEZ, R. et al. Introduction to flash memory. Proceedings of the IEEE, v. 91, n. 4, p. 489-502, abr. 2003.

BIRLA, Shilpi; K. SINGH, R; PATTANAIK, M. Static Noise Margin Analysis of Various SRAM Topologies. International Journal of Engineering and Technology, v. 3, p. 304-309, jan. 2011.

BRINKMAN, W. F.; HAGGAN, D. E.; TROUTMAN, W. W. A history of the invention of the transistor and where it will lead us. IEEE Journal of Solid-State Circuits, v. 32, n. 12, p. 1858-1864, 1997.

CALHOUN, B. H.; CHANDRAKASAN, A. P. Static noise margin variation for sub-threshold SRAM in 65-nm CMOS. IEEE Journal of Solid-State Circuits, v. 41, n. 7, p. 1673-1679, 2006. 
COLINGE, J. P.; COLINGE, C. A. Physics of Semiconductor Devices. [S.1.]: Springer US, 2007.

DICKSON, J. F. On-Chip High-Voltage Generation in MNOS Integrated Circuits Using an Improved Voltage Multiplier Technique. IEEE Journal of Solid-State Circuits, v. 11, n. 3, p. 374-378, 1976.

DICTIONARY, The American Heritage ${ }^{\circledR}$ Science. The American Heritage ${ }^{\circledR}$ Science Dictionary. Nov. 2017. Disponível em: <http://www.dictionary.com/browse/van-allen-belt>. Acesso em: 9 nov. 2017.

FACCIO, F. COTS for the LHC radiation environment: The rules of the game. In: PROCEEDIDNGS, 6TH WORKSHOP ON ELECTRONICS FOR LHC EXPERIMENTS. Cracow, Poland: Anais..., 2000. p. 50-65.

GERACI, A. et al. IEEE Standard Computer Dictionary: A Compilation of IEEE Standard Computer Glossaries. IEEE Std 610, p. 1-217, jan. 1991.

GERARDIN, S. et al. Radiation Effects in Flash Memories. IEEE Transactions on Nuclear Science, v. 60, n. 3, 2013.

HAADE. Solid Angle. 2018. Disponível em:

$<$ https://commons.wikimedia.org/wiki/File:Solid_Angle.png>. Acesso em: 24 abr. 2018.

HOLMES-SIEDLE, A. Handbook of Radiation Effects. [S.1.: s.n.], 2007.

INPE. Histórico do Satélite Sino-Brasileiro de Recursos Terrestres CBERS. Jan. 2018a. Disponível em: <http://www.cbers.inpe.br/sobre_satelite/historico.php>. Acesso em: 24 abr. 2018.

Projeto CITAR testa componente eletrônico tolerante à radiação para uso em sistemas espaciais. Jan. 2018b. Disponível em:

$<$ http://www.inpe.br/noticias/noticia.php?Cod_Noticia=4115>. Acesso em: 24 abr. 2018.

INTEL. 50 Years of Moore's Law. 2015. Disponível em: <http:

//www.intel.com/content/www/us/en/silicon-innovations/moores-law-technology.html>. Acesso em: 20 mai. 2017.

JOHNSTON, A. Reliability and Radiation Effects in Compound Semiconductors. [S.1.]: World Scientific, 2010.

KAPLAN, I. Nuclear Physics. [S.1.]: Addison-Wesley Publishing Company, 1955. (A-W series in nuclear science and engineering).

KNOLL, G.F. Radiation detection and measurement. [S.1.]: Wiley, 1989.

LAPRIE, J. C. Dependable Computing and Fault Tolerance: Concepts and Terminology. In: FAULT-TOLERANT Computing, 1995, Highlights from Twenty-Five Years., Twenty-Fifth International Symposium on. Pasadena, Usa: Anais..., jun. 1995. p. 2-. 
LEITE, F. G. H. et al. The Bias-Dependence Threshold Voltage Shift on Irradiated MOSFETs. In: SEMINATEC 2015. São Bernardo do Campo, SP: Anais..., 2015. p. 4-6.

LEITE, F. G. H. et al. TID and dose rate effects in MOSFET Transistors. In: SEMINATEC 2014. São Paulo, SP: Anais..., 2014. p. 3-4.

LENZLINGER, M.; SNOW, E. H. Fowler-Nordheim Tunneling into Thermally Grown SiO2. Journal of Applied Physics, v. 40, n. 1, p. 278-283, 1969.

LEROY, C.; RANCOITA, P.G. Principles of Radiation Interaction in Matter and Detection. [S.1.]: World Scientific, 2009.

LINARES, R. Estudo Sistemático do Freamento de Íons Pesados em Sólidos no Regime de Baixas Velocidades. 2009. p. 113. Tese (Doutorado em Física) - Universidade de São Paulo, São Paulo, 2009.

MAKOWSKI, Dariusz. The Impact on Electronic Devices with the Special Consideration of Neutron and Gamma Radiation Monitoring. 2006. Tese (Doutorado em Engenharia Elétrica) - Lodz, Tech. U., Lodz, Polõnia.

MATHWORLD., Wolfram. Solid Angle. 2018. Disponível em:

$<$ http://mathworld.wolfram.com/SolidAngle.html>. Acesso em: 24 abr. 2018.

MCLEAN, F. B.; OLDHAM, T. R. Basic mechanisms of radiation effects on electronic materials and devices. Harry Diamond Lab. Tech. Rep., HDL-TR, n. 3, p. 2129, 1989.

NAKAMURA, K; GROUP, Particle Data. Review of Particle Physics. Journal of Physics G: Nuclear and Particle Physics, v. 37, 7A, p. 075021, 2010.

OKUNO, E.; YOSHIMURA, E.M. Física das radiações. [S.1.]: Oficina de Textos, 2010.

OLDHAM, T. R.; MCLEAN, F. B. Total ionizing dose effects in MOS oxides and devices. IEEE Transactions on Nuclear Science, IEEE, v. 50, n. 3, p. 483-499, 2003.

PASCHOAL, M. B. Efeitos da radiação ionizante provenientes de raios-X e feixe de prótons nas propriedades de semicondutores. 2017. p. 71. TCC (Graduação em Engenharia de Materiais) - Centro Universitário da FEI, São Bernardo do Campo, 2017.

PHANSE, A. et al. Carrier mobility degradation in metal-oxide-semiconductor field-effect transistors due to oxide charge. Journal of Applied Physics, v. 74, n. 1, p. 757-759, 1993.

QIN, Murong et al. Solar cycle variations of trapped proton flux in the inner radiation belt. Journal of Geophysical Research: Space Physics, v. 119, n. 12, p. 9658-9669, 2014.

SALA, O.; SPALEK, G. the Nuclear Structure Facility At the University of Sao Paulo. Nuclear Instruments and Methods, v. 122, p. 213-225, 1974.

SCHEICK, L. Z.; SWIFT, G. M.; GUERTIN, S. M. SEU evaluation of SRAM memories for space applications. In: 2000 IEEE Radiation Effects Data Workshop. Reno, USA: Anais..., 2000. p. 61-63. 
SCHWANK, J. R.; SHANEYFELT, M. R.; DODD, P. E. Radiation Hardness Assurance Testing of Microelectronic Devices and Integrated Circuits: Radiation Environments, Physical Mechanisms, and Foundations for Hardness Assurance. IEEE Transactions on Nuclear Science, v. 60, n. 3, p. 2074-2100, jun. 2013.

SCHWANK, J. R. et al. Radiation Effects in MOS Oxides. IEEE Transactions on Nuclear Science, v. 55, n. 4, p. 1833-1853, ago. 2008.

SEDRA, A. S.; SMITH, K.C. Microelectronic Circuits. Oxford, U.K.: Oxford University, 2015. (The Oxford Series in Electrical and Computer Engineering).

SEMICONDUCTOR, Freescale. FRDM-KE02Z User’'s Manual. 2013.

SEMICONDUCTORS, NXP. K60 Sub-Family Reference Manual. 2011.

SINGH, J. et al. A nano-CMOS process variation induced read failure tolerant SRAM cell. In: 2008 IEEE International Symposium on Circuits and Systems. Seattle, USA: Anais..., mai. 2008. p. 3334-3337.

TANZAWA, T.; TANAKA, T. A dynamic analysis of the Dickson charge pump circuit. IEEE Journal of Solid-State Circuits, v. 32, n. 8, p. 1231-1240, 1997.

TOCCI, R.; WIDMER, N.; MOSS, G. Digital Systems. [S.1.]: Pearson Education, 2016.

WANG, S. T. On the I-V characteristics of floating-gate MOS transistors. Electron Devices, IEEE Transactions on, v. 26, n. 9, p. 1292-1294, 1979.

YAO, X. et al. The Impact of Total Ionizing Dose on Unhardened SRAM Cell Margins. IEEE Transactions on Nuclear Science, v. 55, n. 6, p. 3280-3287, dez. 2008.

ZIEGLER, James F.; ZIEGLER, M.D.; BIERSACK, J.P. \{SRIM $\}$ - The stopping and range of ions in matter (2010). Nuclear Instruments and Methods in Physics Research Section B:

Beam Interactions with Materials and Atoms, v. 268, n. 11-12, p. 1818-1823, 2010. 